Prepared for the U.S. Department of Energy under Contract DE-AC05-76RL01830

\title{
Air Dispersion Modeling of Radioactive Releases During Proposed PFP Complex Demolition Activities
}

\section{Report to CH2M HILL Plateau Remediation Company}

BA Napier

JG Droppo Jr.

JP Rishel

January 2011

Pacific Northwest

NATIONAL LABORATORY

Proudly Operated by Battelle Since 1965 


\title{
DISCI.AIMER
}

This report was prepared as an account of work sponsored by an agency of the United States Government. Neither the United States Government nor any agency thereof, nor Battelle Memorial Institute, nor any of their employees, makes any warranty, express or implied, or assumes any legal liability or responsibility for the accuracy, completeness, or usefulness of any information, apparatus, product, or process diselosed, or represents that its use would not infringe privately owned rights. Reference herein to any specific commercial product, process, or service by trade name, trademark, manufacturer, or otherwise does not necessarily constitute or imply its endorsement, recommendation, or favoring by the United States Government or any agency thereof, or Battelle Memorial Institute. The views and opinions of authors expressed herein do not necessarily state or reflect those of the United States Government or any agency thereof.

\author{
PACIFIC NORTHWEST NATIONAI I ABORATORY \\ operated by \\ BA'T"TELLE \\ for the \\ INNTTED STATFS DEPARTMFNT OF FNERGY \\ under Contract DE-AC05-76RL01830
}

Printed in the United States of America

Available to DOE and DOE contractors from the

Office of Scientific and Technical Information,

P.O. Box 62, Oak Ridge, TN 37831-0062;

ph: (865) 576-8401

fax: (865) 576-5728

email: reports@adonis.osti.gov

\begin{abstract}
Available to the public from the National Technical Information Service, U.S. Department of Commerce, 5285 Port Royal Rd., Springfield, VA 22161 ph: (800) 553-6847 fax: $(703) 605-6900$ email: orders@ntis.fedworld.gov online ordering: http://www.ntis.gov/ordering.htm
\end{abstract}




\title{
Air Dispersion Modeling of Radioactive Releases During Proposed PFP Complex Demolition Activities
}

\section{Report to CH2M HILL Plateau Remediation Company}

\author{
BA Napier \\ JG Droppo Jr. \\ JP Rishel
}

January 2011

Prepared for

the U.S. Department of Energy

under Contract DE-AC05-76RL01830

Pacific Northwest National Laboratory

Richland, Washington 99352 



\section{Summary}

This report is part of the planning process for the demolition of the 234-5Z, 236-Z, 242-Z, and 291-Z-1 structures at the Plutonium Finishing Plant (PFP) on the Hanford Site. Pacific Northwest National Laboratory (PNNL) supports the U.S. Department of Energy (DOE) and the CH2M HILL Plateau Remediation Company (CHPRC) demolition planning effort by making engineering estimates of potential releases for various potential demolition alternatives. This report documents an analysis considering open-air demolition using standard techniques. It does not document any decisions about the decommissioning approaches; it is expected that this report will be revisited as the final details of the demolition are developed.

Atmospheric dispersion modeling using estimated release rates has been conducted to provide information on the location and levels of radioactive contamination that may be expected as the result of demolition activities. The close proximity of the PFP facilities to each other has the potential to affect dispersion patterns through various meteorological phenomena, including building wake effects. Hourly meteorological data collected over a 5-year period (2005-2009) were used to examine the effects of wind speed, direction, and stability on projected concentrations of contaminants in air and deposited on nearby surfaces.

The radioactive contamination of concern for the PFP complex is largely transuranic contamination from past operations. Operations are underway to remove a large fraction of this contamination. The source terms modeled in this report are based on the residual contamination levels that are anticipated for the various structures at the time of demolition.

The radiological consequences have been established using the five-factor formula considering material-at-risk, damage ratio, airborne release fraction, respirable fraction, and leak path factor. Radioactive contamination emissions have been calculated by release mechanism and demolition area for on-shift and off-shift activities. The emissions from the applicable sources have been combined to provide emissions estimates for each day from each demolition area.

The U.S. Environmental Protection Agency's (EPA's) AERMOD computer code is used to estimate atmospheric dispersion and deposition of the released radioactive materials in the immediate vicinity of the demolition activities. The modeling is conducted to be inclusive of the weather conditions that are possible (i.e., uses full annual cycles of meteorological data) and representative of the expected demolition period (i.e., models the hours of the day that demolition activities will occur).

Both airborne and surface concentrations are modeled with AERMOD. Hourly derived air concentrations (DAC) are modeled for an array of receptors covering the demolition site and surrounding area. Peak values of time-integrated air concentrations at these receptor points are derived from these hourly values, with modeling results reported as total incremental air concentrations in DAC-hours occurring over the selected time period. Total accumulated deposition amounts are evaluated with AERMOD using the same array of receptors, with results reported as dpm per $100 \mathrm{~cm}^{2}$.

Each building in the PFP complex is considered in terms of its construction and suggested target contamination levels. The results are based on the following demolition scenarios: 
- The preferred option assumed is to entirely demolish $236-Z$ with hydraulic shears. That activity is projected to require about 8 weeks of elapsed time.

- The 242-Z building roof and walls are assumed to be demolished with a multiprocessor that operates hydraulic shears. It was assumed that the overall demolition would require about 1 week.

- The various zones of the 234-5Z building are assumed to be demolished using hydraulic shears. Certain gloveboxes may remain in the building until the time of demolition. The entire demolition process for $234-5 \mathrm{Z}$ is assumed to require 20 weeks.

- The 291-Z-1 stack is assumed to be toppled with explosives; the stack will be directed to fall into a prepared trench. After being toppled, the stack will be broken up into smaller pieces using a multiprocessor. The entire process is assumed to require 1 week.

All demolition scenarios incorporate some assumptions about release mitigation; use of fixatives and misting/spraying is included in all release estimates. Supplementary scenarios (alternative demolition techniques, additional unique sources) are considered to provide information on alternative approaches.

The exposure results from demolition of the 234-5Z, 242-Z structures and the 291-Z-1 stack are presented as a local-area map of potential exposures from demolition activities. The climatologicallybased patterns of predicted weekly air exposure maximum values (expressed as weekly total DAC-hours) for these PFP structures are plotted in Figure S.1. This plot is based on modeling the weekly activities with the highest projected weekly emission rates (related to the demolition of the RMA/RMC lines) for all the 5-day periods occurring in the 5 years of meteorological observations. All other demolition activities associated with demolition activities for these buildings will have lower levels of predicted weekly peak exposures.

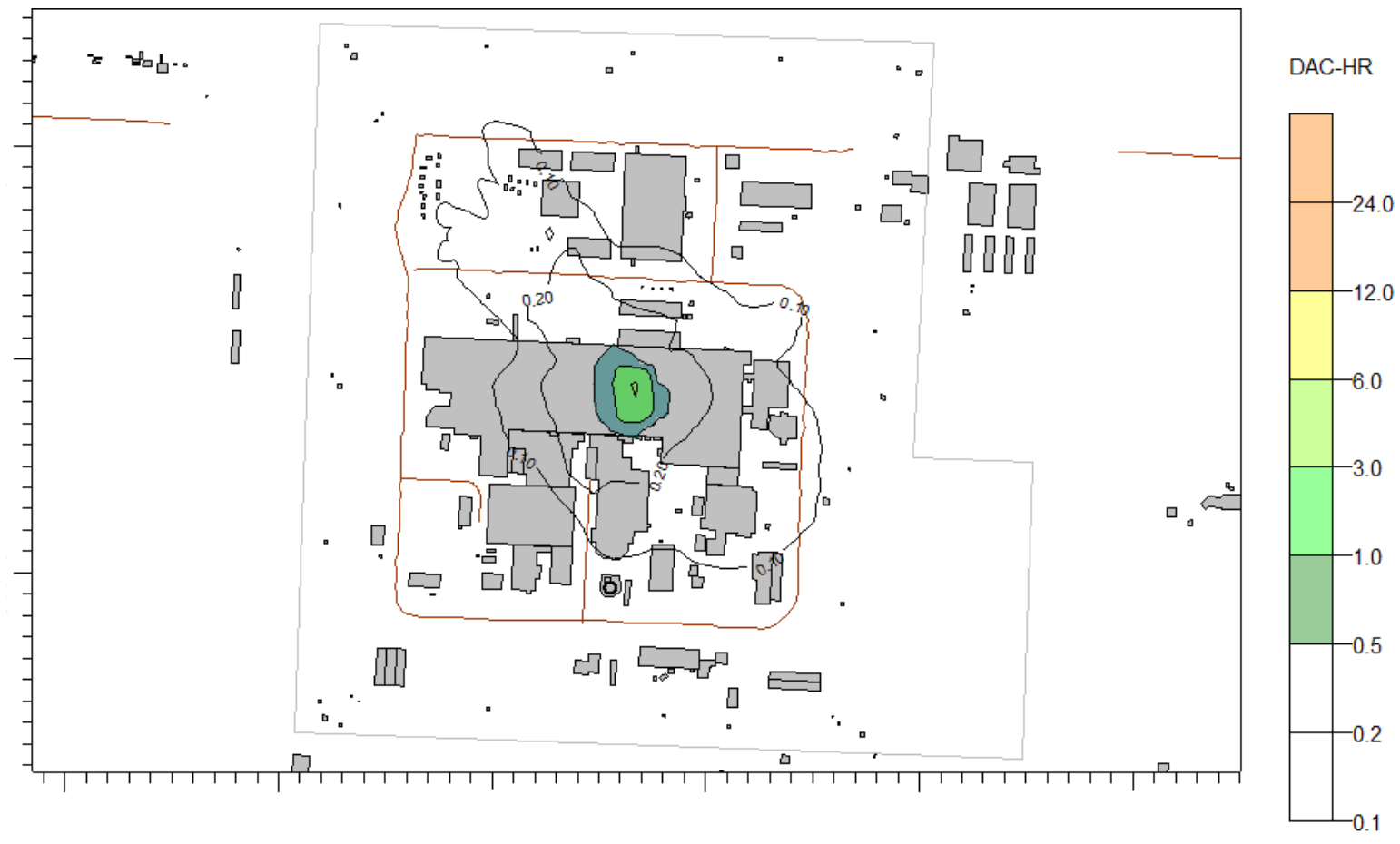

Figure S.1. Weekly Air Exposure Maximum Values for Demolition of 234-5Z, 242-Z and 291-Z-1 
The air exposure modeling results for the demolition of the $236-\mathrm{Z}$ cell and associated buildings with shears are presented in Figure S.2. These structures include areas with the highest contamination levels in the PFP complex. Because the activity weighted emissions from the $236-\mathrm{Z}$ cell alone account for $99.999 \%$ of the projected emissions from demolition of the $236-Z$ cell and associated buildings combined, the results given below are fully attributable to the demolition activities for the $236-\mathrm{Z}$ cell alone.

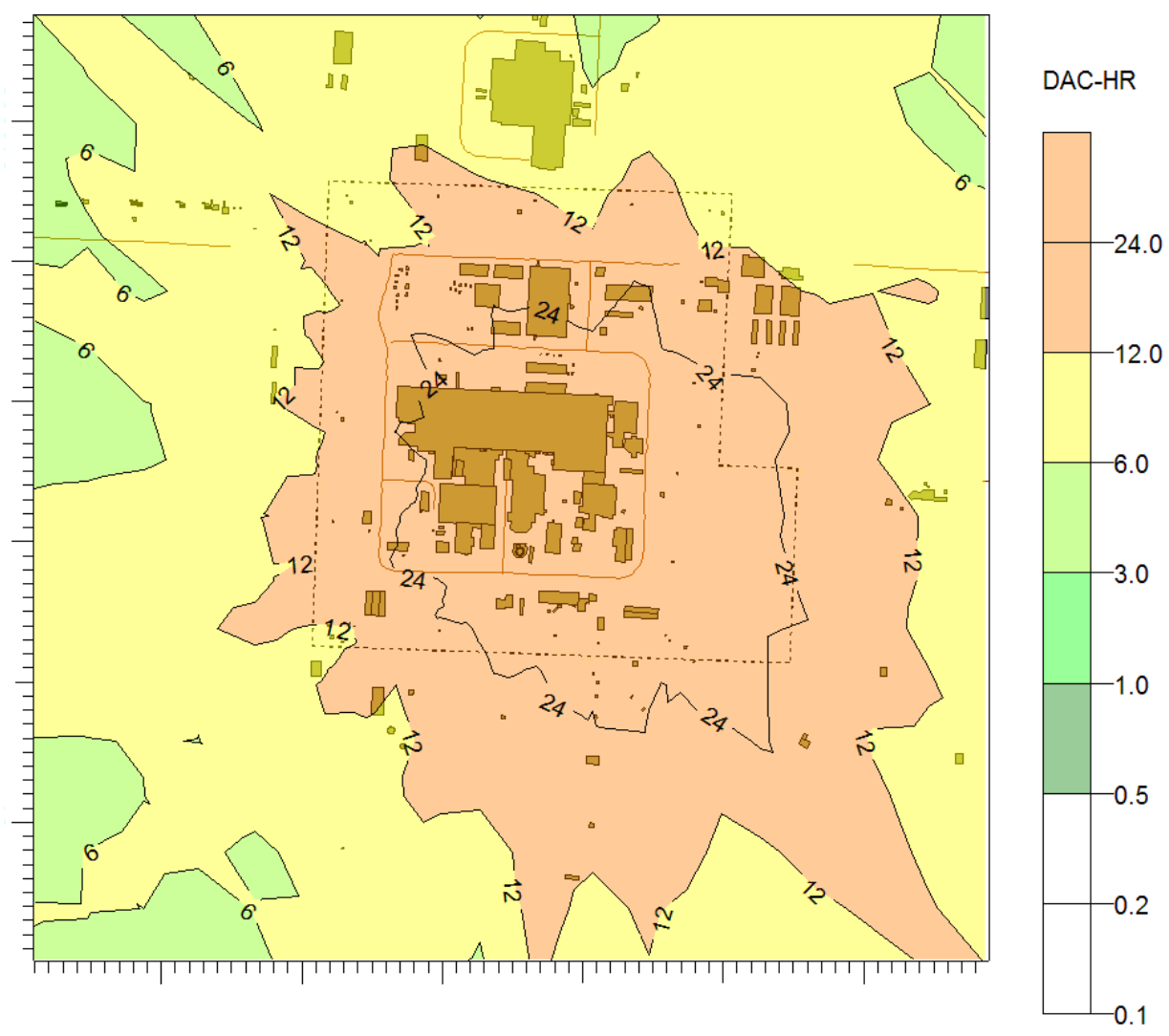

Figure S.2. Predicted Weekly Air Exposure Maximum Values for 236-Z Demolition

The analysis shows that some releases of radioactive material are to be anticipated during the demolition of the PFP structures. The modeling results presented here are closely tied to the details of how the demolition is to be conducted. The results indicate that for the bulk of the PFP facilities, including the PFP stack, the radiological exposures from the planned demolition efforts will be below the designated limits for air and soil exposures. However, the demolition of the $236-\mathrm{Z}$ main process cell has the potential for large releases of alpha-emitting radionuclides. Simple shearing of this portion of the facility without extensive decontamination and preparation beyond that assumed in this report has the potential to spread contamination in excess of Hanford administrative limits beyond the current fenceline of the PFP area. 



\section{Acknowledgments}

The authors would like to extend their appreciation to Richard Bloom of the CH2M HILL Plateau Remediation Company for financial and technical support of this work. Meteorological data from the Hanford Meteorological Station for the period was provided by Ken Burk, Pacific Northwest National Laboratory. Thanks are also extended to Pacific Northwest National Laboratory staff that helped produce this document: Dave Payson of PNNL for editorial input, Sandi Snyder for review of the source term calculations, and John Glissmeyer for peer review. This work was funded by CH2M HILL Plateau Remediation Company under the U.S. Department of Energy Contract DE-AC05-76RL01830. 



\section{Acronyms and Abbreviations}

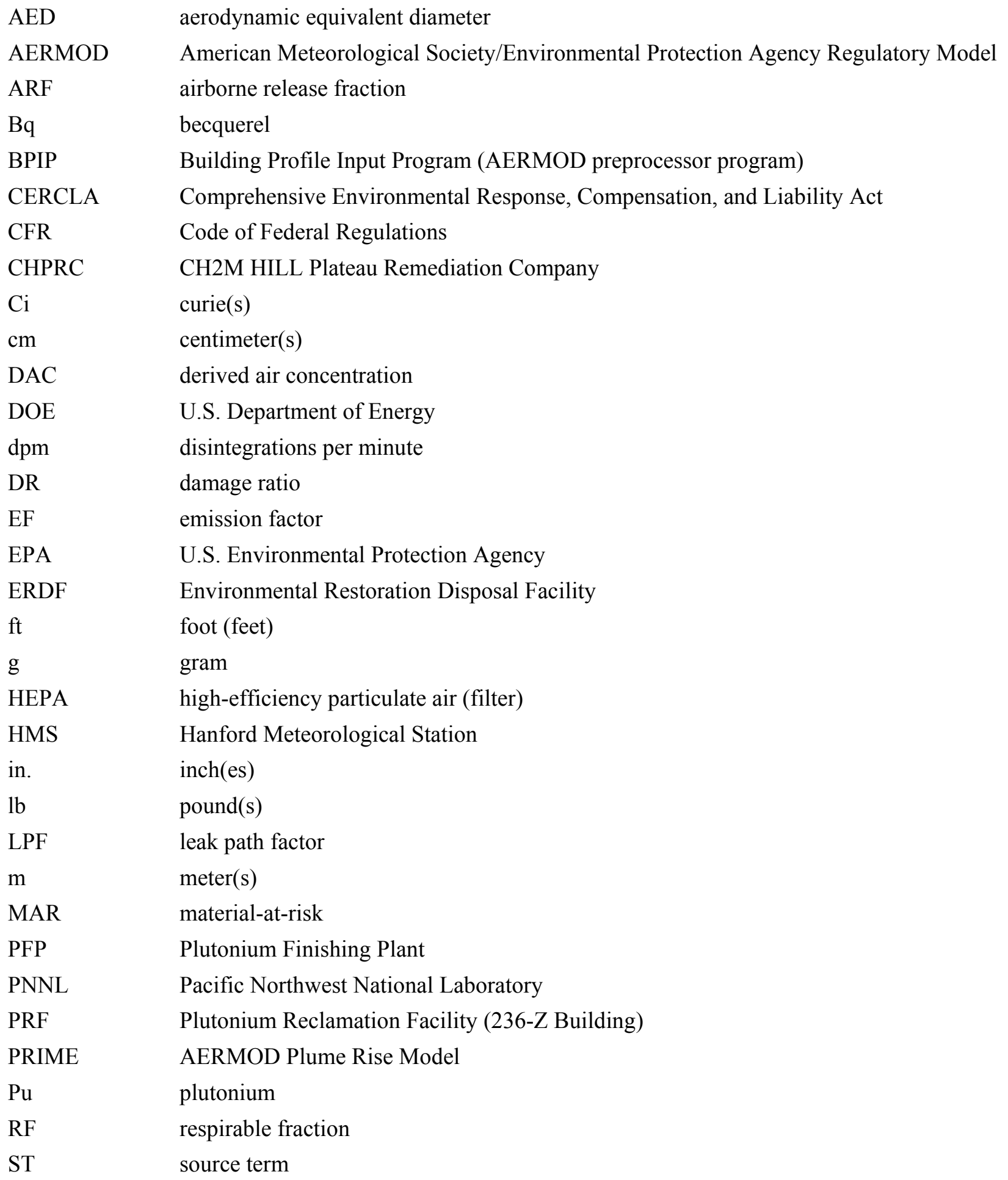





\section{Contents}

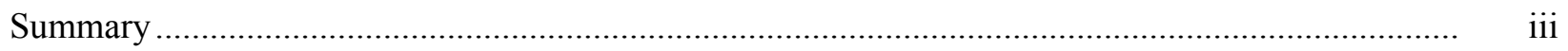

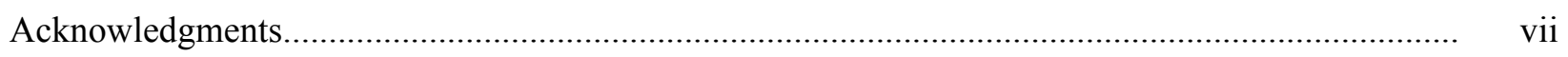

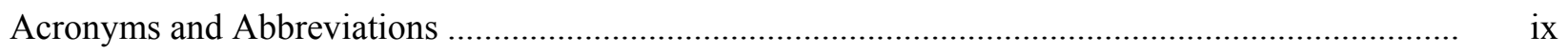

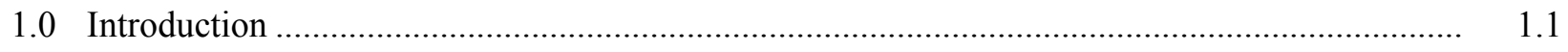

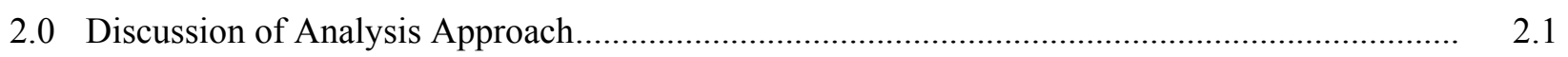

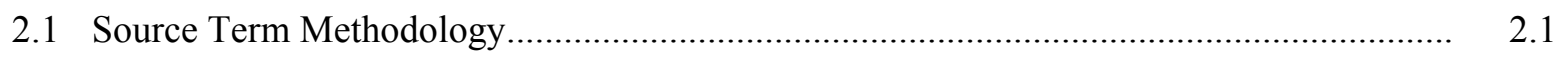

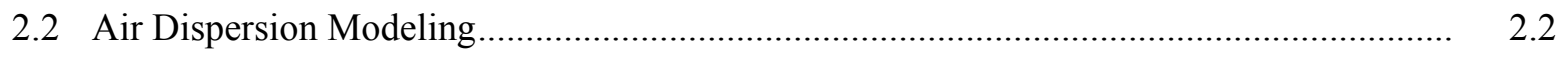

2.3 Airborne Contamination Dosimetry ....................................................................... 2.3

2.4 Summary of Anticipated Radionuclide Inventories ....................................................... 2.4

2.5 Modeling Demolition Scenarios................................................................................. 2.6

2.6 Quality Control Procedures and Documentation.......................................................... 2.8

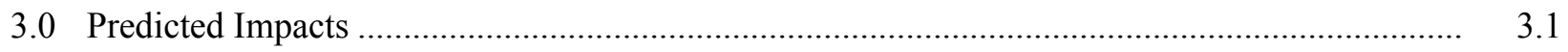

3.1. Building Demolition - Air Concentrations ............................................................... 3.3

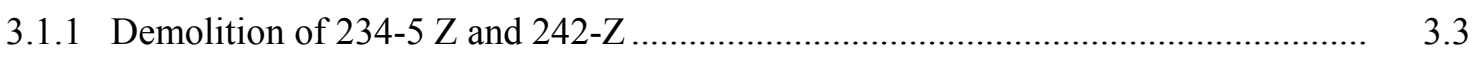

3.1.2 Demolition of 236-Z Cell and Associated Buildings ........................................... 3.4

3.2 Building Demolition - Surface Deposition ............................................................... 3.14

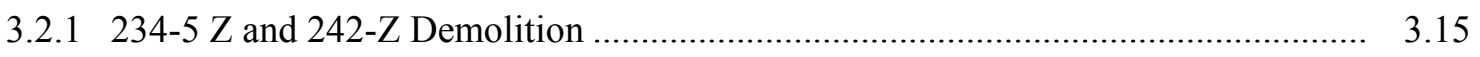

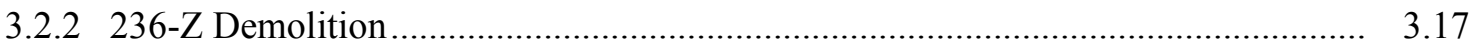

3.2.3 Total Deposition from All PFP Buildings ......................................................... 3.18

3.3 Stack Demolition - Air Concentration and Surface Deposition ...................................... 3.20

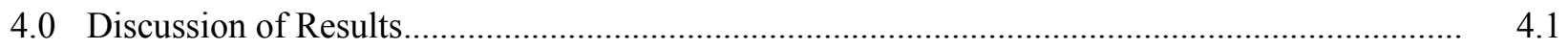

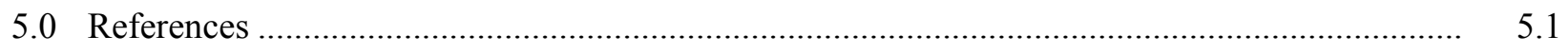

Appendix A - Facility-Specific Source Term Analyses …........................................................ A.1

Appendix B - Atmospheric Model Selection .......................................................................... B.1

Appendix C - Air Dispersion Modeling Assumptions ............................................................. C.1

Appendix D - Alternative Demolition Approaches Considered................................................... D.

Appendix E - Quality Control Procedures ............................................................................. E. 1

Appendix F - Input Data for PFP Building Simulations …....................................................... F.1

Appendix G - AERMOD Output File Listing .............................................................. G. G.1 


\section{Figures}

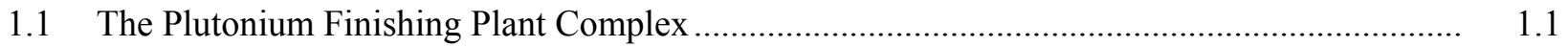

2.1 Demolition Zones Defined for this Analysis................................................................... 2.4

2.2 Weekly-averaged Dust Release Rate during Active Demolition and Load-out Activities ......... $\quad 2.7$

2.3 Weekly-averaged Radioactive Source Term During Active Demolition and Load-out Activities

3.1 PFP Structures Being Considered for Demolition ............................................................ 3.2

3.2 Predicted PFP Zone 6 Demolition Maximum Weekly Air Concentrations ............................... 3.4

3.3 Predicted 236-Z Cell Demolition Maximum Weekly Air Concentrations................................. 3.5

3.4 Predicted 236-Z Cell Demolition January Maximum Air Concentrations.................................. 3.6

3.5 Predicted 236-Z Cell Demolition February Maximum Air Concentrations............................... 3.7

3.6 Predicted 236-Z Cell Demolition March Maximum Air Concentrations.................................. 3.7

3.7 Predicted 236-Z Cell Demolition April Maximum Air Concentrations..................................... 3.8

3.8 Predicted 236-Z Cell Demolition May Maximum Air Concentrations ....................................... 3.8

3.9 Predicted 236-Z Cell Demolition June Maximum Air Concentrations ..................................... 3.9

3.10 Predicted 236-Z Cell Demolition July Maximum Air Concentrations ................................... 3.9

3.11 Predicted 236-Z Cell Demolition August Maximum Air Concentrations.................................. 3.10

3.12 Predicted 236-Z Cell Demolition September Maximum Air Concentrations ........................... 3.10

3.13 Predicted 236-Z Cell Demolition October Maximum Air Concentrations .............................. 3.11

3.14 Predicted 236-Z Cell Demolition November Maximum Air Concentrations ............................ 3.11

3.15 Predicted 236-Z Cell Demolition December Maximum Air Concentrations............................ 3.12

3.16 Predicted Maximum Weekly Air Concentrations at the PFP Site Fenceline for Demolition Excluding the 236-Z Plutonium Reclamation Facility ........................................................ 3.13

3.17 Predicted Maximum Weekly Air Concentrations at the PFP Site Fenceline for the 236-Z Plutonium Reclamation Facility Cell Demolition ........................................................................ 3.14

3.18 PFP Zone 6 Demolition Maximum Average Surface Deposition ............................................ 3.15

3.19 Predicted Surface Deposition for Demolition of Zones 1 to 11 Starting in January 2009......... 3.16

3.20 Predicted Surface Deposition for Demolition of Zones 1 to 11 Starting in Mid-May 2009 ...... 3.17

3.21 Predicted Maximum Average Surface Deposition for 236-Z Cell from Shear Demolition........ 3.18

3.22 Predicted Maximum Average Surface Deposition for Shear Demolition of all PFP

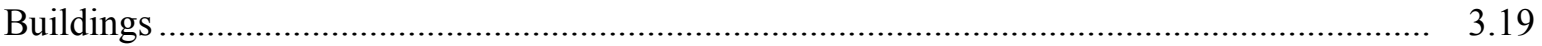

3.23 Predicted Surface Deposition for Shear Demolition of All PFP Buildings Starting in January 2009

3.24 Predicted Surface Deposition for Shear Demolition of All PFP Buildings Starting in MidMay 2009 .

3.25 Predicted Weekly Air Exposure Maximum Values for 291-Z-1 Stack Demolition ................. 3.21

3.26 Maximum Average Surface Deposition for the 291-Z-1 Stack Demolition ............................ 3.22 


\section{Tables}

2.1 Anticipated Inventory of Radionuclides in Defined Demolition Zones of the PFP Complex ....

2.5 



\subsection{Introduction}

The Hanford Plutonium Finishing Plant (PFP), located in the 200 West Area, converted plutoniumbearing chemical solutions to metals and oxides until 1989. The current mission of the PFP requires deactivating and dismantling PFP complex systems and structures to the degree determined appropriate by the Comprehensive Environmental Response, Compensation, and Liability Act (CERCLA) process, thus eliminating significant hazard to workers, the public, and the environment and minimizing long-term surveillance and maintenance risks and costs. U.S. Department of Energy (DOE) and CH2M HILL Plateau Remediation Company (CHPRC) plans call for eventual demolition of many of the PFP structures.

Pacific Northwest National Laboratory (PNNL) supports the demolition planning effort by making engineering estimates of potential releases for various potential demolition alternatives. Atmospheric dispersion modeling has been conducted using those release rates to provide information on the location and levels of radioactivity. This report documents an analysis considering open-air demolition using standard techniques. It does not document any decisions about the decommissioning approaches; it is expected that this report will be revisited when demolition plans have been finalized.

This report is part of the planning process for the demolition of the 234-5Z, 236-Z, 242-Z, and 291-Z-1 structures at the PFP complex; these structures are highlighted in blue in Figure 1.1. A number of the other structures shown in gray in the figure have been, or will be, removed before demolition of the other structures occurs.

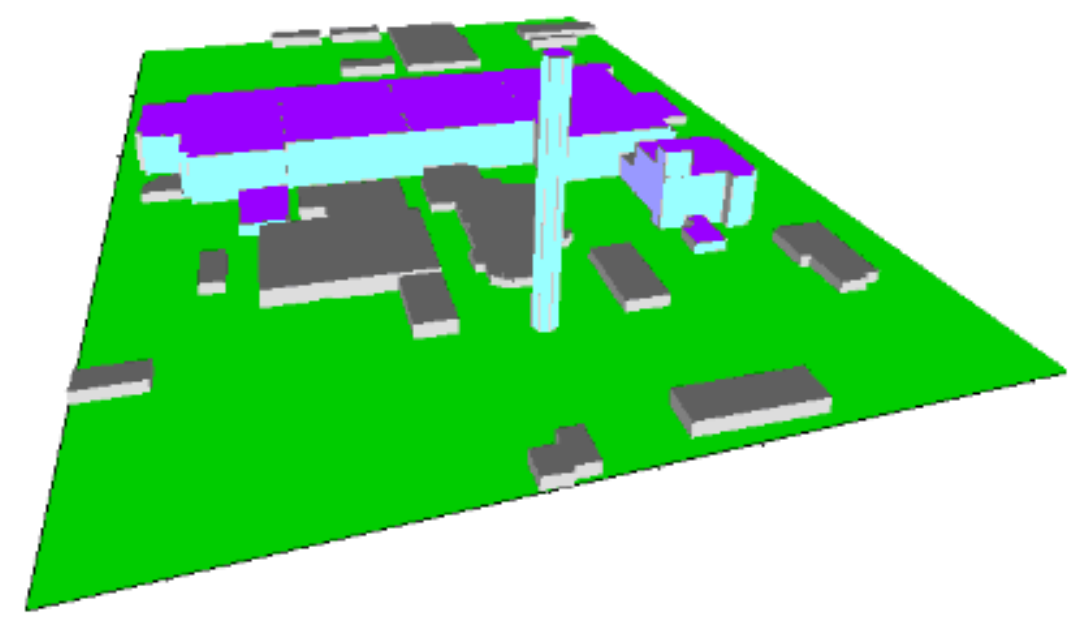

Figure 1.1. The Plutonium Finishing Plant Complex

The PFP complex shown in Figure 1.1 has many large structures that will influence the local atmospheric dispersion. These structures have the potential to affect dispersion and deposition patterns through various meteorological phenomena, including building wake effects. Atmospheric dispersion calculations have been made using the AERMOD (40 CFR 51, Appendix W) dispersion model developed by the U.S. Environmental Protection Agency (EPA). AERMOD is the EPA's recommended dispersion model for regulatory applications; the model incorporates the latest understanding of atmospheric dispersion, and it explicitly accounts for building wake effects. The results from the AERMOD 
calculations are being used to help plan demolition activities that will keep potential contamination within the limits established for the project contamination area and to define exclusion zones.

The $234-5 \mathrm{Z}$ building is approximately $152 \mathrm{~m}(500 \mathrm{ft})$ long and $55 \mathrm{~m}(180 \mathrm{f})$ wide. The floor levels are the basement, the first floor, the duct level, and the second floor. The frame is structural steel with an outer sheathing of aluminum panels over rock wool insulation and 16-guage sheet metal. There are also 20-cm (8-in.) thick interior reinforced concrete walls, principally running in the east-west direction, and two box-type reinforced concrete stairwells. The stairwells extend to the roof; the reinforced concrete walls stop at the second floor. Contamination levels are quite variable within this large structure; the bulk of residual contamination is expected to reside in the central core and on the duct level.

The 236-Z building (also known as the Plutonium Reclamation Facility - PRF) is located south of the southeastern corner of the $234-5 \mathrm{Z}$ building and is connected to it by the $242-\mathrm{Z}$ building. The building is a four-story structure $24 \mathrm{~m}(79 \mathrm{ft})$ by $21.6 \mathrm{~m}(71 \mathrm{ft})$ by about $14.5 \mathrm{~m}(47.5 \mathrm{ft})$ high, surmounted at the southwest corner by a two-story penthouse $6.9 \mathrm{~m}(22.5 \mathrm{ft})$ high. With the exception of the roof, the south end of the process cell, and the fourth-floor ceiling, the building is constructed of reinforced concrete. The roof is constructed of an open-web steel joist frame, a steel deck with rigid insulation of lightweight concrete fill, and gravel-covered built-up roofing. A portion of the south wall is also the 1-ft-thick wall of the process cell. An equipment transfer facility is located against the large south door. The tanks and columns used in the solvent extraction process are located in the process cell-a large three-story room in the center of the $236-Z$ building.

The $242-Z$ building (formerly known as the Waste Treatment Facility) connects the $234-5 Z$ and $236-Z$ buildings. The $242-Z$ building is $12 \mathrm{~m} \mathrm{(40} \mathrm{ft)} \mathrm{wide,} 8 \mathrm{~m}(26 \mathrm{ft})$ long, and $7 \mathrm{~m}(23 \mathrm{ft})$ high. The south wall of the $242-Z$ is reinforced concrete; the remainder of the building has a structural steel frame covered with metal lath and plaster internally and insulating wall panels externally. The roof is constructed of metal decking covered with built-up asphalt and gravel. A serious accident involving an explosion of an americium separation column occurred in this building in 1976, which resulted in extensive ${ }^{241} \mathrm{Am}$ contamination inside the building.

The 291-Z building provides controlled ventilation exhaust for the 234-5Z, 242-Z, and 236-Z buildings. The $291-Z-1$ reinforced concrete stack is located adjacent to the $291-Z$ building. The stack is $61 \mathrm{~m}(200 \mathrm{ft})$ tall.

The main report provides a description of the overall analysis approach used to evaluate the air emissions during demolition (Section 2), the local patterns of predicted incremental air concentrations and deposition rates for the major buildings and stack (Section 3), and a discussion of the results (Section 4). The appendices provide the structure-by-structure details of the source-term analysis and atmospheric dispersion modeling. The source-term appendices include the modeling scenarios, source-term inventories, and demolition options. The air dispersion appendices include modeling assumptions as well as the AERMOD input and output file listings. 


\subsection{Discussion of Analysis Approach}

Atmospheric dispersion modeling has been conducted in support of the demolition of the Plutonium Finishing Plant (PFP) complex using estimated release rates to provide information on the location and levels of radioactive contamination that may be expected as the result of demolition activities. The close proximity of the PFP building structures to each other has the potential to affect dispersion patterns through various meteorological phenomena, including building wake effects. Hourly meteorological data collected over a 5-year period (2005-2009) was used to examine the effects of wind speed, direction, and stability on projected concentrations of contaminants in air and deposited on nearby surfaces.

The radioactive contamination of concern for the PFP complex is largely transuranic contamination from past operations. Operations are underway to remove a large fraction of this contamination. The source terms modeled in this report are based on the residual contamination levels that are anticipated for the various structures at the time of demolition.

The radiological consequences have been established using the methods discussed in DOE-HDBK3010-94 (DOE 1994). This approach was successfully used for the 233-S building (AlphaTRAC 2003a, 2003b), the 232-Z building (Droppo et al. 2006), the $105 \mathrm{KE}$ Basin (Napier et al. 2008), and the 224-U and 224-UA buildings (Napier et al. 2009; Napier et al. 2010).

\subsection{Source Term Methodology}

The source term may be quantified using the five-factor formula ${ }^{1}$

$$
\begin{gathered}
\mathrm{ST}=\mathrm{MAR} * \mathrm{DR} * \mathrm{ARF} * \mathrm{RF} * \mathrm{LPF} \\
\mathrm{ST}=\mathrm{MAR} * \mathrm{EF}
\end{gathered}
$$

where: Source term $(\mathrm{ST})=$ the total quantity of respirable material released to the atmosphere during the demolition

Material-at-risk $(\mathrm{MAR})=$ the total quantity of radionuclides (in grams or curies of activity for each radionuclide) available to be acted on by a given physical stress

Damage ratio $(D R)=$ the fraction of the MAR actually impacted by the demolition conditions

Airborne release fraction (ARF) $=$ the fraction of a radioactive material suspended in air as an aerosol and thus available for transport due to a physical stress from a specific activity

Respirable fraction $(\mathrm{RF})=$ the fraction of airborne radionuclides as particles that can be transported through air and inhaled into the human respiratory system and is commonly assumed to include particles $10-\mu \mathrm{m}$ aerodynamic equivalent diameter (AED) and less

Leak path factor $(\mathrm{LPF})=$ the fraction of the radionuclides in the aerosol transported through some confinement system (e.g., facility rooms, ductwork), filtration mechanism (e.g., high-efficiency particulate air [HEPA] or sand filters), and emission mitigation methods (e.g., misters or foggers).

The last four factors are sometimes combined into an Emission Factor (EF) to be multiplied with the MAR, where $\mathrm{EF}=\mathrm{DR} * \mathrm{ARF} * \mathrm{RF} * \mathrm{LPF}$.

\footnotetext{
${ }^{1}$ The following discussion is adapted from GENII Computer Code Application Guidance for Documented Safety Analysis, DOE-EH-4.2.1.4-Interim-GENII, Rev. 1, U.S Department of Energy, Washington, D.C.
} 
For these analyses, the MAR is defined as the inventory that is on the surface area being demolished. While it is permissible to exclude material forms that are considered to be unaffected from the MAR, experience suggests that for these forms the DR is usually best set to zero for the release mechanism. The overall result using either approach is the same. However, by assigning DR values to each combination of inventory form and release mechanism, there is the expectation that each credited form is also reviewed against secondary events and, therefore, less likely to be overlooked.

Details of the source term analysis for each component of PFP are presented in Appendix A. Radioactive contamination emissions (STs) have been calculated by release mechanism and demolition area for on-shift and off-shift activities. The emissions from the applicable sources have been combined to provide emissions estimates for each day from each demolition area.

\subsection{Air Dispersion Modeling}

The U.S. Environmental Protection Agency's (EPA's) AERMOD dispersion model is used to estimate atmospheric concentration and surface deposition of the released radioactive materials in the immediate vicinity of the demolition activities. AERMOD provides hourly estimates for the time periods that demolition is planned by accounting for the ambient meteorological conditions as well as the effect of the nearby buildings on the air flow. The hourly estimates can be used to analyze longer time periods from within AERMOD or through post-processing. The rationale for the selection and use of the AERMOD dispersion model is documented in Appendix B.

The modeling is conducted to be inclusive of the weather conditions that are possible (i.e., uses full annual cycles of meteorological data) and representative of the expected demolition period (i.e., models the hours of the day that demolition activities will occur). The air concentrations and deposition rates are modeled for an array of receptors covering the demolition site and surrounding area. Peak weeklyaveraged values of air concentrations are evaluated with modeling results reported as time-integrated incremental derived air concentrations in DAC-hours; total estimated depositions from all activities are presented as disintegrations per minute $(\mathrm{dpm})$ per $100 \mathrm{~cm}^{2}$.

The modeling analysis defines the potential levels of air and surface exposures from the proposed demolition activities. Potential air exposures are defined in terms of 1) spatial patterns of average and peak concentrations and 2) the distribution of occurrences of peak concentrations at measurement locations and control boundaries. The potential surface depositions are defined in terms of total deposited concentrations of alpha- and beta/gamma-emitting materials.

Using these methods, emission and air dispersion computations were made to assess the potential concentrations from different sets of demolition assumptions. The analysis process consisted of three steps:

1. Estimate the emission rates for the proposed demolition activities - Step 1 starts with an estimate of the amount of contamination in the structure, what form it is in, and where it is located. Demolition methods and associated activities are identified in this step. These data are combined to generate estimates of emissions during the demolition activities.

2. Compute the airborne and deposited concentrations - Step 2 takes the emission rate estimates from Step 1 and produces estimates of environmental concentrations. An assumed 1-hour release is used to define potential peak exposures. The main intermediate products are hourly peak air concentrations and hourly surface deposition. 
3. Determine if the potential concentration levels are acceptable - Step 3 uses standards to evaluate the viability of the demolition option that has been modeled. For air exposures, a limit of 12 DAC-hours per week is used. For deposition, a limit of $20 \mathrm{dpm} / 100 \mathrm{~cm}^{2}$ removable alpha contamination is used. If none of the locations within the selected areas show values that exceed these limits, then the demolition is deemed clearly viable.

The potential emission rates associated with proposed demolition activities are estimated based on specific methods of execution. Appendix A provides a detailed definition of those activities including the assumptions and approximations that are required to provide a context for the demolition for each of the PFP components.

The air dispersion modeling with AERMOD requires a number of assumptions related to model options, source-term input definition, analysis products, time scales, and receptor locations. The details of those assumptions are discussed in Appendix C.

\subsection{Airborne Contamination Dosimetry}

The dosimetry depends on the mixture of radioisotopes present. The inventories listed in Table 2.1 are assumed to represent the contamination present in the various PFP complex buildings and equipment. The spectrum of radionuclides is based on the best information available for each structure.

U.S. Department of Energy (DOE 1998) regulations specify in 10 CFR 835.2, "Definitions," that an airborne radioactivity area means any area accessible to individuals where the concentration of airborne radioactivity above natural background exceeds or is likely to exceed the DAC, or an individual present in the area without respiratory protection could receive an intake exceeding $12 \mathrm{DAC}$-hours in a week. If radionuclides " $\mathrm{A}$," "B," and " $\mathrm{C}$ " are present in concentrations $\mathrm{C}_{\mathrm{A}}, \mathrm{C}_{\mathrm{B}}$, and $\mathrm{C}_{\mathrm{C}}$, and if the applicable DACs are $\mathrm{DAC}_{\mathrm{A}}, \mathrm{DAC}_{\mathrm{B}}$, and $\mathrm{DAC}_{\mathrm{C}}$, respectively, then the concentrations shall be limited so that the following relationship exists:

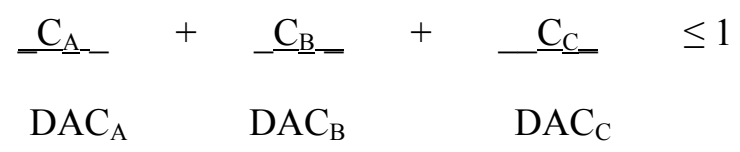

For a mixture of radionuclides where the concentrations of each are expressed in terms of a fraction, $\mathrm{f}$, of a total, $\mathrm{DAC}_{\mathrm{T}}$, this can be written as:

$$
\begin{aligned}
& \underline{\mathrm{f}}_{\mathrm{A}} * \mathrm{DAC}_{\mathrm{T}_{-}}+\underline{\mathrm{f}}_{\mathrm{B}} * \mathrm{DAC}_{\mathrm{T}_{-}}+\underline{\mathrm{f}}_{\mathrm{C}} * \mathrm{DAC}_{\mathrm{T}_{-}} \leq 1 \\
& \begin{array}{lll}
\mathrm{DAC}_{\mathrm{A}} & \mathrm{DAC}_{\mathrm{B}} & \mathrm{DAC}_{\mathrm{C}}
\end{array}
\end{aligned}
$$

This relationship can be used to determine a maximum total concentration that meets the requirements as:

$$
\begin{aligned}
& \underline{\mathrm{f}_{\mathrm{A}}}-+\underline{\mathrm{f}_{\mathrm{B}}}-\quad+\quad \underline{\mathrm{f}}_{\underline{\mathrm{C}}_{-}}=-1 \\
& \mathrm{DAC}_{\mathrm{A}} \quad \mathrm{DAC}_{\mathrm{B}} \quad \mathrm{DAC}_{\mathrm{C}} \quad \mathrm{DAC}_{\mathrm{T}}
\end{aligned}
$$




\subsection{Summary of Anticipated Radionuclide Inventories}

Because the various buildings and rooms within each building have different anticipated contamination levels at the time of demolition, for the purposes of demolition planning the complex has been subdivided into demolition planning zones. These zones are illustrated in Figure 2.1. In this figure, numbers 1-26 and Letters A-J represent lines of support columns within the 234-5Z building. Dashed lines represent the $291-Z$ fanhouse, which is not included in the demolition planning, although it is connected to the 291-Z-1 stack.

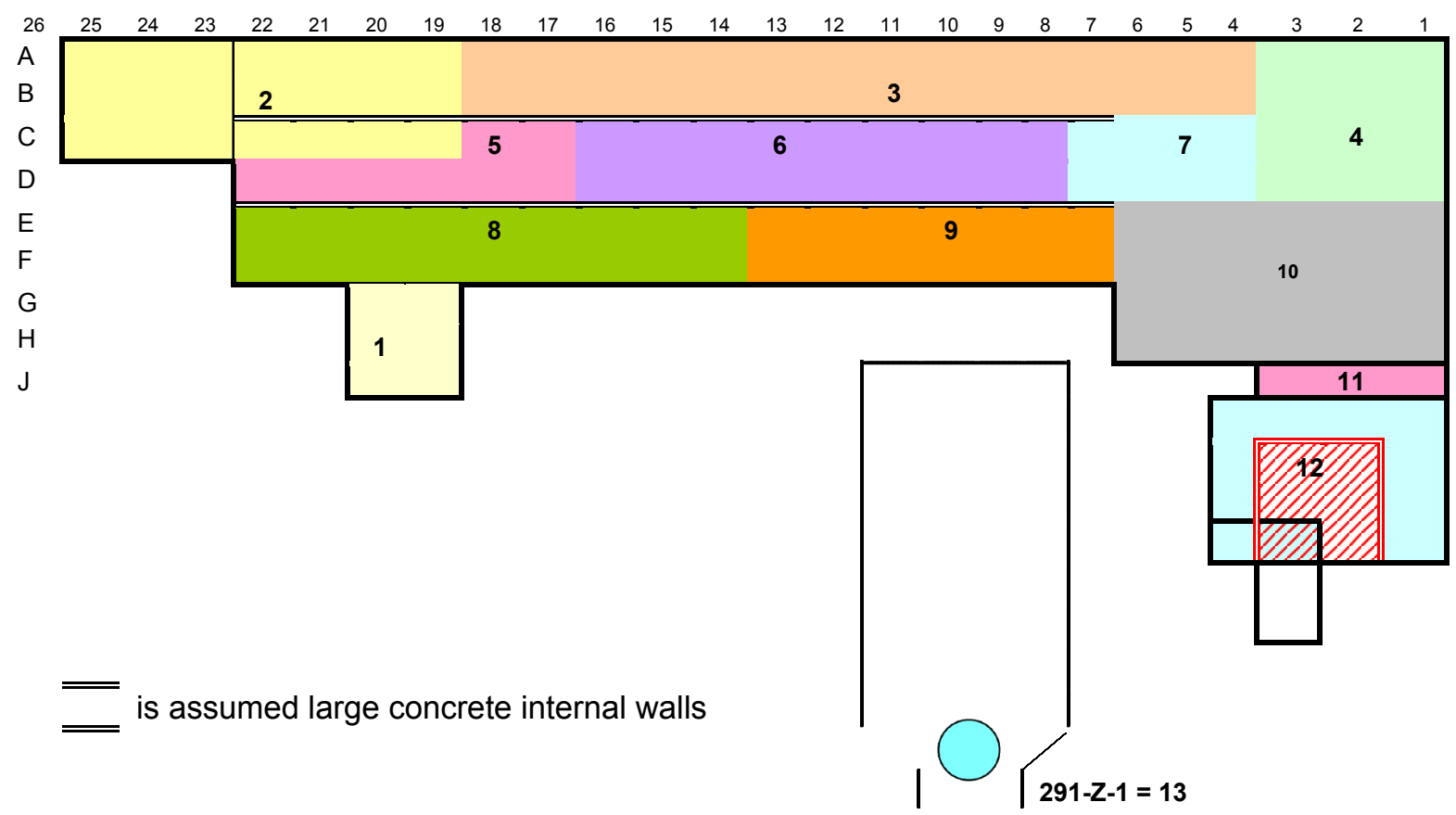

Figure 2.1. Demolition Zones Defined for this Analysis

The radioactive contamination of concern for the PFP building demolition is located on surfaces, under paint and tiles, within ducts, and in other inaccessible places. Table 2.1 is a summary of the inventories used in the structure-specific source term analyses in Appendix A. The total inventories are estimated based on the listed levels of residual contamination assumed at the time of demolition. 
Table 2.1. Anticipated Inventory of Radionuclides in Defined Demolition Zones of the PFP Complex

\begin{tabular}{|c|c|c|c|}
\hline Zone & & $\begin{array}{l}\text { Contamination } \\
\left(\text { dpm } / 100 \mathrm{~cm}^{2}\right) \\
\end{array}$ & $\begin{array}{r}\text { Inventory } \\
\text { (alpha curies) }\end{array}$ \\
\hline \multirow[t]{2}{*}{1} & 234-5Z Office Annex & & \\
\hline & 1 st story & 2000 & 0.000116 \\
\hline \multirow[t]{4}{*}{2} & 234-5Z Vault Annex plus NW cornes & & \\
\hline & 1st story & 2000 & 0.000282 \\
\hline & duct level & 2000 & 0.000172 \\
\hline & 2nd story & 2000 & 0.000168 \\
\hline \multirow[t]{4}{*}{3} & 234-5Z Northern quarter & & \\
\hline & 1st story & 2000 & 0.000373 \\
\hline & duct level & 2000 & 0.000403 \\
\hline & 2nd story & 2000 & 0.000544 \\
\hline \multirow[t]{4}{*}{4} & 234-5Z Northeast corner & & \\
\hline & 1st story & 2000 & 0.000234 \\
\hline & duct level & 2000 & 0.000180 \\
\hline & 2nd story & 2000 & 0.000213 \\
\hline \multirow[t]{4}{*}{5} & 234-5Z Original metalworking area & & \\
\hline & 1st story & $200,000(a)$ & 0.008761 \\
\hline & duct level & 200,000 & 0.009811 \\
\hline & 2nd story & 52,000 & 0.002305 \\
\hline \multirow[t]{4}{*}{6} & 234-5Z RMA/RMC areas & & \\
\hline & 1st story & $200,000(a)$ & 0.023894 \\
\hline & duct level & 200,000 & 0.025768 \\
\hline & 2nd story & 2,000 & 0.000448 \\
\hline \multirow[t]{4}{*}{7} & 234-5Z RECUPLEX area & & \\
\hline & 1 st story & 200,000 & 0.016732 \\
\hline & duct level & 2,000 & 0.000144 \\
\hline & 2nd story & $82,000(b)$ & 0.009702 \\
\hline \multirow[t]{4}{*}{8} & 234-5Z Development lab area & & \\
\hline & 1st story & 50,000 & 0.006180 \\
\hline & duct level & 2,000 & 0.000218 \\
\hline & 2nd story & 2,000 & 0.000259 \\
\hline \multirow[t]{4}{*}{9} & 234-5Z Southern quarter & & \\
\hline & 1st story & 2,000 & 0.000207 \\
\hline & duct level & 2,000 & 0.000152 \\
\hline & 2nd story & $30,000(\mathrm{c})$ & 0.004090 \\
\hline \multirow[t]{5}{*}{10} & 234-5Z Analysis lab area & & \\
\hline & 1 st story & 50,000 & 0.010071 \\
\hline & duct level & 2,000 & 0.000224 \\
\hline & 2nd story & 2,000 & 0.000248 \\
\hline & $234-5 Z \mathrm{C}$ & & 0.121901 \\
\hline \multirow[t]{10}{*}{11} & $242-\mathrm{Z}$ & & \\
\hline & Control room walls & 200,000 & 0.002156 \\
\hline & Control room ceiling & 200,000 & 0.000536 \\
\hline & Tank room walls & 200,000 & 0.001925 \\
\hline & Tank room ceiling & 200,000 & 0.000335 \\
\hline & Annex walls & 10,000 & 0.000022 \\
\hline & Annex ceiling & 10,000 & 0.000007 \\
\hline & Hall walls & 10,000 & 0.000022 \\
\hline & Hall ceiling & 10,000 & 0.000009 \\
\hline & $242-\mathrm{Z} \mathrm{Ci}$ & & 0.005010 \\
\hline \multirow[t]{4}{*}{12} & $236-Z$ & & \\
\hline & Process Cell & $50 \mathrm{nCi} /$ gram & 48.00000 \\
\hline & Remainder of 236 & 2,000 & 0.000500 \\
\hline & $236-\mathrm{Z} \mathrm{Ci}$ & & 48.00050 \\
\hline \multirow[t]{2}{*}{13} & 291-Z-1 Stack & & \\
\hline & Stack inner lining & 10,000 & 0.000420 \\
\hline
\end{tabular}

(a) 1 st \& duct level

(b) $2 / 10$ ths top floor $(\mathrm{Rm} 320)$

(c) 2/14ths of top floor ( $\mathrm{Rm} 320)$ 


\subsection{Modeling Demolition Scenarios}

The modeling analysis requires definition of representative demolition scenarios. Those scenarios include both the activities and a plan for performing those activities. The most-accessible equipment and sections of the buildings are assumed to be removed before less-accessible components. The analyses credit the use of misting, water, and fixatives throughout the demolition and load out process to minimize airborne contamination spread.

Each building in the PFP complex is considered in terms of its construction and anticipated contamination levels (see details in Appendix A). All demolition and load out will only occur when sustained wind speeds are less than 15 miles per hour. The results, which are presented in Section 3, are based on the following demolition scenarios:

- 236-Z: The preferred option assumed is to entirely demolish $236-\mathrm{Z}$ with hydraulic shears. That activity is projected to require about eight weeks of elapsed time.

- 242-Z: The 242-Z building roof and walls are assumed to be demolished with a multiprocessor operating hydraulic shears. It was assumed that the overall demolition would require about one week.

- 234-5Z: The various zones of the 234-5Z building are assumed to be demolished using hydraulic shears. Certain gloveboxes may remain in the building until the time of demolition; these are discussed in Appendix D. The entire demolition process for $234-5 \mathrm{Z}$ is assumed to require 20 weeks.

- 291-Z-1: The 291-Z-1 stack is assumed to be toppled with explosives; the stack will be directed to fall into a prepared trench. After being toppled, the stack will be broken up into smaller pieces using a multiprocessor. The entire process is assumed to require 1 week.

Supplementary scenarios (alternative demolition techniques, additional unique sources) are described in Appendix D. Appendix D includes the results of a supplemental computation based on an alternative 236-Z demolition approach. ${ }^{2}$

The demolition scenarios assume that, even with fixatives, misting, and other controls, a certain amount of dust will escape from the demolition activities. The amount of dust released as a function of time from the start of demolition is shown in Figure 2.2. The actual radiation risk is related to the amount of residual radioactive contamination contained in the dust, which varies with the various parts of the facility being demolished. An inventory-weighted plot of the source term is shown in Figure 2.3. It can be seen in Figure 2.2 that the portion of the demolition related to demolishing the outer, low-contaminated portions of the 236-Z building has the largest continuous amount of dust released (approximately weeks 30 to 34). The modeling assumed that only moderate controls would be applied to this portion of the demolition because of the low inventory. In Figure 2.3, it can be seen that the radioactive source term resulting from this portion of the demolition is quite low. The later weeks of demolition of $236-\mathrm{Z}$ has an oscillating pattern of dust release in Figure 2.2, caused by the alternation of demolition and load-out, but the corresponding pattern in Figure 2.3 is more level because of the varied controls assumed. Notice that

\footnotetext{
${ }^{2}$ Because the largest projected releases from the PFP structure demolition activities are associated with the shearing demolition of 236-Z, a supplementary $236-\mathrm{Z}$ non-shearing demolition scenario based on use of a wire saw was considered. This second scenario is a very labor-intensive approach that provides a lower bound for the potential emission rates. This second approach is projected to have a much longer (18 month) time period for the overall demolition of $236-Z$ compared to the shearing approach.
} 
the latter portions of the demolition of $236-Z$ show the largest releases of radioactive material; this is the largest part of the assumed source term, caused by the assumption that the cell contamination averages $50 \mathrm{nCi} / \mathrm{g}$ of cell mass. The peak at the start of cell demolition (about week 35) results from the dust (and radioactive material) released during the demolition of the cell ceiling and dropping of the rubble to the ground.

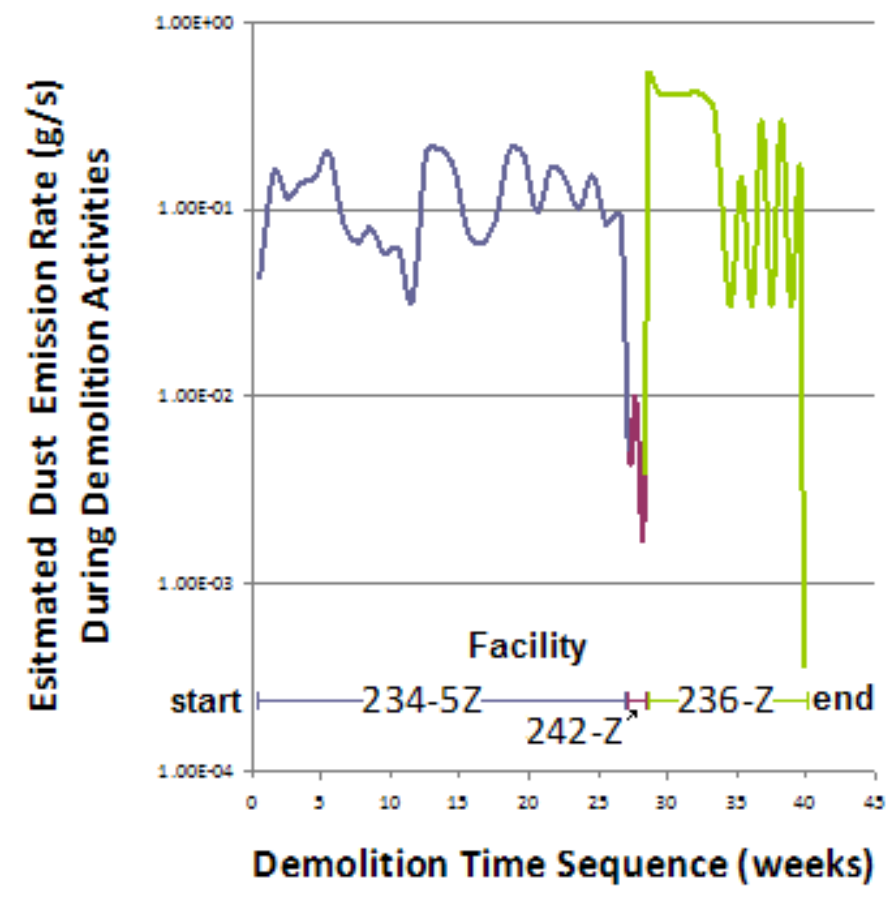

Figure 2.2. Weekly-averaged Dust Release Rate during Active Demolition and Load-out Activities 


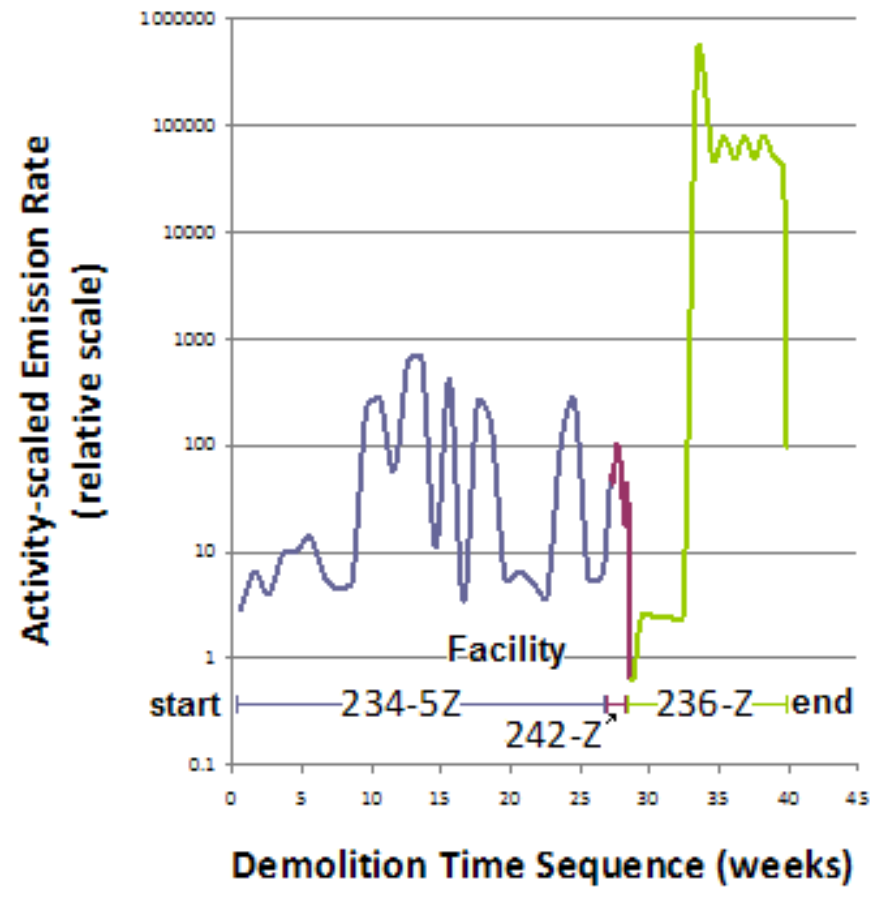

Figure 2.3. Weekly-averaged Radioactive Source Term During Active Demolition and Load-out Activities

\subsection{Quality Control Procedures and Documentation}

The quality control procedures for conducting these analyses are discussed in Appendix E. Source term and emission rate worksheets are documented in Appendix F. Appendix G documents the contents of selected AERMOD input and output files. These output files contain listings of both modeling inputs and results. 


\subsection{Predicted Impacts}

The air concentration and surface deposition modeling efforts were conducted for demolition of all the PFP buildings as described in terms of demolition zones 1 through 12 in Section 2. The predicted potential impacts from demolition of all the PFP buildings are presented in Sections 3.1 and 3.2; impacts from the 291-Z-1 stack demolition are in Section 3.3. Component-based contributions to impacts are also presented for 1) the least contaminated structures and 2) the most contaminated structures.

The results presented in this section use a PFP facility area map shown in Figure 3.1 as a base map. The map includes the facility fenceline (black) and the major roads (brown). The buildings and subsets of buildings being considered for demolition are shown as colored overlays. Structures shown in gray, some of which will be gone at the start of the PFP demolition activities, are not part of structures considered in this report. The structures marked in green including 234-5Z (demolition zones 1 to 10) and 242-Z (demolition zone 11) are the buildings in the PFP complex grouped as having lower overall contamination levels. The structures marked in orange including 236-Z cell and associated structures (zone 12) are the areas with higher levels of contamination. Also shown in Figure 3.1 is the PFP stack (marked in blue); the demolition of this structure is considered in Section 3.3.

The air exposure results presented below are the increments predicted to result from the demolition modeling - and as such do not contain a background component. The air monitoring stations in the immediate vicinity of the PFP complex will be only able to detect increments in air exposures from demolition if those increments are large enough to be distinguished from the local background. The background for this area is estimated to be on the order of 0.015 and 0.03 DAC-hours for 1-week and 2-week background exposures, respectively. ${ }^{1}$

The air dispersion modeling of the PFP building demolition addresses air concentration and surface deposition. Air concentration is characterized in terms of derived air concentration (DAC)-hour exposures summed over work-week time periods. Surface deposition is characterized in terms of cumulative deposition expressed in disintegrations per minute $(\mathrm{dpm})$ per $100 \mathrm{~cm}^{2}$ modeled over the elapsed time for the specific demolition activities under consideration.

\footnotetext{
${ }^{1}$ In an analysis of the routine air samplers (Napier et al. 2010), the mean of background air samples at the Hanford 200-West monitoring stations is shown to be about $1.2 \times 10^{-15} \mu \mathrm{Ci} / \mathrm{ml}$ of gross alpha-emitters. The DAC for the worst-case analysis of $236-\mathrm{Z}$ is about $1.43 \times 10^{-11} \mathrm{uCi} / \mathrm{ml}$ of alpha-emitters. Most of the background will be natural alpha-emitting radionuclides, primarily progeny of the uranium chain. If the background is assumed to have the same radionuclide spectrum as the contamination of the 236-Z building (which is conservative from a dosimetric sense), the background levels of air concentration are at about 0.0001 DAC; 1-week and 2-week background exposures are estimated to be about 0.015 and 0.03 DAC-hours, respectively.
} 


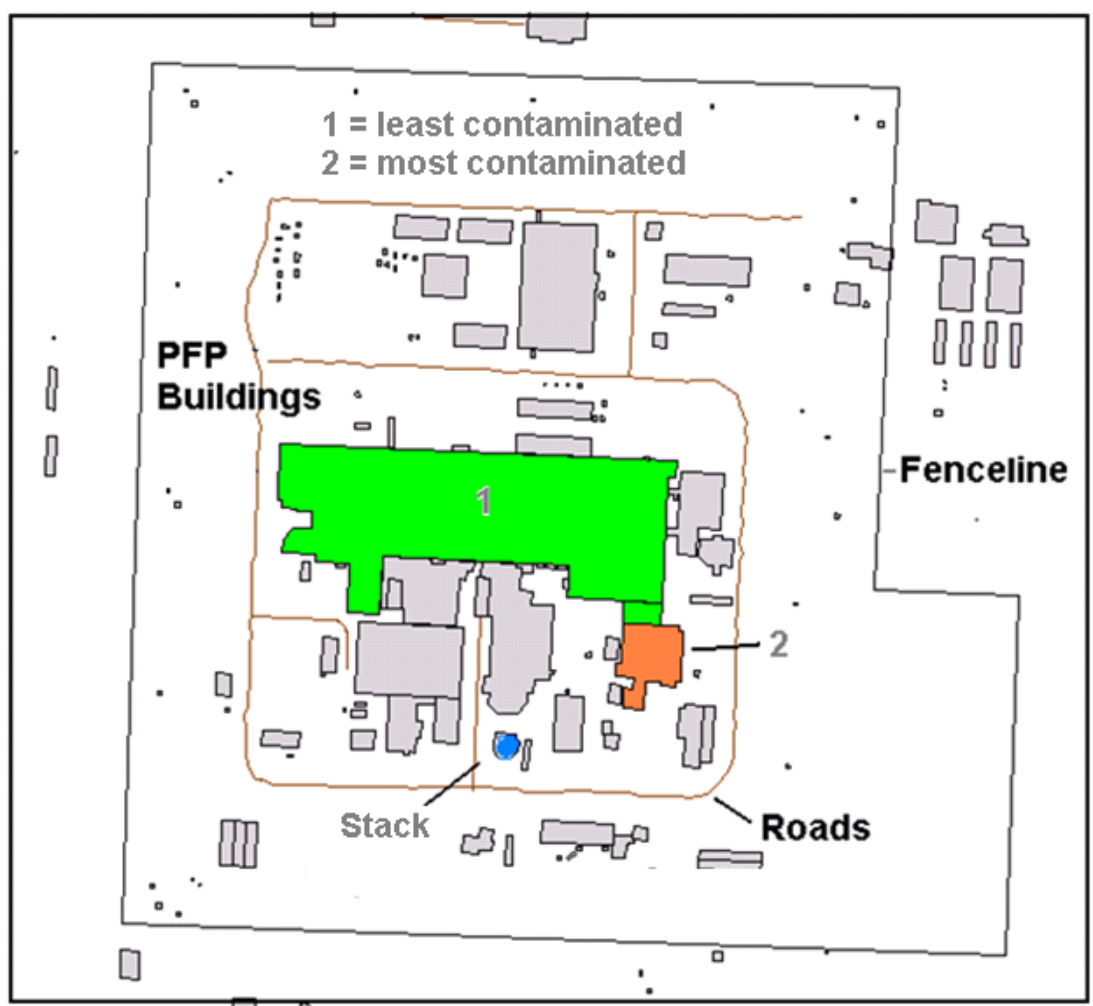

Figure 3.1. PFP Structures Being Considered for Demolition

To evaluate the potential exposure levels from the planned demolition activity scenarios listed in Section 2 and detailed in appendices, the local patterns of air concentrations and surface deposition amounts were computed for each demolition-hour using annual cycles of 5 years of recent meteorological data (2005-2009). All activities are assumed to occur during the day shift. Allowing for weekends and holidays, the start-to-finish demolition period for all the demolition activities is projected to be about 10 months.

The modeling of the potential impacts of this 10-month period of projected activities required characterization of the full sequence of day-to-day demolition activities. Two modeling approaches are used in AERMOD to analyze the potential air concentration and surface deposition:

1. Maximum-impact model runs were conducted for "worst case" demolition weeks (i.e., demolition sequences resulting in the greatest activity-based weekly emission rates) using the entire 5-year meteorological data period. The results of these runs provide a basis for climatologically defining the maximum impacts that could occur during any of the demolition activities.

2. Case-study model runs were conducted for the full projected sequence of releases. The results of these runs provide an indication of the order of magnitude of impacts that can be expected for sequences starting during different times of the year.

To maximize the number of time periods used in the climatological definition of peak exposure values, the air quality modeling of climatological peak exposures is conducted using 5-day instead of 7-day weeks. For air concentrations, each 5-day cumulative DAC exposure is the same that would be computed based on an expanded 7-day period (with no emissions on a 2-day weekend). For surface depositions, the modeling of each demolition activity is based on the number of demolition work-days 
rather than the elapsed time. Because the surface depositions are based on cumulative deposition, the use of demolition work-days will provide predicted values for deposition computed over a shorter time period. The effect of using shorter times for computing peak surface depositions is considered conservative because they will tend to cover narrower ranges of ambient dispersion conditions. The demolition activities for all the PFP structures involve about 200 work-days. Of those efforts, a total of 56 work-days are projected for the $236-Z$ structures, including the penthouse (22 days) and the cell demolition (34 days).

Maximum impact results for air concentration and soil deposition are presented separately for structures with the least contamination (234-5Z demolition in zones 1 to 11) and most contamination (236-Z cell and associated structures in zone 12). These zones are shown above in Figure 3.1

\subsection{Building Demolition - Air Concentrations}

This section presents the air concentration modeling results for the shear demolition of the PFP buildings, 234-5Z, 242-Z, and 236-Z. The results are presented as contour plots of maximum air concentrations that represent the overall composite pattern of the maximum weekly air concentrations at each receptor.

Maximum-impact modeling runs are used to define the worst-case time-integrated air concentrations. The occurrence of the highest air concentrations will be associated with a coincidence of 1) demolition operations with the largest projected release rates and 2) the occurrence of the most limiting meteorological dispersion conditions. Although the operations for the PFP structures will extend over many months, the demolition of the more highly contaminated portions (i.e., areas that have the highest potential release rates) are projected to occur over a relatively short time period. To obtain the worst-case air concentrations, the maximum emission rates expected during planned work periods are modeled as potentially occurring anytime during the five-year (2005-2009) meteorological period.

Air concentrations are presented as contour plots of maximum values (expressed as total DAC-hours) resulting from weekly demolition activities. The highest, 5-day source term from the source term analysis discussed in Section 2.0 is used to define the worst-case emission rate in AERMOD. The resulting daily AERMOD concentrations outputs are post-processed to determine the maximum 5-day air concentration at each PFP receptor location; the maximum air concentration contour plot presents the overall composite pattern of the maximum weekly air concentration at each receptor.

The air concentration contour plots represent the worst weekly exposure that could occur at a given location during demolition using a five-year period of historical (2005-2009) onsite meteorological data. The meteorological dataset is of sufficient duration that it is expected to include worst-case meteorological conditions that lead to bounding weekly air concentrations. Actual air concentrations that will occur during demolition will be defined by the ambient meteorological conditions that occur during the demolition process and are expected to be less than the predicted bounding values.

\subsubsection{Demolition of 234-5 Z and 242-Z}

This section presents the air concentration modeling results for the $234-5 \mathrm{Z}$ and $242-\mathrm{Z}$ structures from shear demolition. These structures, which are labeled as demolition zones 1 through 11 in Figure 2.1, 
have less contamination than the 236-Z structure. As described in Section 3.1, the results are presented as contour plots of maximum air concentration that represent the overall composite pattern of the maximum weekly air concentration at each receptor.

Figure 3.2 is the resulting contour plot of the maximum weekly air concentration (expressed as weekly total DAC-hours) for the 234-5Z and 242-Z PFP structures. Demolition zone 6 (see Figure 2.1) results in the greatest weekly emission rate; all other demolition activities associated with zones 1 to 5 and zones 7 to 11 (see Figure 2.1) have lower weekly emission rates and therefore will have lower levels of predicted weekly peak exposures.

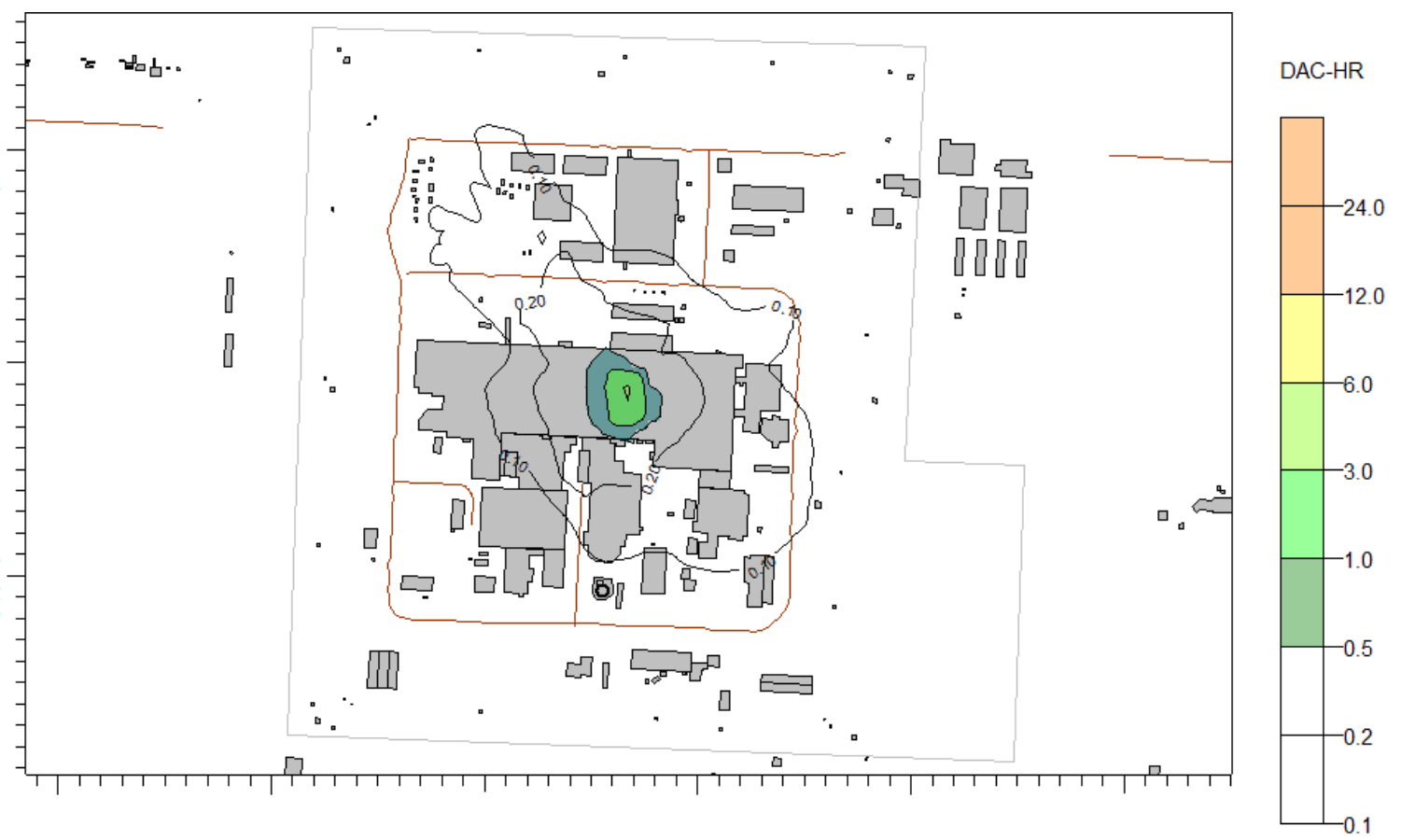

Figure 3.2. Predicted PFP Zone 6 Demolition Maximum Weekly Air Concentrations

\subsubsection{Demolition of 236-Z Cell and Associated Buildings}

This section presents the air concentrations modeling results for the shear demolition of the $236-Z$ structure, which includes the cell and other associated buildings. The structure, which is denoted by demolition zone 12 in Figure 2.1, contains areas with the highest contamination levels in the PFP complex. Because the activity-weighted emissions from the $236-Z$ cell account for $99.999 \%$ of the projected emissions from all the $236-Z$ structures, the results presented in this section are associated with the demolition activities for the $236-Z$ cell.

Seven weeks of activities are projected in Section 2 for the shearing demolition of the 236-Z cell. During those 7 weeks, the activity-weighted emissions from 236-Z (demolition 12) account for more than $99.7 \%$ of the total emissions from all buildings (demolition zones 1 to 12 ). Also the highest weekly activity-based emission rate for demolition for zones 1 to 11 is only $0.5 \%$ of the average weekly rate for zone 12. Thus the levels of air exposures for demolition other buildings will be much less that those predicted for 236-Z demolition seven week period -- much lower air exposures will occur for the other 8 to 9 months of demolition activities. 
The weekly emission rates for $236-Z$ vary with the portion of the structure being demolished. The first week that includes the dropping of the ceiling has the highest projected emission rate. Two of the weeks are projected to have emission rates that are only slightly less than the first week. Two weeks have projected emission rates that are about one half of the highest week's rate and the remaining two weeks have projected emission rates that are about a factor 13 lower than the highest week's rate.

Three output products are provided for the $236-Z$ cell air exposure modeling: 1) maximum weekly air concentration contour plots for all dispersion conditions, 2) maximum weekly air concentration contour plots for monthly dispersion conditions, and 3) maximum weekly air concentration values at the facility fenceline.

\subsubsection{Maximum Concentrations - All Dispersion Conditions}

Five-years (2005-2009) of onsite meteorological data were used to account for bounding, worst-case dispersion conditions leading to maximum predicted air exposure (expressed as weekly total DAC-hours) for the 236-Z cell; the resulting maximum air concentration contour plot is presented in Figure 3.3. The results are based on the highest projected weekly emission rate during the $236-\mathrm{Z}$ cell demolition, which is assumed to occur over any week within the five-year period. All other demolition activities associated with 236-Z cell and associated buildings demolition activities will have lower levels of weekly predicted peak exposures.

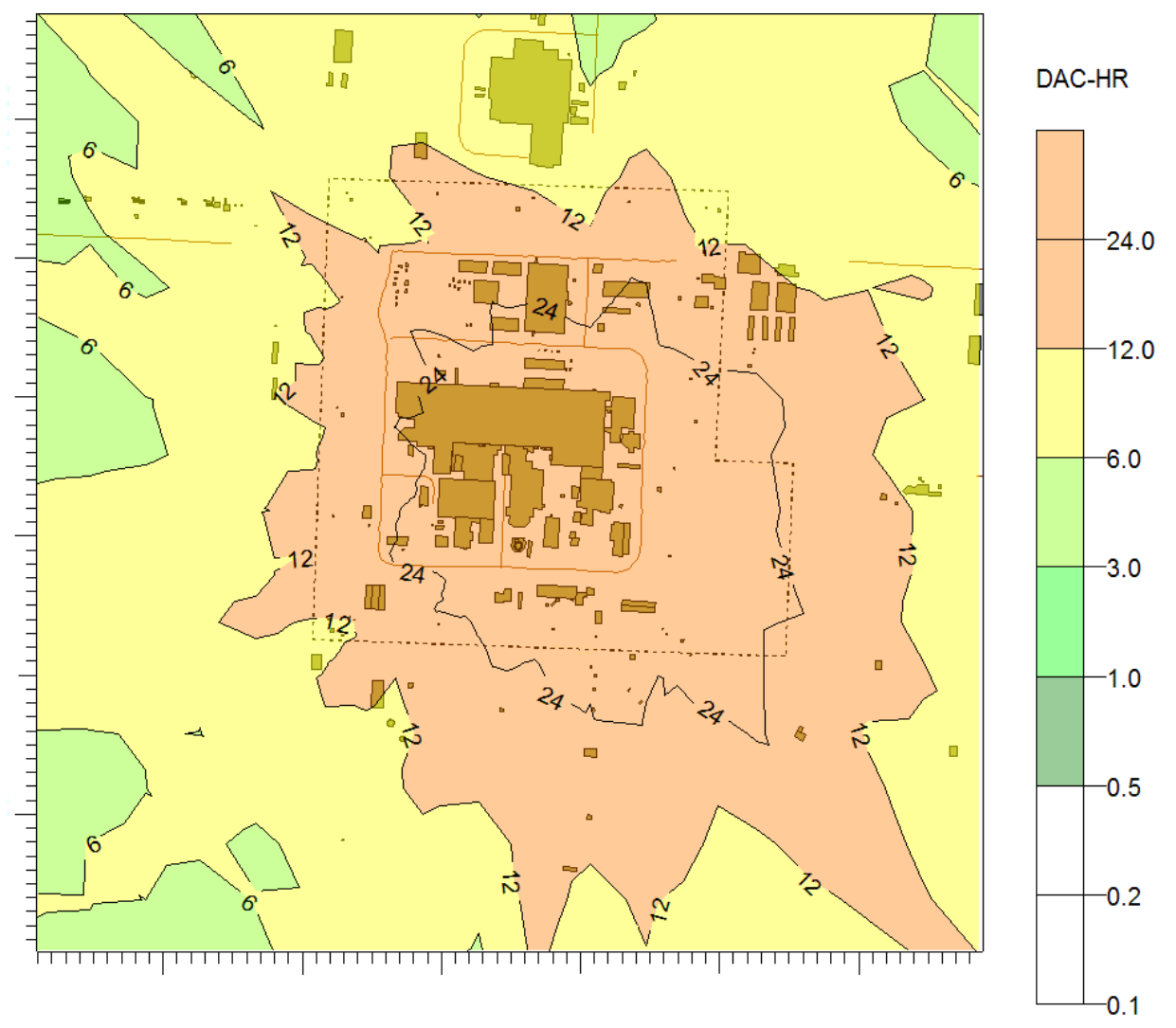

Figure 3.3. Predicted 236-Z Cell Demolition Maximum Weekly Air Concentrations 


\subsubsection{Maximum Concentrations - Monthly Dispersion Conditions}

Atmospheric conditions change with the seasons and the bounding values for the maximum concentrations from a demolition activity can be expected to vary with the time of year. The seasonal implications for the maximum concentrations are analyzed by computing monthly maximum concentrations from the 5- year (2005-2009) period in the same manner as described in Section 3.1.2.1.

Figures 3.4 to 3.15 are monthly maximum air concentration contour plots for shear demolition of the 236-Z cell structures as described in Section 2. In all plots, the integration time is for one week. The maximum one-week values for the given month from a 5-year (2005-2009) period are contoured in the plots.

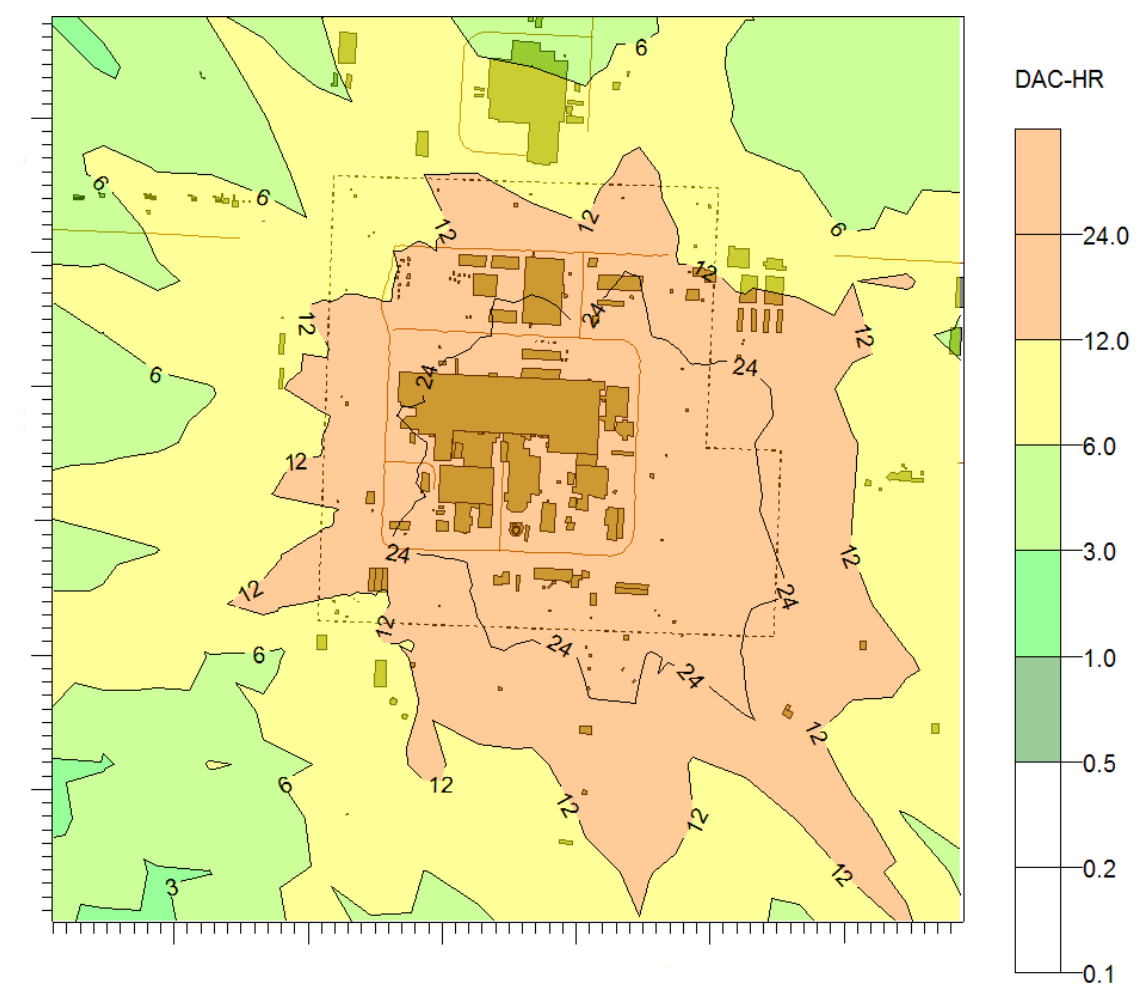

Figure 3.4. Predicted 236-Z Cell Demolition January Maximum Air Concentrations 


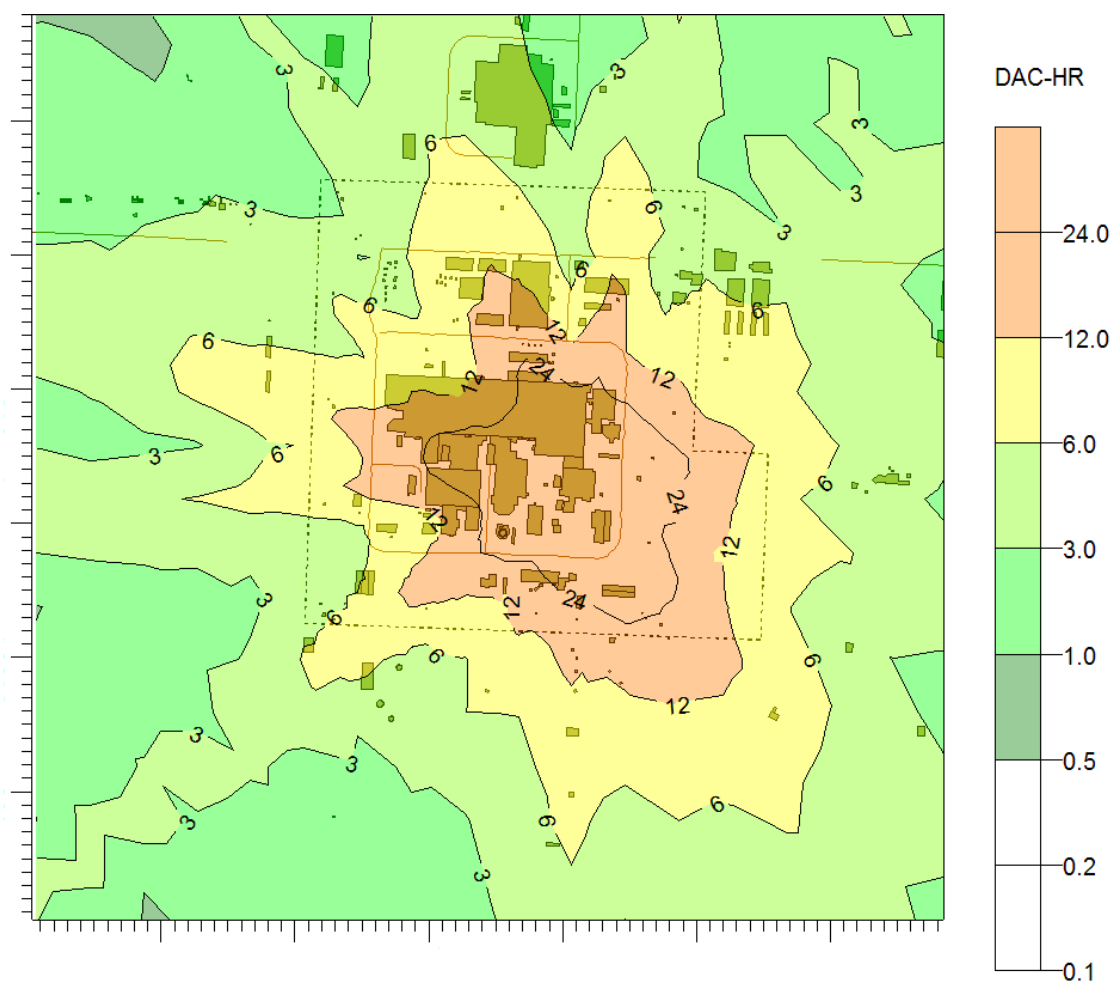

Figure 3.5. Predicted 236-Z Cell Demolition February Maximum Air Concentrations

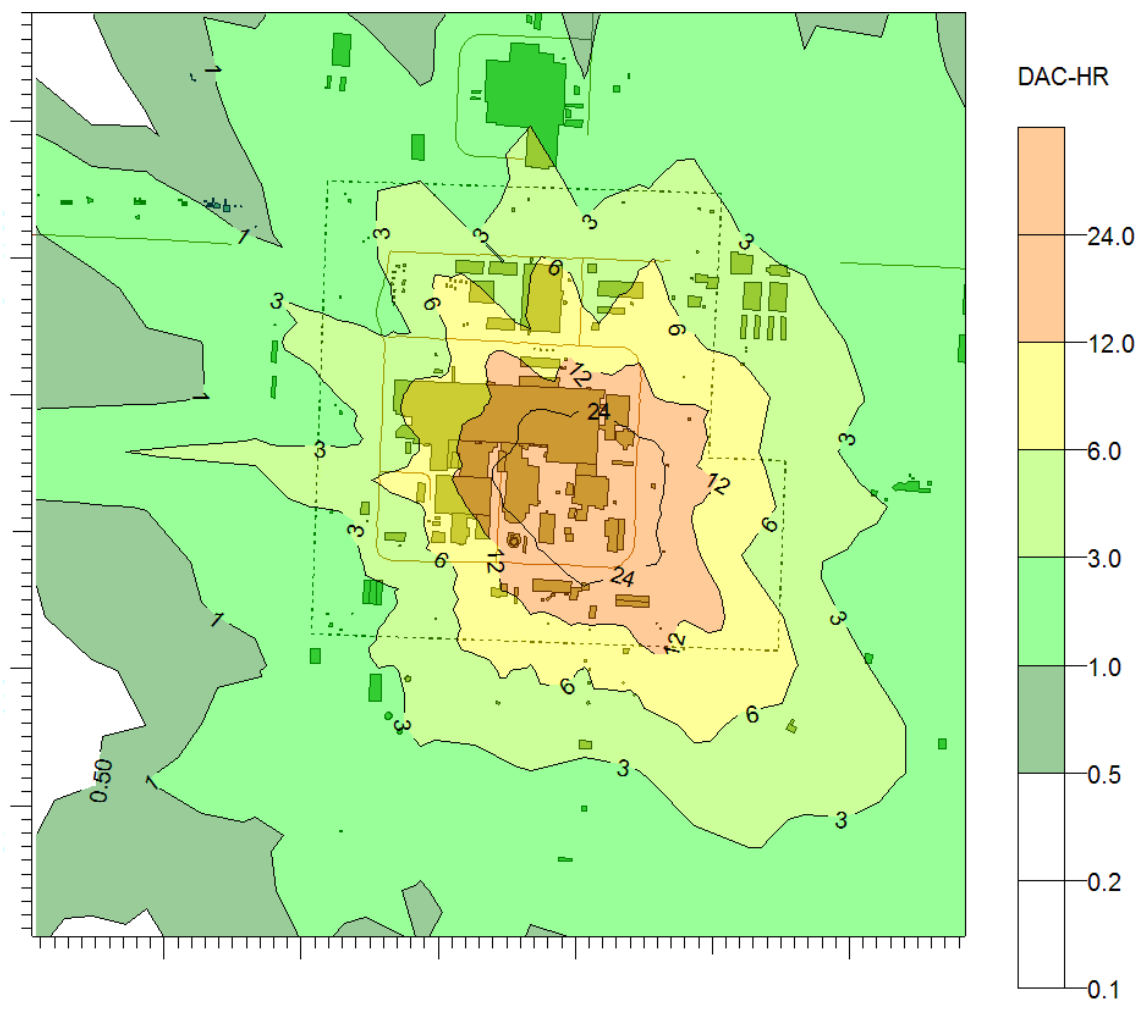

Figure 3.6. Predicted 236-Z Cell Demolition March Maximum Air Concentrations 


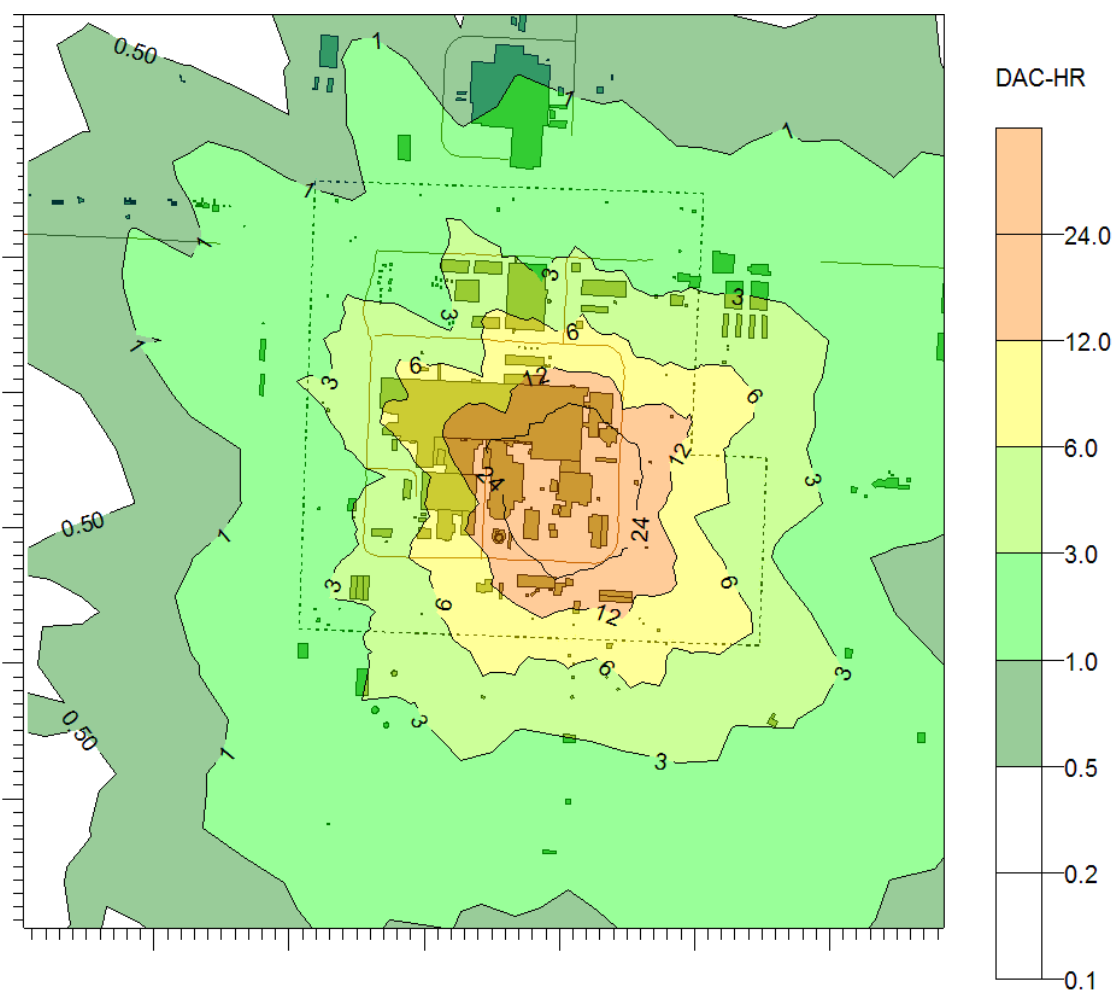

Figure 3.7. Predicted 236-Z Cell Demolition April Maximum Air Concentrations

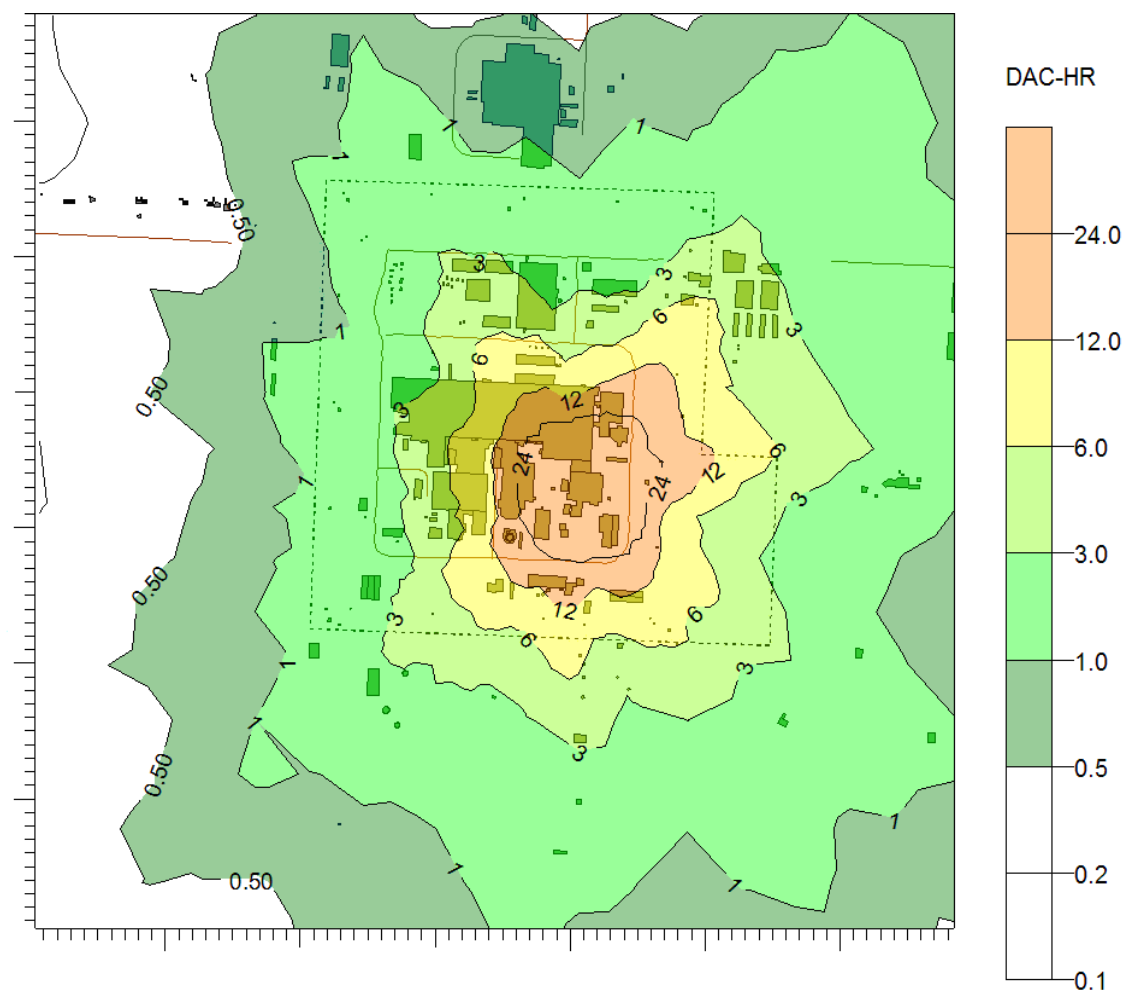

Figure 3.8. Predicted 236-Z Cell Demolition May Maximum Air Concentrations 


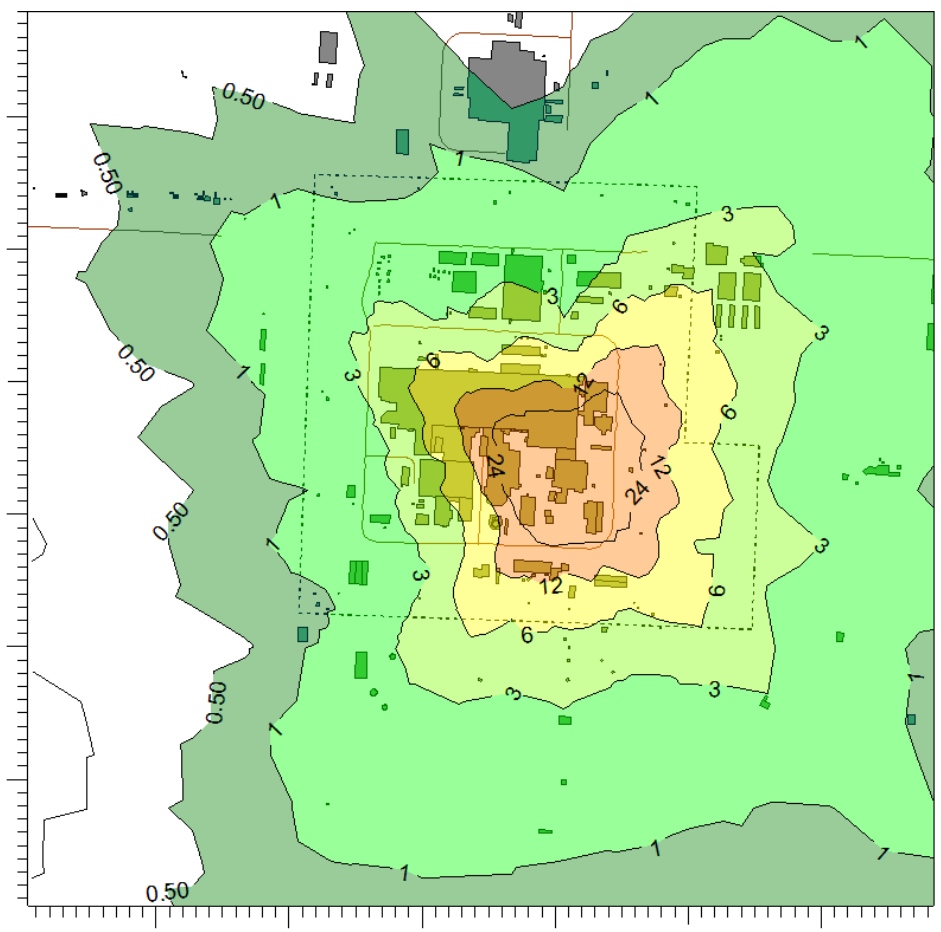

DAC-HR

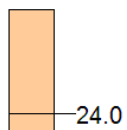

Figure 3.9. Predicted 236-Z Cell Demolition June Maximum Air Concentrations

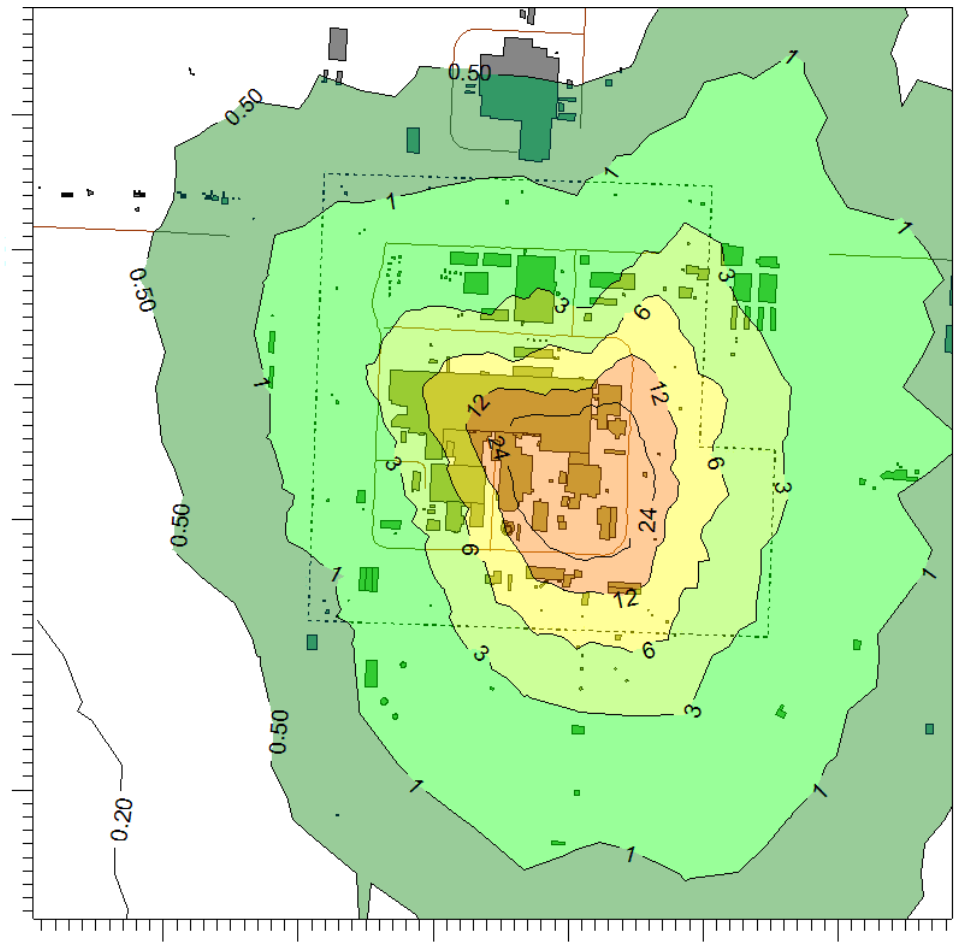

DAC-HR

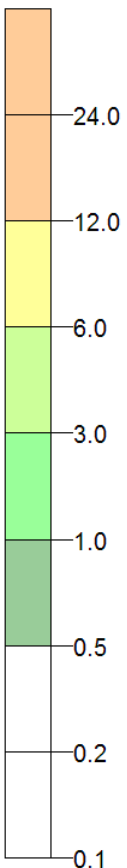

Figure 3.10. Predicted 236-Z Cell Demolition July Maximum Air Concentrations 

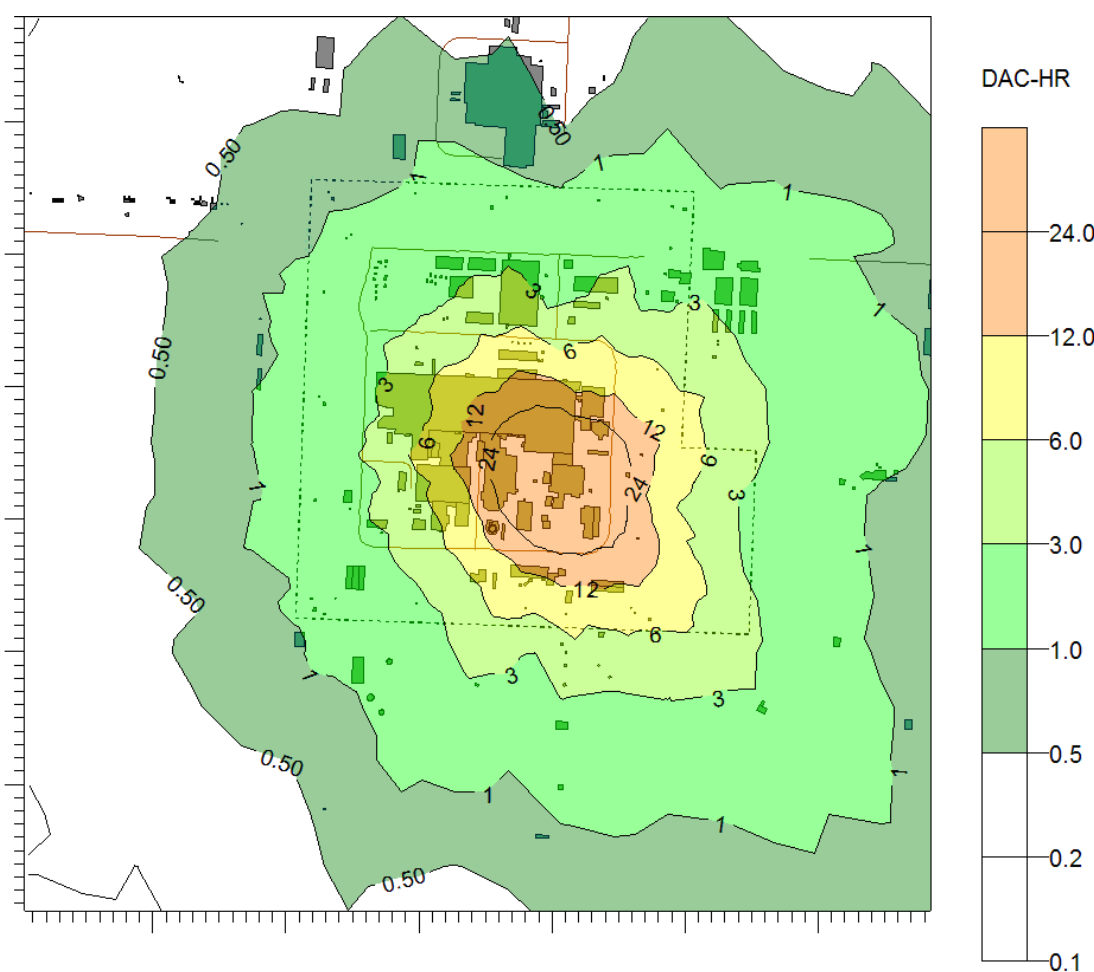

Figure 3.11. Predicted 236-Z Cell Demolition August Maximum Air Concentrations

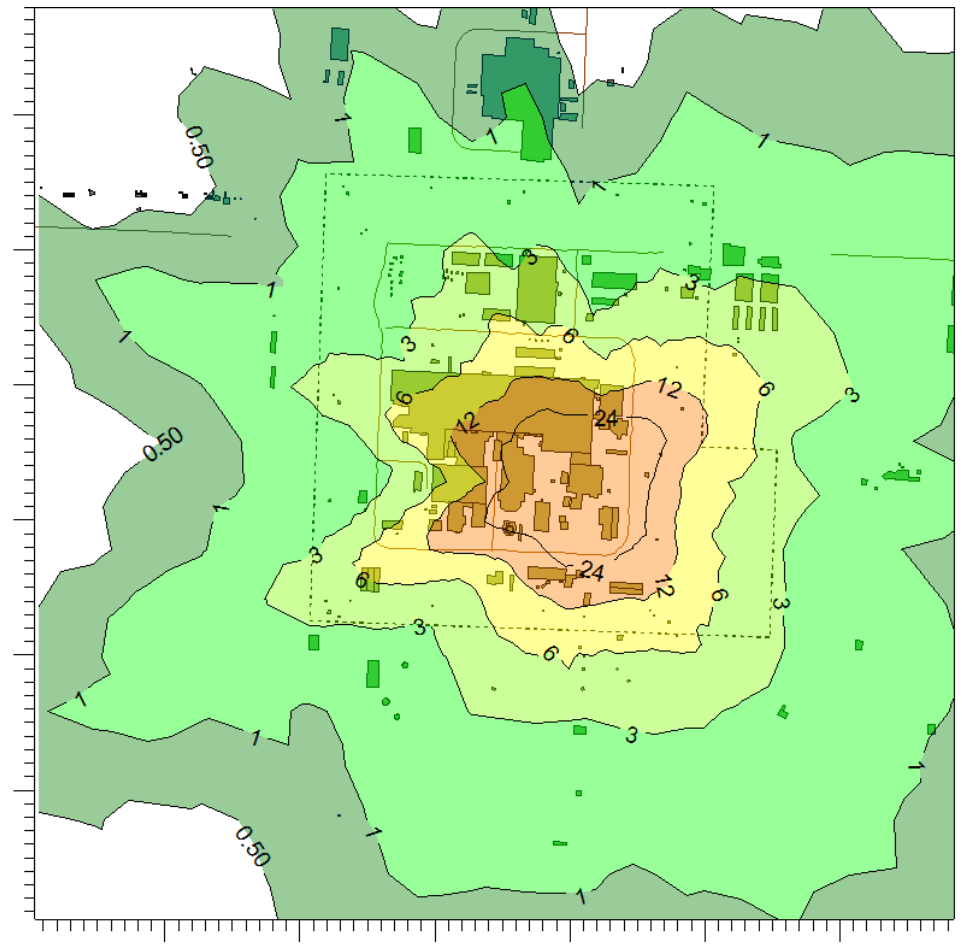

DAC-HR

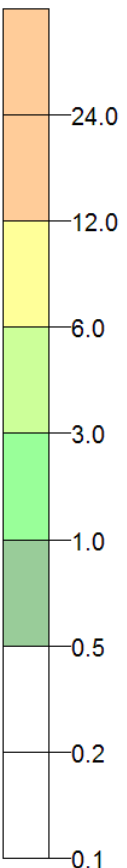

Figure 3.12. Predicted 236-Z Cell Demolition September Maximum Air Concentrations 


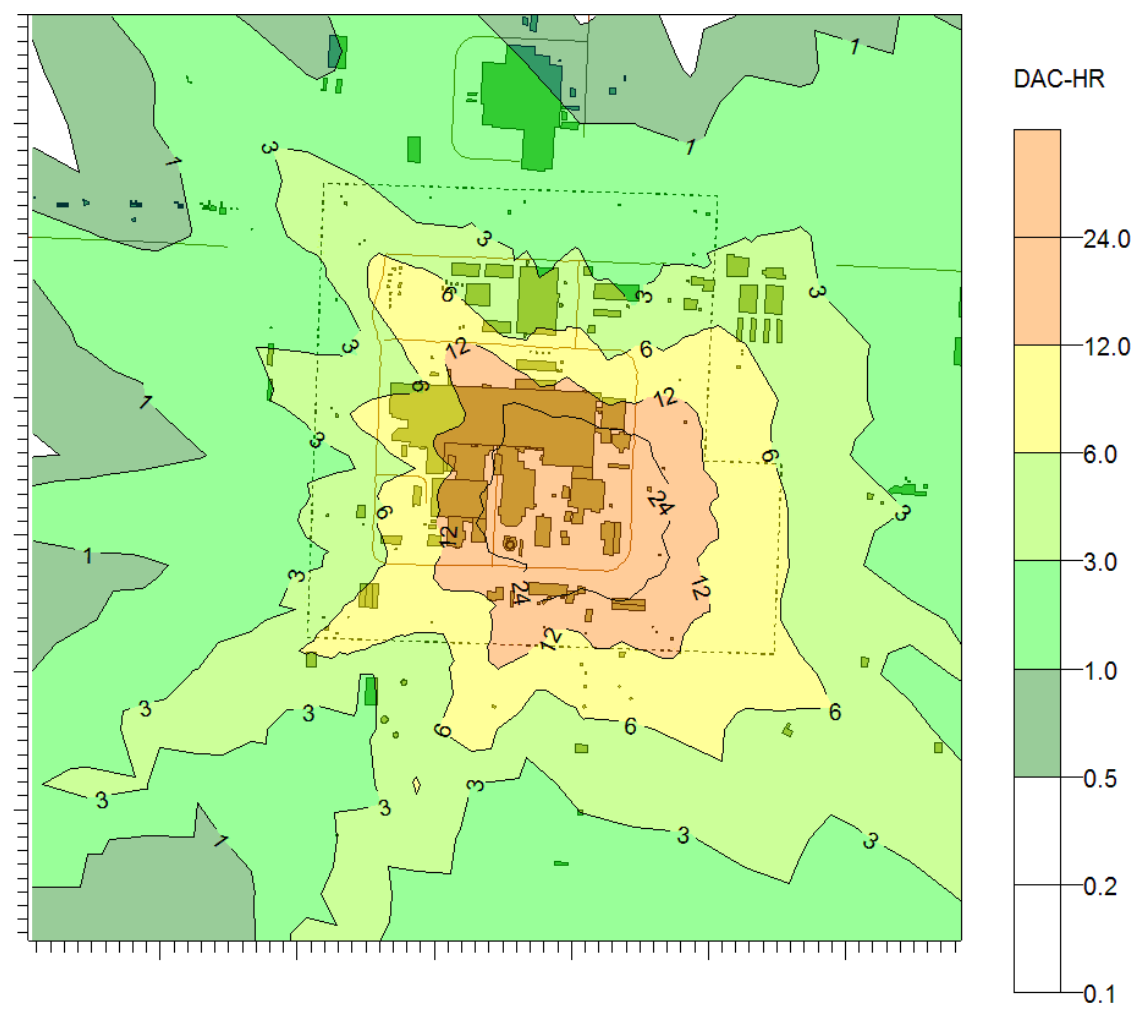

Figure 3.13. Predicted 236-Z Cell Demolition October Maximum Air Concentrations

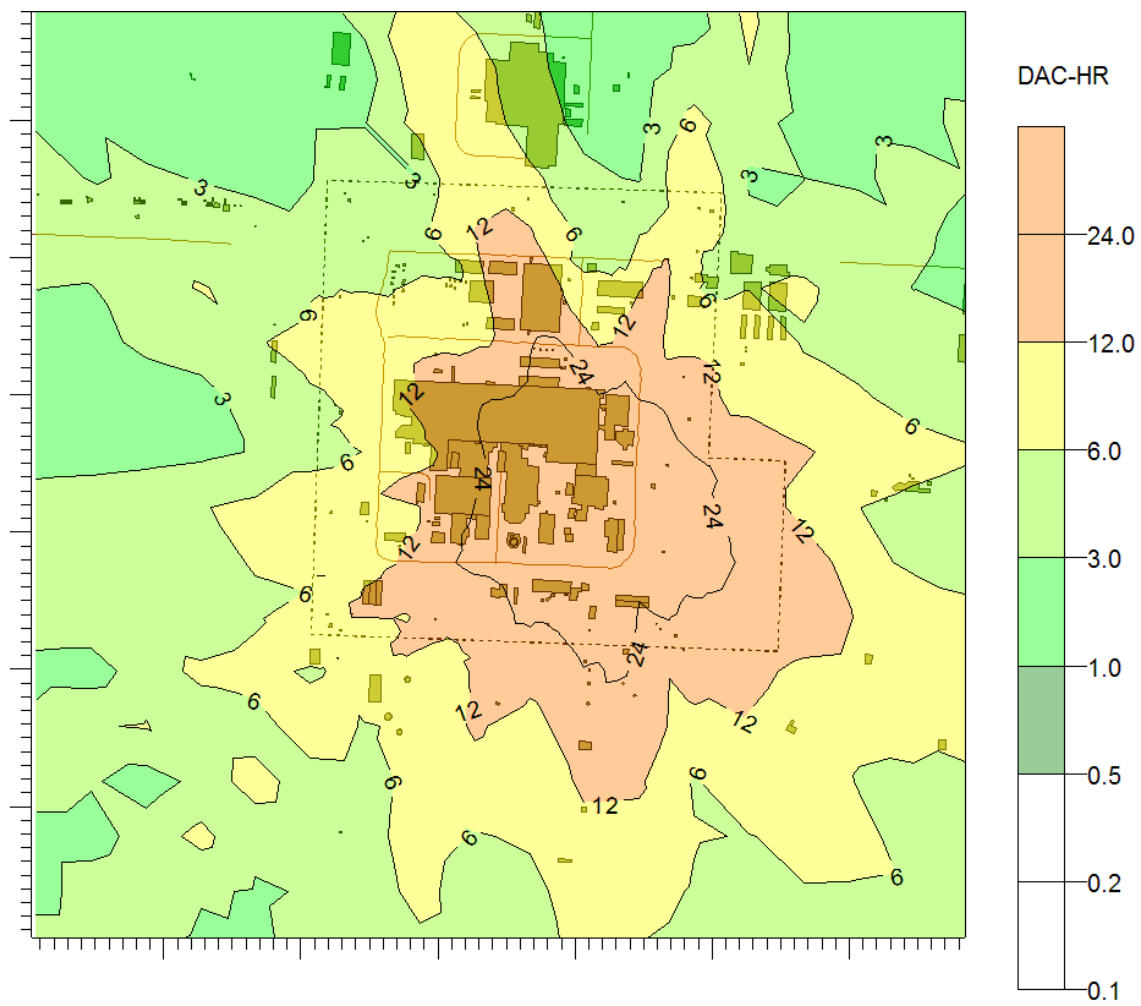

Figure 3.14. Predicted 236-Z Cell Demolition November Maximum Air Concentrations 


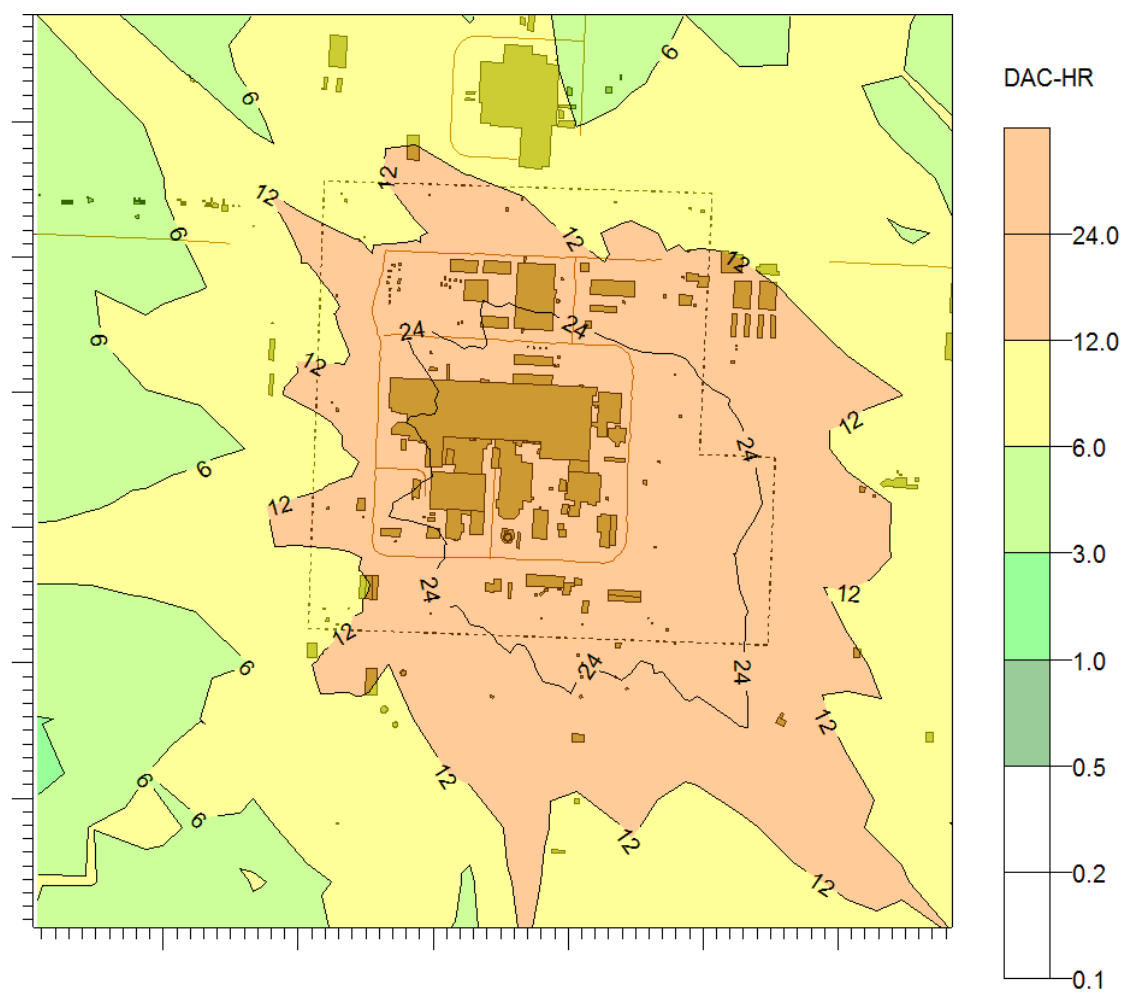

Figure 3.15. Predicted 236-Z Cell Demolition December Maximum Air Concentrations

\subsubsection{Maximum Concentrations at Facility Fenceline}

The concentrations on the facility fenceline were modeled for a series of receptors located on that boundary. Figure 3.16 provides the resulting spatial distribution of the highest predicted weekly air concentrations (with units of weekly total DAC-hour) for each fenceline receptor for all of the PFP complex, excluding the $236-\mathrm{Z}$ building demolition. Zero values are reported in this figure for all air exposures below 0.1 DAC-hours per week. Figure 3.17 provides the same information for only the $236-Z$ building demolition. It is apparent that open-air demolition of the $236-\mathrm{Z}$ building results in the largest contribution to airborne concentrations of radioactive materials.

The results in Figures 3.16 and 3.17 represent the highest estimated emission rates occurring under the most restrictive dispersion conditions. The actual exposures during demolition activities will be a function of combinations of emission rates and ambient atmospheric conditions that occur during those activities. 


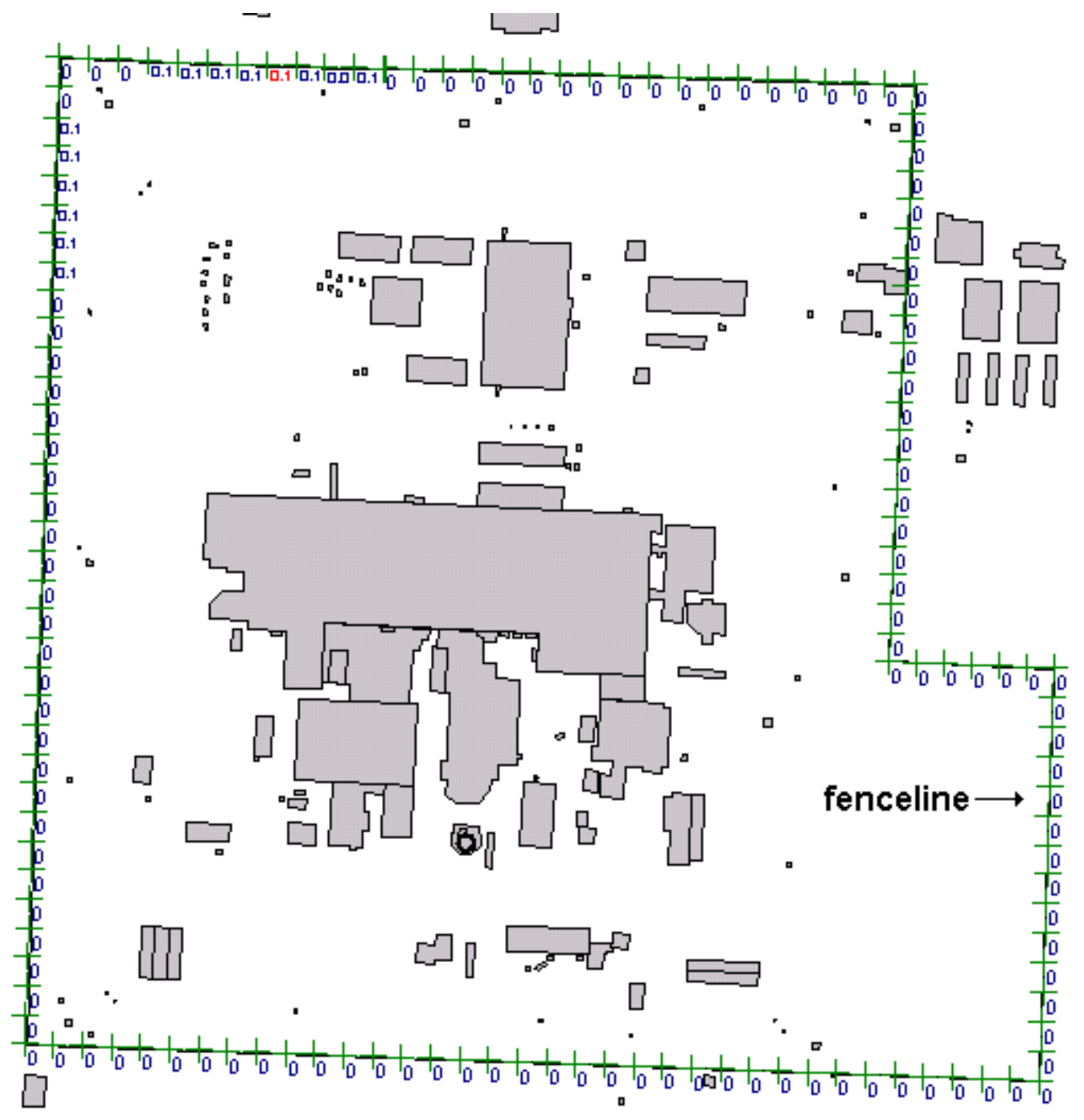

Figure 3.16. Predicted Maximum Weekly Air Concentrations at the PFP Site Fenceline for Demolition Excluding the 236-Z Plutonium Reclamation Facility (DAC-hours) 


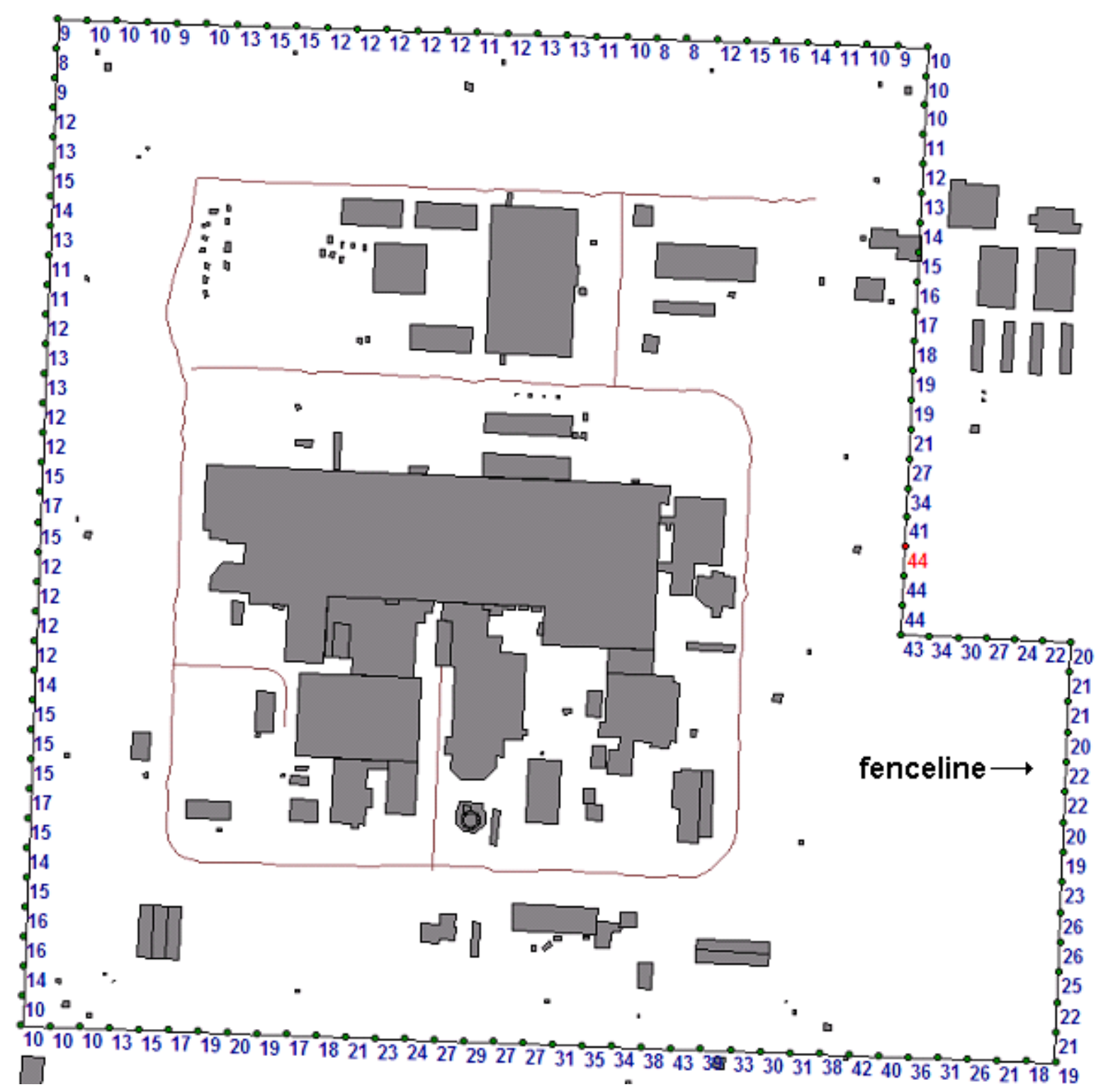

Figure 3.17. Predicted Maximum Weekly Air Concentrations at the PFP Site Fenceline for the 236-Z Plutonium Reclamation Facility Cell Demolition (DAC-hours)

\subsection{Building Demolition - Surface Deposition}

Surface deposition is analyzed through maximum average impact modeling and case-study runs. Maximum average surface deposition is determined by modeling the average emission rate for a given demolition activity over the entire 5-year (2005-2009) meteorological period. The resulting modelcalculated daily surface deposition values are then summed over the actual number of days the activity is expected to be performed and the maximum total deposition value at each receptor location is retained. These maximum average contour plots are presented in this section for a variety of demolition activities; contours are expressed in units of alpha disintegrations per minute (dpm) per $100 \mathrm{~cm}^{2}$. 
Actual surface deposition that will occur during demolition will be defined by the ambient meteorological conditions that occur during the demolition activities. Example case studies of surface deposition based on an assumed demolition sequence are run for January and mid-May start dates.

\subsubsection{4-5 Z and 242-Z Demolition}

This section presents the predicted maximum average surface deposition modeling results for the 234-5Z and 242-Z structures from shear demolition. These structures, which are labeled as demolition zones 1 through 11 in Figure 2.1, have less contamination than the 236-Z structure. Of these 11 zones, demolition zone 6 has approximately $25 \%$ of the total activity-based emissions and will therefore dominate the surface deposition pattern. The 234-5Z and 242-Z activities leading to surface deposition from shear demolition were projected to occur for a total of 133 days and 9 days, respectively.

Figure 3.18 is the resulting contour plot of the maximum average surface deposition (expressed as alpha dpm per $100 \mathrm{~cm}^{2}$ ) for demolition zone 6. As noted in Section 3.3, the maximum average deposition is determined by modeling the average emission rate for a given demolition activity over the entire 5-year (2005-2009) meteorological period. The resulting model-calculated daily surface deposition values are then summed over the actual number of days the activity is expected to be performed and the maximum total deposition value at each receptor location is retained for contour plotting.
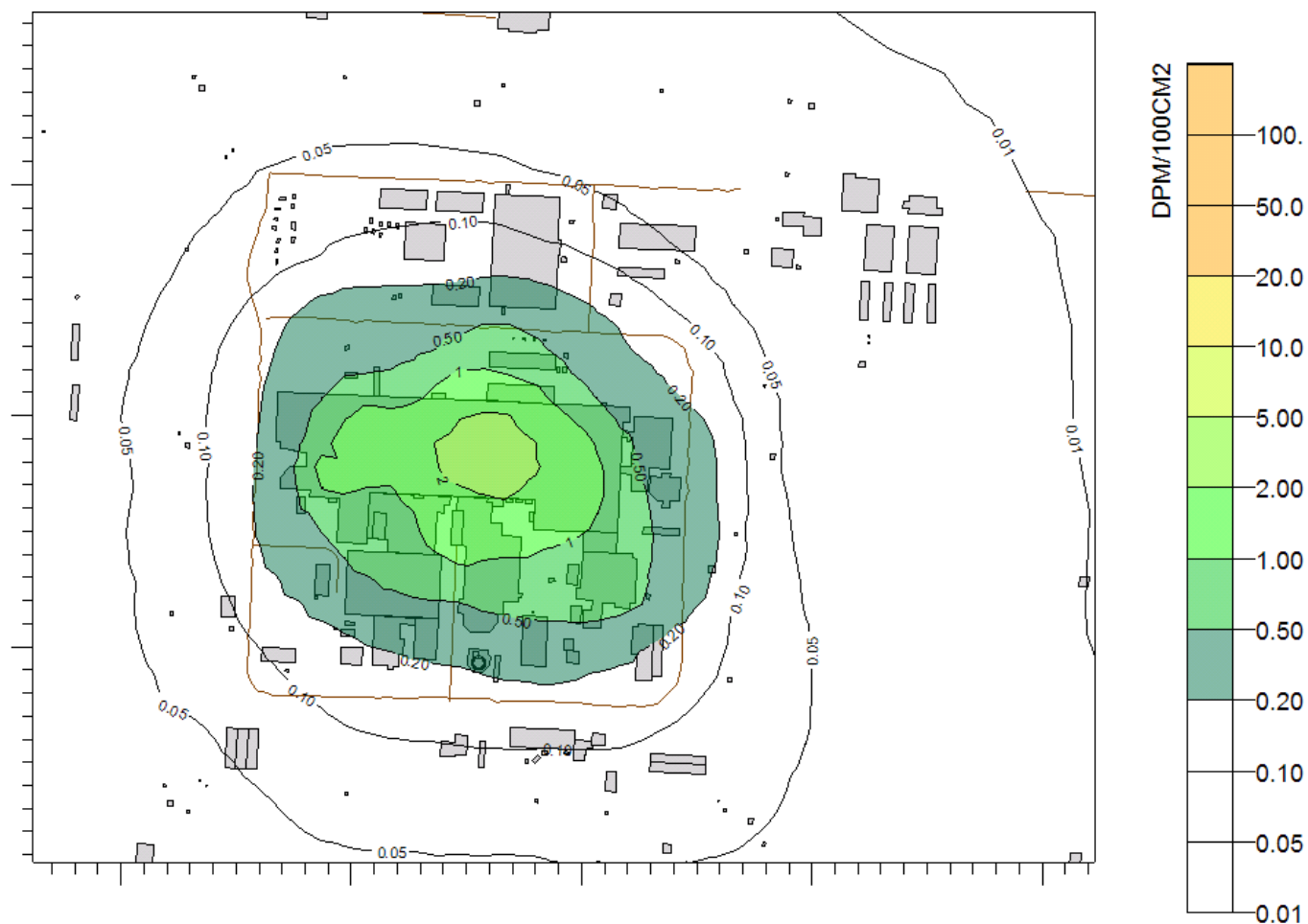

Figure 3.18. PFP Zone 6 Demolition Maximum Average Surface Deposition

The total deposition for the projected demolition activities projected for $234-5 \mathrm{Z}$ and $242-\mathrm{Z}$ is addressed by two case studies. Figure 3.19 and Figure 3.20 present the deposition patterns for January and mid-May start dates in the year 2009, respectively. 
The case-study predicted patterns of deposition (Figure 3.19 and Figure 3.20) have the same order of magnitude as the maximum average surface deposition pattern (Figure 3.19). It is anticipated other case studies for different time periods and years may have lower or higher predicted values. The upper bound for such values is about four times higher than the values in Figure 3.19. ${ }^{2}$
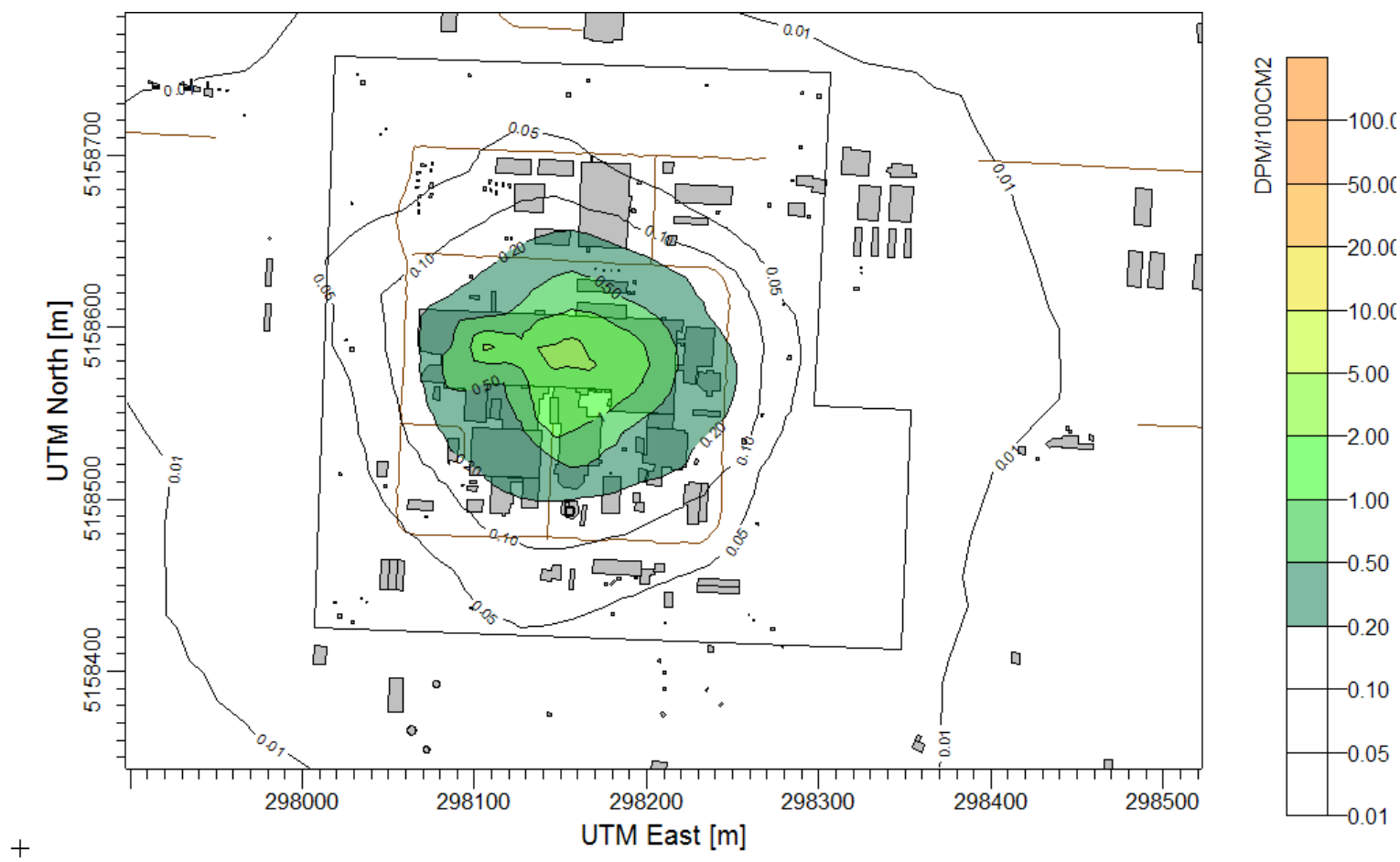

Figure 3.19. Predicted Surface Deposition for Demolition of Zones 1 to 11 Starting in January 2009

\footnotetext{
${ }^{2}$ If all the releases were co-located, the predicted maximum concentrations from all the demolition activities for 234-5Z and 242-Z would be exactly four times greater than the highest single-activity concentrations shown in Figure 3.19. Because the zones are not co-located, the values will be lower and spread over a greater area.
} 


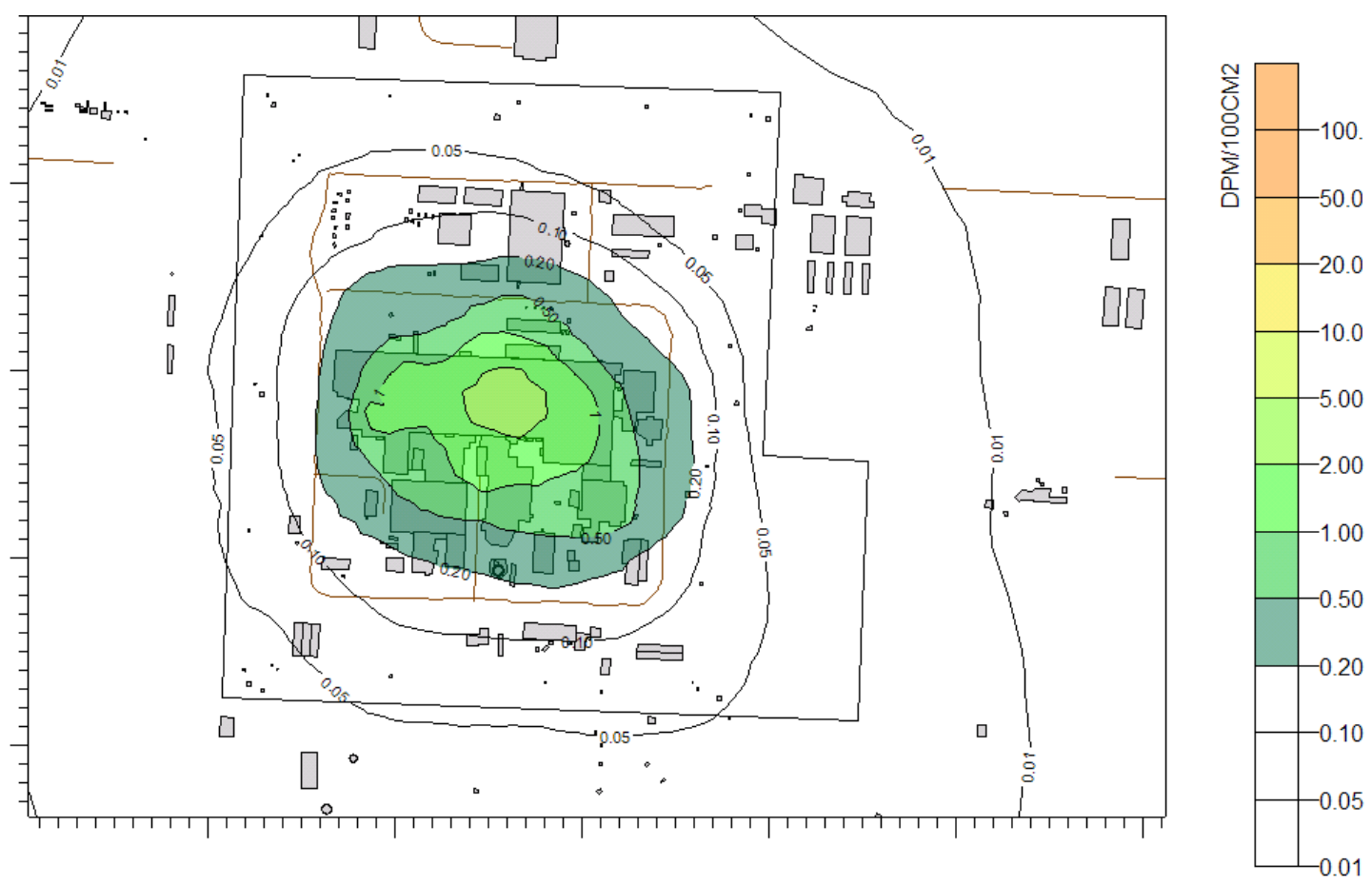

Figure 3.20. Predicted Surface Deposition for Demolition of Zones 1 to 11 Starting in Mid-May 2009

\subsubsection{6-Z Demolition}

This section presents the surface deposition modeling results for the $236-\mathrm{Z}$ cell and associated buildings; these structures are identified as demolition Zone 12 in Figure 2.1. The 236-Z structures have the highest contamination levels in the PFP complex. Because the activity-weighted emissions from the $236-Z$ cell account for $99.999 \%$ of the projected emissions from demolition of all the $236-Z$ structures, the results presented in this section are associated with the demolition activities for the $236-Z$ cell. The 236-Z structure demolition activities leading to surface deposition were projected to occur for a total of 57 days of which 30 days are related to the $236-Z$ cell.

Figure 3.21 is the resulting contour plot of the maximum average surface deposition (expressed as alpha dpm per $100 \mathrm{~cm}^{2}$ ) for shear demolition of the $236-Z$ cell. As noted in Section 3.2, the maximum average deposition is determined by modeling the average emission rate for a given demolition activity over the entire 5-year (2005-2009) meteorological period. The resulting model-calculated daily surface deposition values are then summed over the actual number of days the activity is expected to be performed and the maximum total deposition value at each receptor location is retained for contour plotting. For the 236-Z cell, activities leading to surface deposition from shear demolition were projected to occur for a total of 37 days.

The air exposures in Figure 3.21 are the peak values that could occur during the demolition of 236-Z cell structures. Because the severity of air exposure impacts is expressed in terms of total weekly air concentrations, this week with the highest projected emissions also represents the highest possible air exposures from the demolition of all buildings. 

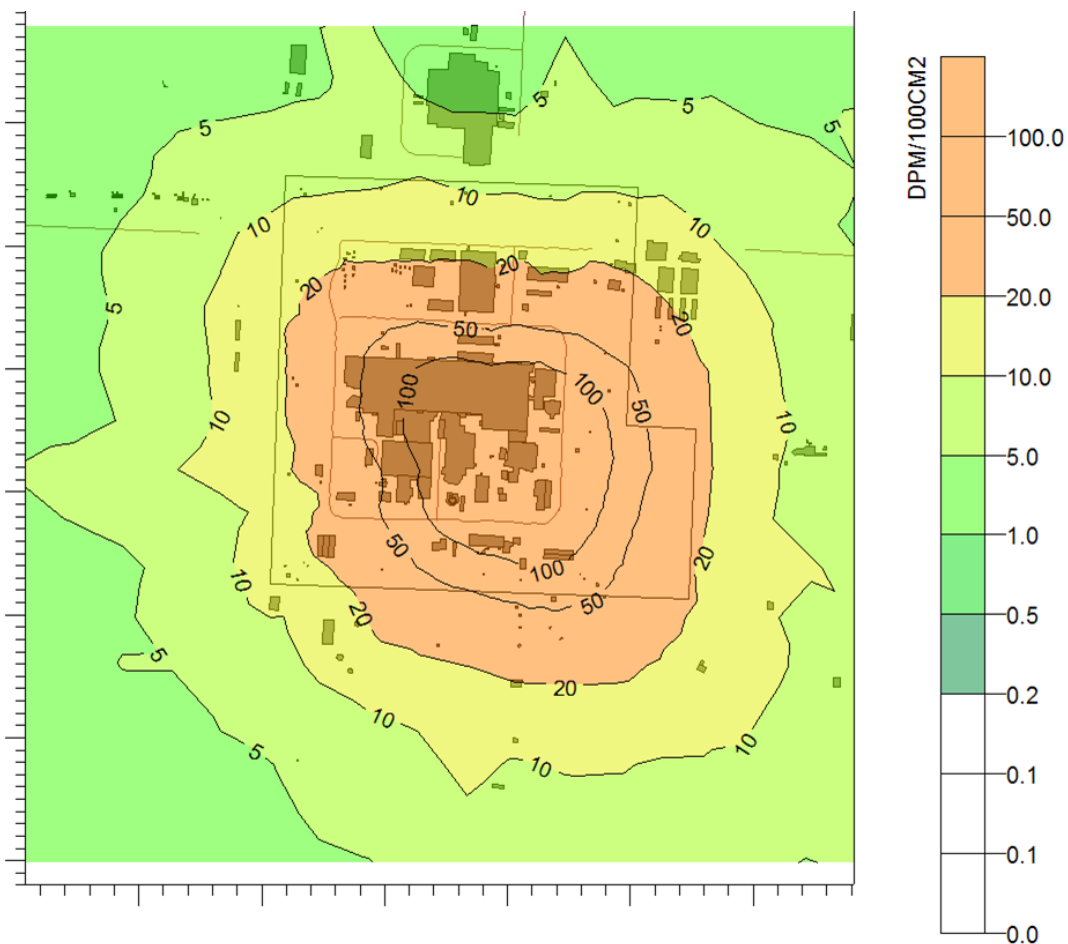

Figure 3.21. Predicted Maximum Average Surface Deposition for 236-Z Cell from Shear Demolition

\subsubsection{Total Deposition from All PFP Buildings}

The climatologically-based pattern of predicted maximum soil exposures (expressed as DPM per $100 \mathrm{~cm}^{2}$ ) from demolition of all PFP buildings is shown in Figure 3.22. This plot is based on the sum of the patterns in Figures 3.20 and 3.21. The plot for all buildings is essentially identical to the plot for 236-Z that represented more than $99.5 \%$ of the total projected emissions from demolition of all the PFP buildings. The activities leading to surface deposition from demolition of all the PFP buildings were projected to occur for a total of about 200 days.

The time of year that the actual demolition commences will define the seasons under which the various demolition activities will occur. Figures 3.23 and 3.24 present the deposition predicted patterns for 236-Z demolition for January and mid-May start dates in the year 2009, respectively. Figure 3.23 has the 236- $Z$ demolition occurring under summer conditions, and Figure 3.24 has that activity occurring under winter conditions. The predicted patterns of deposition for eleven zones based on specific historical time periods have the same order of magnitude as the worst-zone climatologically-based pattern (Figure 3.22).

Although the $236-Z$ cell clearly dominates the predicted potential soil exposure impacts, there is a possibility the pattern of maximum predicted soil deposition for 236-Z (Section 3.2) could be slightly increased when the deposition from the other buildings is included. To address this issue, case studies of impacts of the full campaign are included. 

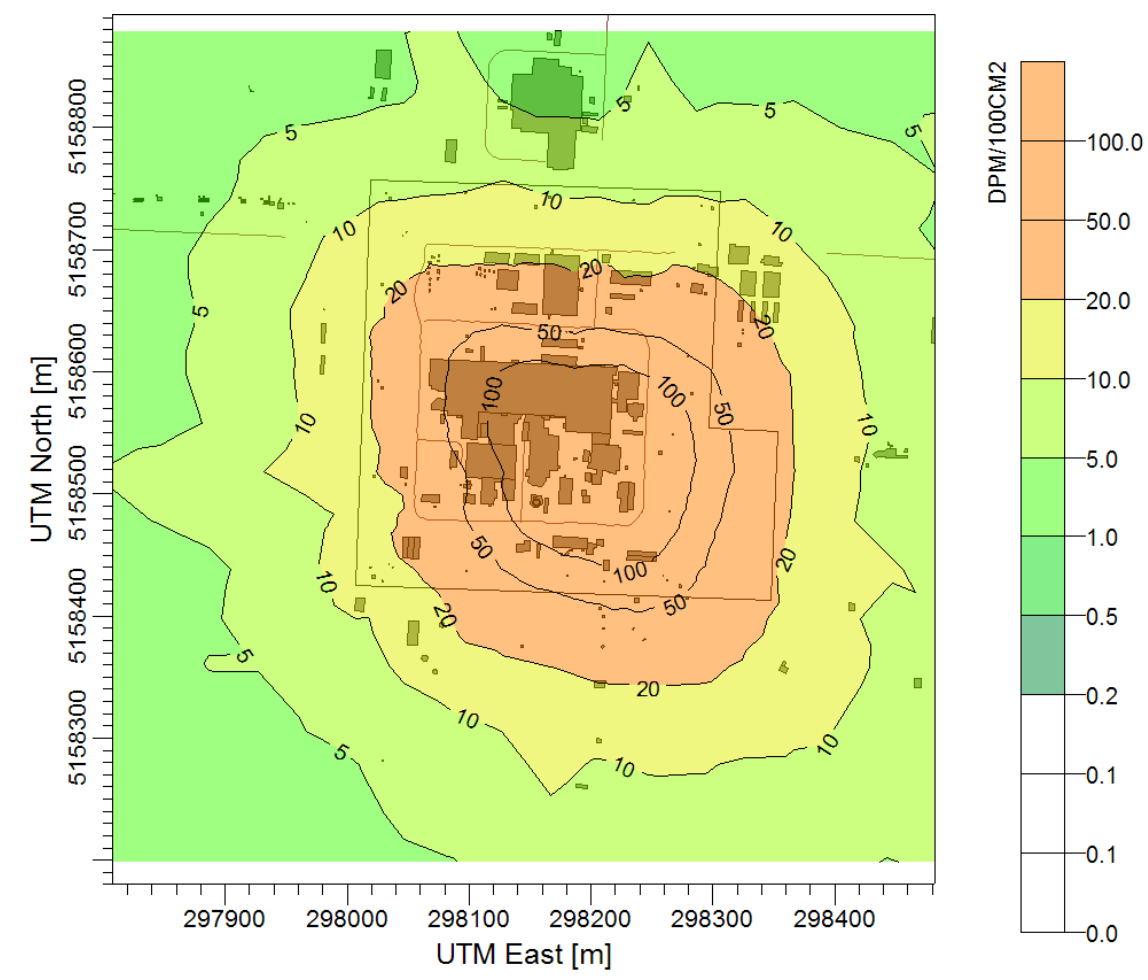

Figure 3.22. Predicted Maximum Average Surface Deposition for Shear Demolition of all PFP Buildings
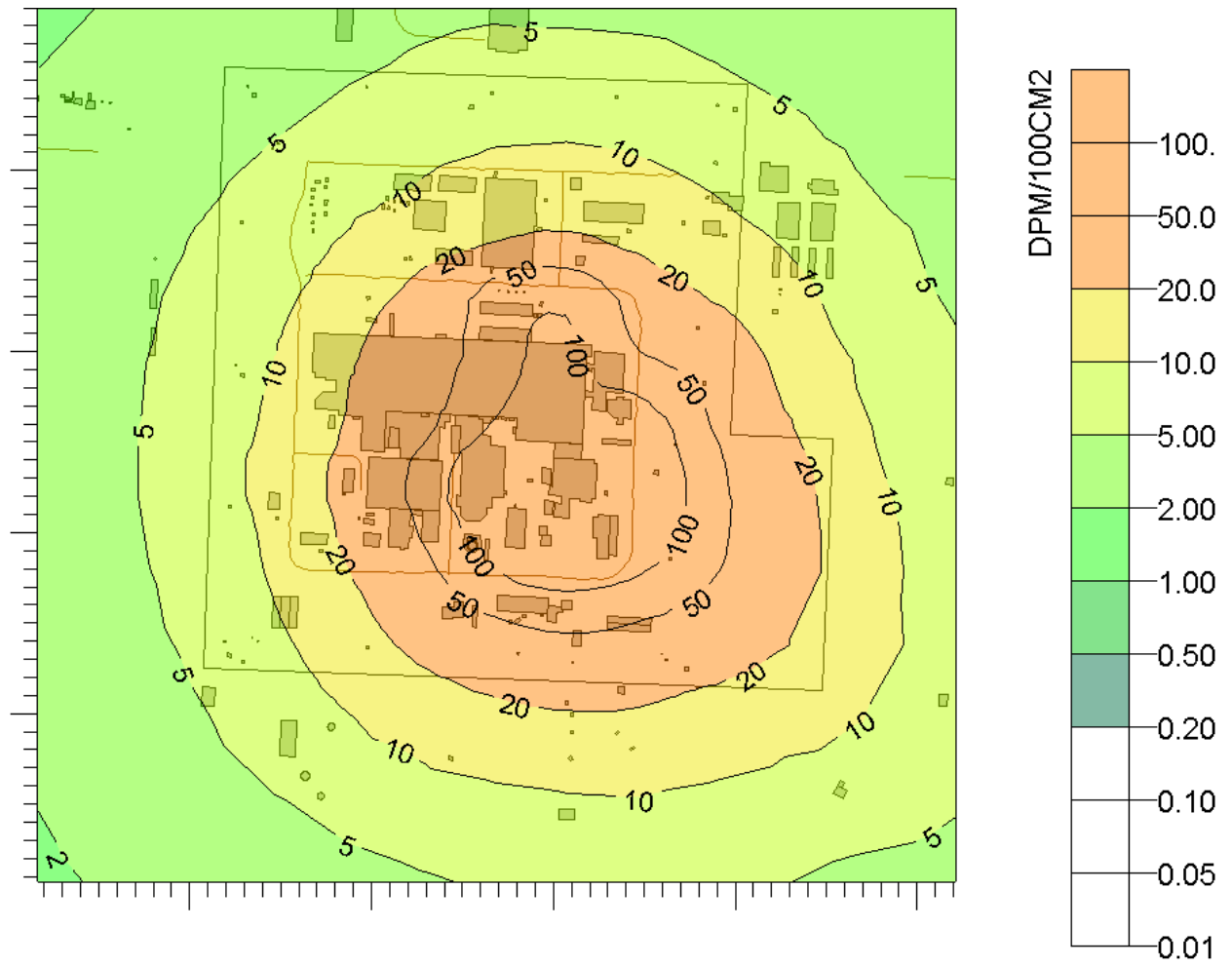

Figure 3.23. Predicted Surface Deposition for Shear Demolition of All PFP Buildings Starting in January 2009 

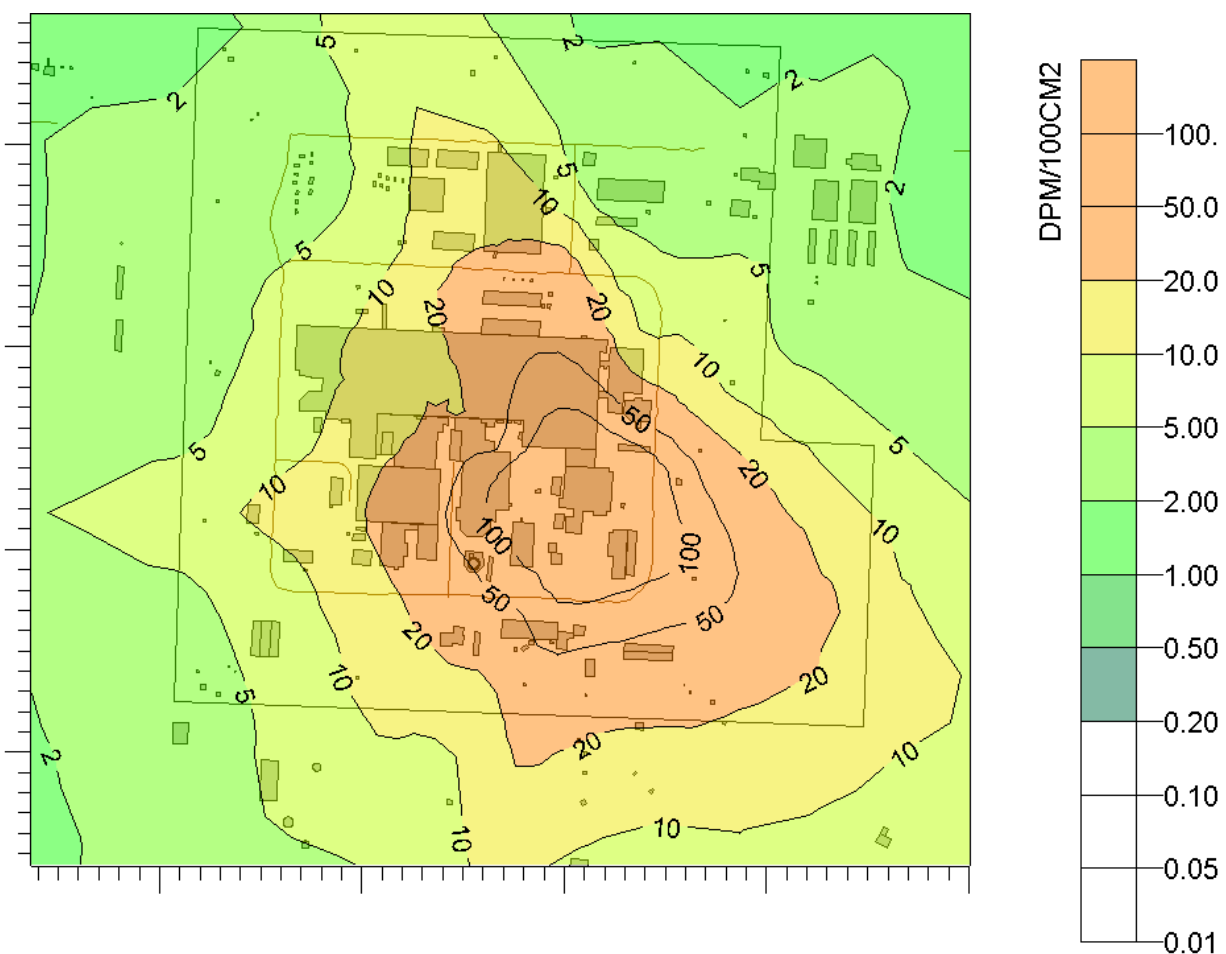

Figure 3.24. Predicted Surface Deposition for Shear Demolition of All PFP Buildings Starting in Mid-May 2009

\subsection{Stack Demolition - Air Concentration and Surface Deposition}

The 291-Z-1 (demolition Zone 13) demolition scenario is detailed in Section 2. The maximum air concentration and surface deposition values were modeling in the same manner as described in Sections 3.1 and 3.2 .

Figure 3.25 presents the resulting maximum air concentration for demolition of the 291-Z-1 stack structure. The integration time is for one week. The maximum one-week value from a 5-year (2005-2009) period is contoured.

Figure 3.26 presents the resulting maximum average surface deposition for the demolition of the 291-Z-1 stack structure. Five years (2005-2009) of meteorological data are used in estimating the maximum average deposition.

The predicted worse-case air concentration and deposition values occur in the immediate vicinity of the demolition activity - and have very low values; no additional analyses of the potential air exposures were conducted. The modeling indicates that the worst-case concentration increments from the stack demolition will be too small to be detectable. 


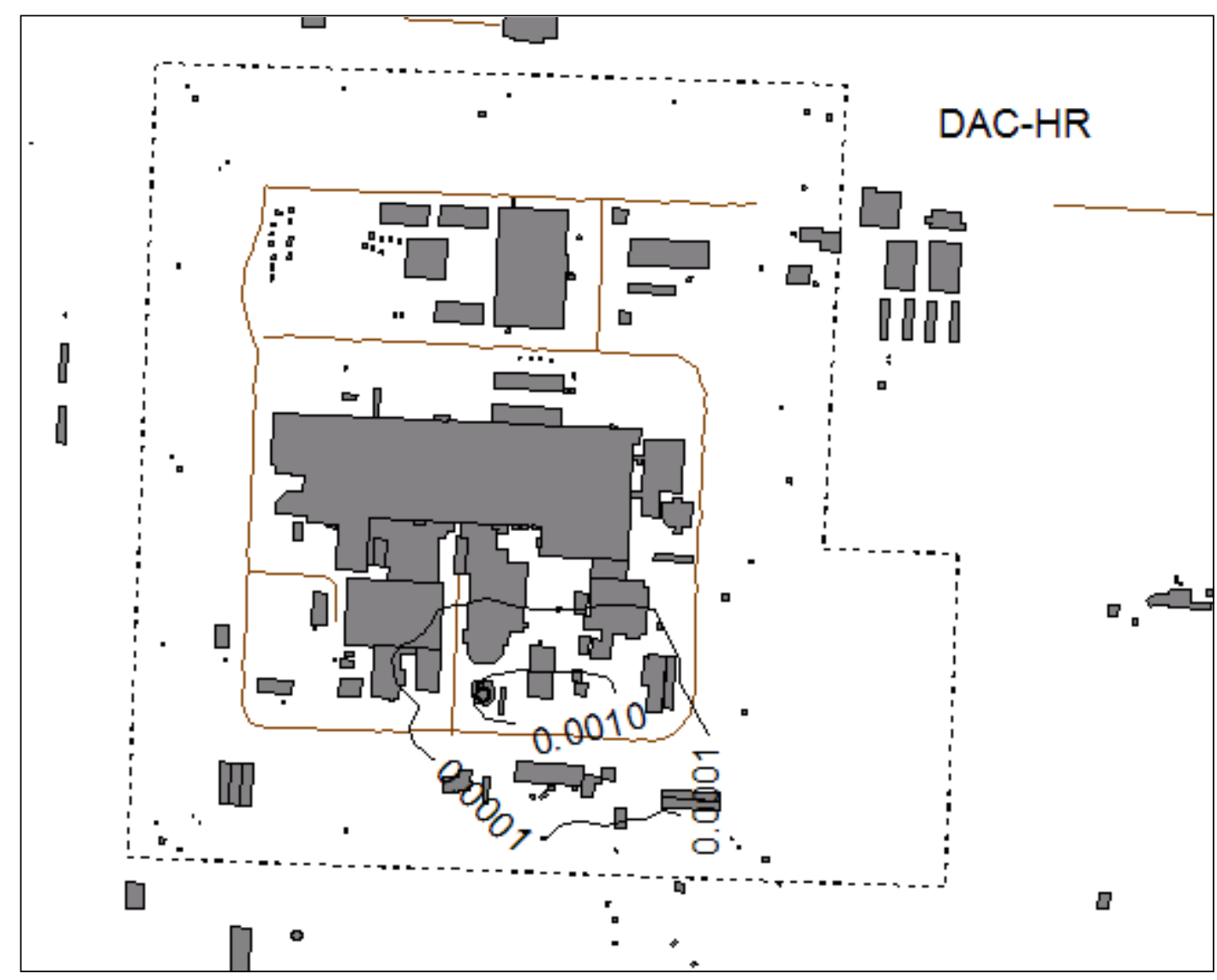

Figure 3.25. Predicted Weekly Air Exposure Maximum Values for 291-Z-1 Stack Demolition 


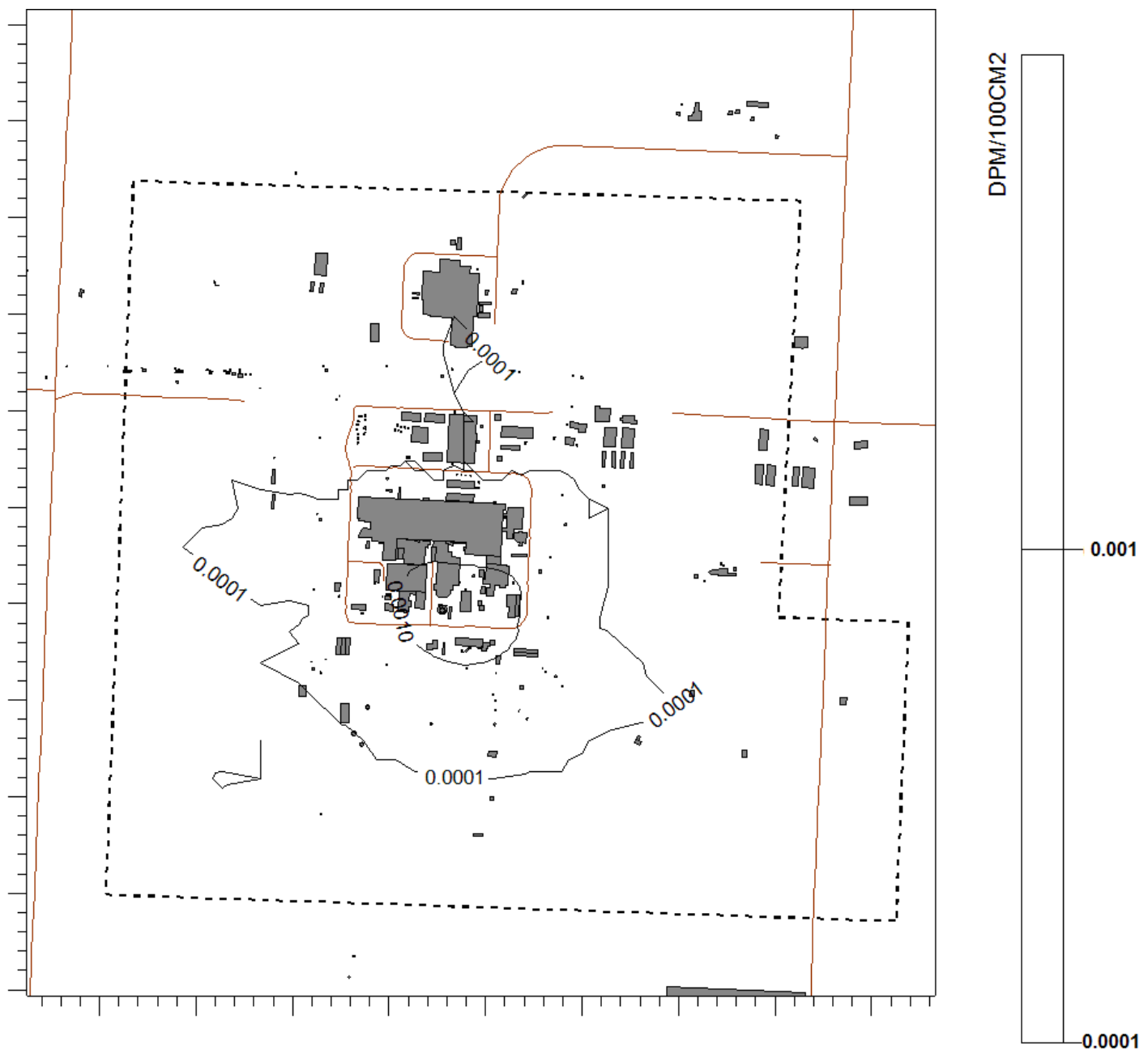

Figure 3.26. Maximum Average Surface Deposition for the 291-Z-1 Stack Demolition 


\subsection{Discussion of Results}

The source-term analysis projected the levels of releases of radioactive material that is to be anticipated during the demolition of the Plutonium Finishing Plant (PFP) facilities. The modeling results presented here are closely tied to the details of how the demolition is to be conducted. The shearing option using emission mitigation methods was considered for all the proposed demolition activities. This option represents a standard demolition approach that has been used in several past demolition efforts at Hanford. These modeling results indicate that the radiological exposures from the planned demolition efforts will be below the designated limits for air and soil exposures for the bulk of the PFP facilities, including the PFP stack.

The releases from $236-\mathrm{Z}$ (and in particular the $236-\mathrm{Z}$ cell) produce predicted air concentration increments that are of concern in terms of the projected worst-case levels of air exposures. The assumed shearing demolition option that includes extensive pre-demolition structure decontamination and preparation is widely used for demolition of structures with hazardous contamination. However, for demolition of this portion of the facility using this demolition option, the modeling results indicate a

potential to spread contamination in excess of Hanford administrative limits beyond the current fenceline of the PFP area. It needs to be noted that the analysis assumed remaining contamination levels in the $236-\mathrm{Z}$ cell are at an average of $50 \mathrm{nCi} / \mathrm{gram}$. It is possible that different methods and/or extensive decontamination could reduce the contamination levels, and thus reduce the levels of potential exposures.

In summary, this report documents anticipated releases and environmental contamination that could be expected for open-air demolition of the PFP facilities for a basic scenario using typical demolition techniques. These results are provided for planning purposes. This report does not document any decisions about the decommissioning approaches; it is expected that this report will be revisited as the final details of the demolition are developed. 



\subsection{References}

40 CFR Part 51. Code of Federal Regulations, Title 40, Protection of Environment, Part 51, "Revision to the Guideline on Air Quality Models: Adoption of a Preferred General Purpose (Flat and Complex Terrain) Dispersion Model and Other Revisions; Final Rule.”

AlphaTRAC. 2003a. Demolition Scenarios and Source Terms for Atmospheric Modeling. AlphaTRAC, Inc., 8670 Wolff Court, Suite 120, Westminster, Colorado 80031.

AlphaTRAC. 2003b. Technical Review of Atmospheric Modeling for the 233-S Demolition Project at the Hanford Site. AlphaTRAC, Inc., 8670 Wolff Court, Suite 120, Westminster, Colorado 80031.

Ballinger, MY., JW Buck, PC Owczarski, and JE Ayer. January 1988. Methods for Describing Airborne Fractions of Free Fall Spills of Powders and Liquids, NUREG/CR-4997 (PNL-6300), Pacific Northwest Laboratory, Richland, Washington.

CHPRC - CH2M HILL Plateau Remediation Company. 2010. Statement of Work, Inter-Contractor Work Order, Contract 00036402, Release 00147 Air Dispersion Modeling - PFP - D\&D - ARRA $(2 / 12 / 2010)$.

CRC (Chemical Rubber Company). 1986. CRC Handbook of Chemistry and Physics, $67^{\text {th }}$ Edition. CRC Press, Boca Raton, Florida.

DOE - U.S. Department of Energy. 1994. DOE Handbook, Airborne Release Fractions/Rates and Respirable Fractions for Nonreactor Nuclear Facilities, Volume 1 - Analysis of Experimental Data. DOE-HDBK-3010-94, Washington, D.C.

DOE - U.S. Department of Energy. 1998. Title 10, U.S. Code of Federal Regulations, Part 835. Occupational Radiation Protection. FR 63:213, pp. 59662-59689, Washington, D.C

Droppo JG and Napier BA. 2006. Analysis of Radioactive Releases During Proposed Demolition Activities for the 232-Z Building, PNNL-15851, Pacific Northwest National Laboratory, Richland, Washington.

Droppo JG, Jr, BA Napier, ER Lloyd, DS Mantooth, MJ Minette, and EM Mattlin. 2007. "Operational Limitations for Demolition of a Highly Alpha-Contaminated Building - Modeled Versus Measured Air and Surface Activity Concentrations ." In 2007 Midyear Topical Meeting - Decontamination,

Decommissioning, and Environmental Cleanup, January 21 - 24, 2007, Knoxville, Tennessee. PNNLSA-52608, Pacific Northwest National Laboratory, Richland, Washington.

EPA - U.S. Environmental Protection Agency. 1995. Compilation of Air Pollutant Emission Factors AP-42, Fifth Edition, Volume 1: Stationary Point and Area Sources. Research Triangle Park, North Carolina.

EPA - U.S. Environmental Protection Agency. 2008. Technology Transfer Network Support Center for Regulatory Air Models, http://www.epa.gov/scram001/(Access last checked 6/5/2008). 
Hoitink, DK., KW Burk, JV Ramsdell Jr., and WJ Shaw. 2005. Hanford Site Climatological Data Summary 2004 with Historical Data. PNNL-15160, Pacific Northwest National Laboratory, Richland, Washington.

Napier BA, Droppo JG, Rishel JP. 2008. Analysis of Radioactive Releases During Proposed Demolition Activities for the 105-KE Basin, PNNL-17631, Pacific Northwest National Laboratory, Richland, Washington.

Napier BA, JP Rishel, and JG Droppo Jr. 2009. Analysis of Radioactive Releases during Proposed Demolition Activities for the 224-U and 224-UA Buildings. PNNL-18332, Pacific Northwest National Laboratory, Richland, Washington.

Napier BA, JP Rishel, JG Droppo Jr., DJ Strom, and KE Joyce. 2010. Analysis of Radioactive Releases during Proposed Demolition Activities for the 224-U and 224-UA Buildings. PNNL-18332 Addendum, Pacific Northwest National Laboratory, Richland, Washington.

Slinn, WGN 1984. "Precipitation Scavenging." Chapter 11 in Atmospheric Science and Power Production, D Randerson, ed., DOE/TIC-27601, U.S. Department of Energy, Washington, D.C. 
Appendix A

Facility-Specific Source Term Analyses 



\section{Appendix A - Facility-Specific Source Term Analyses}

\section{A.1 236-Z (Plutonium Reclamation Facility)}

The 236-Z building (also known as the Plutonium Reclamation Facility - PRF) is located south of the southeastern corner of the $234-5 Z$ building and is connected to it by the $242-\mathrm{Z}$ building. The building is a four-story structure $24 \mathrm{~m}(79 \mathrm{ft})$ by $21.6 \mathrm{~m}(71 \mathrm{ft})$ by about $14.5 \mathrm{~m}(47.5 \mathrm{ft})$ high, surmounted at the southwest corner by a two-story penthouse $6.9 \mathrm{~m}(22.5 \mathrm{ft})$ high. With the exception of the roof, the south end of the process cell, and the fourth-floor ceiling, the building is constructed of reinforced concrete. The roof is constructed of an open-web steel joist frame, a steel deck with rigid insulation of lightweight concrete fill, and gravel-covered built-up roofing. A portion of the south wall is also the 1-ft-thick wall of the process cell. An equipment transfer facility is located against the large south door. The tanks and columns used in the solvent extraction process were located in the process cell-a large three-story room in the center of the $236-\mathrm{Z}$ building. Most of the residual contamination is expected to be in the process cell and on the outer walls of the process cell.

Amounts, locations, and isotopic mixtures of residual contamination in PFP complex buildings including $236-Z$ were provided by a Fluor-SAIC team (Rich Hoyt and Joe Teal). These were provided as a series of spreadsheets, which were later formalized as Plutonium Finishing Plant Characterization for Demolition Air Modeling Studies, HNF-26042 Rev 0. These source terms were modified and simplified through discussions with CHPRC staff. Hoyt and Teal assumed that all the plutonium is in an oxide form, and assumed to be in small, dispersed particles (see HNF-SD-PRP-HA-002, Rev.5, Section 4.2.1.4); the nature of the activities in the $236-\mathrm{Z}$ building - and the residual liquid stains on the walls tend to the idea that the material in this building is largely in the chemical form of soluble nitrates.

The assumed conditions of $236-\mathrm{Z}$ prior to demolition include:

- all process equipment, tanks, and piping removed

- all gloveboxes removed

- all filter boxes removed except the HEPA filters in room 26

- all E-4 duct piping removed up to room 26

- The canyon floor is cleaned and covered with a layer of clean sand (or equivalent) for the duration of the demolition

- all above-grade plutonium nitrate transfer lines and encasements removed

- all liquid waste lines that depart the building will be isolated and capped at sufficient distance from the building as to no longer be involved in the air modeling equations.

Contamination is on surfaces, under floor tile, under paint, etc. Hoyt and Teal suggest a total of about 500 grams of plutonium remain in the building (about 59 alpha curies/229 total curies); this estimate includes a large amount under the metal pans on the process cell floor. A separate analysis based on radionuclide concentrations in cell rubble not exceeding $50 \mathrm{nCi} /$ gram and internal walls in the habitable portions of the building being at $1 / 10$ of $20,000 \mathrm{dpm} / 100 \mathrm{~cm}^{2}$ - at the direction of CHPRC staff - yields 48 alpha curies ( 177 total) in the cell mass and only 0.5 alpha $\mathrm{mCi}$ in the rest of the building. (This 
excludes the contents of the Room 26 HEPA filters, which it is assumed will be removed as intact units with minimal leakage, as well as the residual contamination in the jumper receptacles embedded in the walls of the main cell, which are assumed to be removed as intact units and treated as TRU waste.) These two estimates are compatible to within the accuracy of their initial assumptions.

It would be desirable to entirely demolish $236-Z$ with hydraulic shears; however, this option has the potential to have large release fractions. Two options have been considered - the preferred one comprising demolition with shears and a second in which shears are used on the lesser-contaminated portions of the building and a wire saw is used for the main cell. The wire saw option is described in Appendix D.

The demolition schedule is undefined. It is assumed that the overall demolition would require about 18 months. A working schedule was developed for each building; that for $236-Z$ varies depending upon demolition technique selected. Using concrete shears, the demolition could be as short as 3 months; using a wire saw, the demolition could be as long as 6 months. It is assumed that the 236-Z building is one of the last to be demolished - this schedule essentially works from one end of the complex to the other.

\section{A.1.1 Initial Building Demolition}

Demolition will begin on the upper levels of the building. One day is allocated for removal of the top story of the 236-Z penthouse structure (because of the height and the necessity to lower debris to ground level). A second day is allocated for removal of the second story of the penthouse.

Major demolition begins with removal of the main building roof and walls of the $4^{\text {th }}$ story. Five working days (one week) is allocated for this demolition. A similar period is allocated for removal of the $4^{\text {th }}$ story floor $/ 3^{\text {rd }}$ story ceiling and walls - with the exception of the ceiling of the main cell, which constitutes part of the $4^{\text {th }}$ story floor. The second story holds a bank of air filters. It is assumed that most ducting is removed prior to major demolition but that the filter banks remain. It is assumed that an opening is made and the filters are removed essentially intact. This is assumed to take 5 working days (one week). Then the remainder of the $2^{\text {nd }}$ story ceiling $/ 3^{\text {rd }}$ story floor is removed along with walls over one working week. Finally, the remainder of the outer portions of the $1^{\text {st }}$ story are removed. As a result of this work, only the 2-foot-thick walls and ceiling of the main cell remain. All work on these sections of the building is assumed to be performed with hydraulic concrete shears mounted on a long boom on a track-mounted vehicle from ground level.

The bulk of the contamination within the $236-\mathrm{Z}$ building is associated with the inner and outer walls of the main cell. Leaks and spills of plutonium solutions have contaminated the insides of the cell and also the back walls of the gloveboxes on both sides on the first and second stories. The high contamination levels may require precision demolition techniques. In order to determine whether such techniques may be needed, a parametric approach is taken to the following analyses. Two options are considered: the preferred one uses the hydraulic concrete shears. As an alternative, a more labor- and time-intensive method using a wire saw to separate portions of the cell walls is discussed in Appendix D.

As noted above, there is a large number of penetrations through the cell walls on the first and second stories, originally within the gloveboxes on the west and east side walls. These penetrations contained the piping and connectors for the jumpers to the pencil tanks. It is assumed that significant contamination remains within the piping and components of these jumper receptacles, and that each will need to be 
removed and treated as transuranic (TRU) waste separately from the general rubble of the cell walls. This adds to the complexity of the cell wall demolition; each of the several-dozen jumper receptacles will need to be individually removed and packaged - which will require slow demolition with time and effort to recover these pieces. These pieces must be individually cut out of the wall (or the wall carefully removed from around them).

\section{A.1.2 Demolition of Cell with Shears}

The first, less-conservative option is to remove the cell walls with the multiprocessor hydraulic shears. The walls are to be demolished from the top down, using a large excavator to manipulate the multiprocessor. This device will crush the concrete into roughly 1-foot pieces. (The ERDF acceptance criteria include requirements that the pieces be sized into less than one-foot cubes.) A hypothetical schedule is described, upon which is based the emissions estimates. Misting, water, and fixatives will be used throughout the demolition process and load-out to minimize spread of airborne contamination. Demolition will only occur when sustained wind speeds are less than 15 miles per hour.

For structural reasons, it is assumed that the ceiling/roof of the cell is removed in one day. The floor of the cell is assumed to be covered with sand (or a similar substance) to absorb the impact of falling debris and to minimize suspension of floor contamination. This action opens the main cell to the atmosphere for the remainder of the demolition.

Structural materials high in the cell are assumed to be removed the second and third days. The crane maintenance platform at the north end of the cell, and the crane itself, are removed. The Maintenance Station in the northeast corner of the cell is removed, including the small shield wall.

In order to make access easier, the south wall is then removed. This wall is thinner ( 1 foot) and contains a 12-foot wide door extending into the second story. The door is topped with a concrete beam; above that construction is of cinder block. Demolition of this wall takes one day.

Demolition of the east and west side walls is complicated by the inclusion of numerous jumper receptacles, which are assumed to require handling as TRU waste. The upper portion of the wall above the top line of jumper receptacles is crushed and dropped to ground level. The areas between the jumper receptacles are then crushed and the receptacles themselves knocked out one at a time for recovery and packaging. One day is allocated for demolition of the upper portion of the wall (the third story and top few feet of the second story), and 3 days for the first line of receptacles (about 6 per day). The next portion of wall is removed ( 1 day) and then the next line of receptacles ( 3 days). This process is repeated for the wall and receptacles of the lower story ( 1 plus 3 days, twice) and a final day is allocated for removal of the lowest portion of the wall below the lowest line of penetrations. The entire process is then duplicated for the opposite wall.

Finally, the north wall is removed. Three days is allocated for this activity, including any final cleanup of the area.

Falling rubble is generally directed into the cell, rather than out into the surrounding area. Pick-up of rubble is done with a front loader and thumb-and-bucket on the excavator. The rubble will be picked up and placed into transfer boxes just outside the location of the door in the south wall, in the general area of the Equipment Transfer Facility. Material in the transfer boxes may be further staged at a sorting station 
located nearby. No additional containment structures (tents, etc.) are assumed for this activity; however, like the demolition itself, misting, water, and fixatives will be used to minimize airborne contamination spread. All sorting will only occur when sustained wind speeds are less than 15 miles per hour.

\section{A.1.3 Damage Ratio}

Mechanical shears will be used to demolish the penthouse and outer portions of the 236-Z structure. The radioactive material at risk (MAR) is assumed to be evenly distributed over the entire contaminated area being worked on (wall segment, etc.). The damage ratio (DR) is that portion or percentage of the contaminated area acted on by the shear force, or the portion or percentage of the contamination acted on by shear forces. Shears are assumed to fracture, crush, spall, or otherwise impact the surface being sheared. The fraction of surface rubblized during shear operations is taken to be 0.9 .

The effectiveness of the fixative on the rubblized material (approximately $90 \%$ of the sheared material) will conservatively be considered totally lost (i.e., all of the contamination on these pieces will be considered removable). The fixative covering the larger pieces (approximately $10 \%$ of the sheared material, essentially all of the cut material) will be considered largely intact and remain effective. All of the material cut by shears will be piled on the ground until placed in the ERDF boxes. Approximately $90 \%$ of the sheared material will be subject to resuspension as rubble, while $10 \%$ will be subject to resuspension as larger pieces. The large panels will have minimal resuspension.

The rubble material will be subject to resuspension processes while lying on the ground. Water sprays will be used during work; a layer of fixative will be applied during interim periods.

\section{A.1.4 Airborne Release Fraction}

DOE's factors for impaction stress due to vibration shock were selected as the most representative release fractions for the crushing processes; the factors selected were 0.001 for removable contaminants and one-tenth that (0.0001) for fixed contaminants (DOE 1994). The EPA's (EPA 1995) compilation of airborne release fractions includes a range of uncontrolled release fractions for crushing of ores and rocks that range from 0.012 to 6 pounds per ton of ore, which relates to an ARF of $6 \times 10^{-6}$ to $3 \times 10^{-3}$ - these ranges overlap, supporting the selection of the DOE values.

Fixatives, as the name implies, serve to fix contamination to the surfaces where it is found. In most instances, the contamination particulates become integral with the fixative as opposed to merely being shielded or covered. Fixatives are extremely effective in preventing the migration of contamination from surfaces experiencing little or no traffic. When used during demolition, however, one must consider the impact of the demolition method on the fixative surface structure (e.g., the propensity of the demolition method to produce airborne particulates of the fixative surface containing radioactive contaminants). In this analysis, fixatives are assumed to reduce the production of airborne particulates on surfaces not directly involved with the shearing or cutting processes; however, the shearing process breaks up the material so severely that fixatives are assumed to be only $10 \%$ effective for concrete shears.

Surfaces not directly impacted by cutting will be disturbed from a variety of sources, including the cutting process (especially for shear cutting), movement and placement of material, general shaking of the building surface, vibrations from heavy equipment, and vibration from fall of rubble to the floor surface. 
Releases from these surfaces will be controlled by existing fixative, periodic application of fresh fixative, continually wet surfaces, and water spray/mist in the air. These controls are assumed to be sufficient to prevent any emissions from vibration of noncontact surfaces.

As the material falls to the ground from the elevated location on the walls where it originates, it will be subject to entrainment in the air. The EPA considers its emission factor equation for aggregatehandling and storage piles to be applicable to the drop of bulk material onto piles (adapted from EPA 1995):

$$
\left.\mathrm{ARF}_{\mathrm{DROP}}=1.6 \times 10^{-6}\left((\mathrm{WS} / 2.2)^{1.3}\right) /\left((\mathrm{M} / 2)^{1.4}\right)\right)
$$

where: WS = characteristic wind speed over drop of material $(\mathrm{m} / \mathrm{s})$ - A characteristic wind speed for rubble drop was calculated using a characteristic wind speed for the site estimated by examining a wind climatology from the Hanford Site. A compilation of average wind speeds was provided in the climatology. The ARF is more influenced by periods of higher winds (such as wind gusts). The characteristic wind speed for rubble-handling was estimated to be $3.2 \mathrm{~m} / \mathrm{s}$ (AlphaTRAC 2003); the result is not sensitive to this assumption. Further conservatism was incorporated because the shielding effect of the building walls and the shielded flow around the other PFP buildings are not considered.

$\mathrm{M}=$ moisture value associated with dry material (control effectiveness of water spray handled separately) (\%). Because water spray and mist are applied to the pile, a moisture value of $2 \%$ for a wet construction aggregate was chosen, based on past experience. Small changes in assumed moisture content result in large variation of the resulting ARF, the ARF decreases more than exponentially with $\mathrm{M}$; the $2 \%$ value selected is believed to be conservatively low, resulting in a calculated ARF that should overestimate the releases via this route.

The EPA equation includes a particle-size multiplier ranging from about 0.1 to 0.8 . For this analysis, this was conservatively set to 1.0 for all particle sizes. Using these values, the ARF for rubble-handling is estimated to be $2.3 \times 10^{-6}$.

Surfaces exposed to the atmosphere between shifts will be subject to resuspension processes. A fresh coat of fixative will be applied to all exposed surfaces (covering any gaps and material deposited on the existing fixative) at the end of demolition operations for a day. Therefore, it is assumed that there is no resuspension between shifts.

\section{A.1.5 Leak Path Factor}

The LPF is the fraction of the radionuclides in the aerosol transported through some confinement deposition or filtration mechanism. For the purpose of this study, the LPF is used to address any controls applied during and after the demolition process. This includes the effects of water mists, sprays, and fixatives applied to surfaces and rubble after demolition.

The application of a water mist to contaminated surfaces during demolition serves to reduce the percentage of airborne particulates in the respirable size range. The efficiency of the mist varies with each application and depends on, among other variables, mist particle size, water flow rate, and the size of 
potential airborne particles. For the purposes of this analysis, water-mist application is assumed to reduce the quantity of airborne particulates by $90 \%$. The efficiency of the water-mist process must be weighed in light of the generated waste stream and the need to confine and capture runoff from the misting process. Thus, the LPF for concrete crushing is assumed to be 0.1 . This value is slightly lower than that used for the 233-S building (0.3), based on observations of the effectiveness of the misting on that facility ${ }^{(1)}$ and during demolition of 232-Z.

As the material falls to the ground and is entrained in the air, a separate LPF may be used. The EPA has published size-specific control-effectiveness values for mist eliminators. The values for $<250$ FPM mist eliminators is used to represent the water/mist spray controls applied to materials-handling operations at the 236-Z building. The EPA control-effectiveness values as presented were interpolated to the particles' size ranges identified for this source type. The maximum reported control-effectiveness was assumed for particle sizes larger than those reported in the reference, rather than extrapolating upward from the EPA values. The following LPFs result (EPA 1995):

- $0-2.5 \mu \mathrm{m}: 0.95$

- $2.5-5 \mu \mathrm{m}: 0.60$

- $5-10 \mu \mathrm{m}: \quad 0.30$

- $10-15 \mu \mathrm{m}: 0.25$

- $15-30 \mu \mathrm{m}: 0.25$

- $>30 \mu \mathrm{m}: \quad 0.25$

\section{A.1.6 Respirable Fraction}

The RF is the fraction of airborne radionuclides as particles that can be transported through air and inhaled into the human respiratory system. The RF is assumed to include particles 10- $\mu \mathrm{m}$ AED and less. In this study, all of the suspendable material is addressed (not just the respirable portion). It is estimated that most radioactive particles in the contamination are respirable in size. In this study, the radioactive particles are considered bound to particles of dust from the rubble and are transported as a size distribution of particles representative of construction dust. These particulates are removed from the plume and placed on the ground through dry deposition, a process that removes nonrespirable particles much more effectively than respirable particles. It is conservatively assumed that all radioactive particles separate from any associated rubble particles upon entry into the respiratory system. The result of these considerations is that radioactive particles are modeled to transport as a mixture of particle sizes representative of dust from the rubble and are modeled to impact the respiratory system as all respirable particles.

(1) Private communication with Dan Mantooth, 26 May 2004. A continuous application of water from an atomizer (e.g., a "fog cannon") is assumed. 
A particle-size distribution is given by EPA for conventional aggregate-handling and storage piles (EPA 1995):

\begin{tabular}{lc} 
Diameter & Percent of Mass \\
\hline $0-2.5 \mu \mathrm{m}:$ & $11 \%$ \\
$2.5-5 \mu \mathrm{m}:$ & $9 \%$ \\
$5-10 \mu \mathrm{m}:$ & $15 \%$ \\
$10-15 \mu \mathrm{m}:$ & $13 \%$ \\
$15-30 \mu \mathrm{m}:$ & $26 \%$ \\
$>30 \mu \mathrm{m}:$ & $26 \%$
\end{tabular}

A shift in particle size distribution is expected to occur as a result of the mitigation actions. The planned demolition activities include the use of very effective mitigation techniques for capturing the dust that is generated by these operations; only a very small fraction of the dust generated will be released from the demolition activity. There will be a heavy reliance on misting and spraying to both keep the surfaces wet and to scavenge any dust that is generated. Water droplets are well known to be highly effective in removing larger particles and to be very ineffective in removing smaller particles (Slinn 1984). The collection efficiency differences for small droplets changes by almost four orders of magnitude between 1 and 10 micron particles. Assuming that the mitigation will only be an order of magnitude more effective for the larger particles, the particle-size distribution for materials from the demolition activities becomes:

\begin{tabular}{lc} 
Diameter & Percent of Mass \\
\hline $0-2.5 \mu \mathrm{m}:$ & $72 \%$ \\
$2.5-5 \mu \mathrm{m}:$ & $24 \%$ \\
$5-10 \mu \mathrm{m}:$ & $2 \%$ \\
$10-15 \mu \mathrm{m}:$ & $0.9 \%$ \\
$15-30 \mu \mathrm{m}:$ & $0.17 \%$ \\
$>30 \mu \mathrm{m}:$ & $0.17 \%$
\end{tabular}

The revised size distribution values listed above are AERMOD input parameters that are used for transport and deposition computations. This adjustment in the size-distribution towards smaller particles will reduce the modeled deposition by about an order of magnitude immediately downwind of the demolition activity and increase the modeled deposition at extended distances. The change also will result in slightly higher modeled airborne exposure rates. This change is supported by the observation that the deposition rates in the vicinity of the demolition activity were being over-predicted by at least an order of magnitude in a previous similar modeling effort (Droppo et al. 2007). Given the very large experimental differences in collection efficiencies, the actual shift to smaller particles may well be much greater that the assumed order of magnitude shift. However with the lack of experimental data to confirm such a large shift in the particle-size distribution, any larger factor to account for this process other than that supported by the previous modeling effort is felt to be inappropriate.

A respirable fraction of 1.0 is applied in the Source Term equation because the removal of nonrespirable particles from the plume is treated separately as a transport and dispersion function within the AERMOD modeling, and only about $1 \%$ of the particles escaping are greater than $10 \mu \mathrm{m}$ in diameter. 


\section{A.2 242-Z Waste Treatment Facility}

The 242-Z Waste Treatment Facility began operation in 1963 to recover plutonium from aqueous waste streams from the PFP. An ${ }^{241} \mathrm{Am}$ recovery process was installed in a glovebox in $242-\mathrm{Z}$ and began operation in May 1965. The recovery process was converted from batch to continuous in 1969. In April 1976, the 242-Z facility was shut down as a result of a labor strike. In August 1976, during restart of the americium recovery process, an explosion occurred in a cation ion exchange column that contained approximately $100 \mathrm{~g}$ of ${ }^{241} \mathrm{Am}$. This resulted in substantial americium internal exposure to a worker and extreme contamination to most of the building. As a result, the $242-\mathrm{Z}$ facility was permanently closed. Gross contamination from the explosion was removed. Doors into the operating area were welded shut and re-entry into the facility for final cleanup only began in April 2010.

The 242-Z facility was a 1000-square-foot building located on the south side of the southeast corner of the 234-5 building. It was 40 feet wide, 26 feet long, and 23 feet high (Figure A.1). The south portion of the building was 40 feet wide and 10 feet long and consisted of a tank room (tank cell). This room extended the full inside building height. The north portion was designated the control room, and had a mezzanine over its west half for chemical addition tanks. The building was constructed of structural steel with an aluminum panel outer sheath, rock wool insulation and 16-gauge sheet steel. The floor was concrete and the south wall was reinforced concrete. The rest of the building had plaster inside and insulating material wall panels outside. The roof was slightly peaked and composed of metal decking covered by insulation and built-up asphalt and gravel.

There is an annex on the west side of the building that allows access to 234-5. This annex was entered by three people immediately following the accident, who noticed the door open to the operating/control room and left immediately; they were found to be contaminated. It will be assumed that there is some level of contamination in the annex. The operators and HPs exited via the enclosed hallway on the east side of the building; this will also be assumed to be contaminated to a low level.

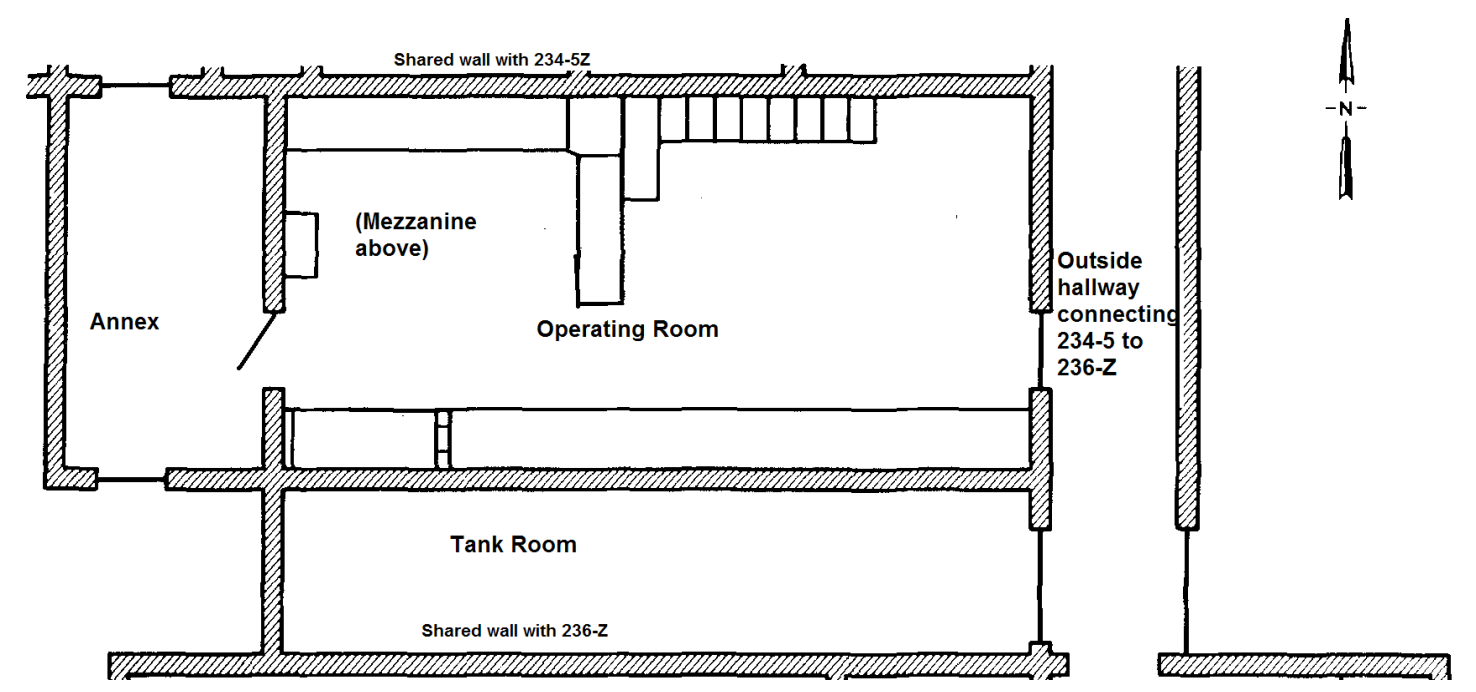

Figure A.1. Floor Plan of the 242-Z Building and Nearby Structures

Contamination in the $242-\mathrm{Z}$ facility is extensive. Hoyt and Teal suggested a total of 10 grams of $\mathrm{Pu}$ mixture in the building, excluding residual americium from the explosion. If it is assumed that $99 \%$ of the ${ }^{241} \mathrm{Am}$ has been recovered, there is still 1 gram of ${ }^{241} \mathrm{Am}$ remaining. Combined, this would be over 5 alpha curies of radioactive materials. If some of this is in the floors and if the total combined mass of 
the building structure is less than 30 metric tons, the entire structure would be classified as transuranic waste. At an average of $50 \mathrm{nCi} /$ gram, the building would still contain over 2 alpha curies in above-floor structural components.

CHPRC staff have suggested that all tanks, piping, gloveboxes, and equipment will be removed from the building. Because this process equipment contains the bulk of the contamination, this is considered to be prudent and desirable.

CHPRC staff have recommended that all facilities will be cleaned up to a minimum of $10,000 \mathrm{dpm} / 100 \mathrm{~cm}^{2}$ for "light contamination" areas and $200,000 \mathrm{dpm} / 100 \mathrm{~cm}^{2}$ for "heavy contamination" areas. For the purposes of this analysis, the operating/control room and tank room are assumed to have "heavy" contamination, and the annex and outside hallway are assumed to have "light" contamination. Contaminated areas, exclusive of removed equipment, are listed in Table A.1. The nature of the activities in the $242-\mathrm{Z}$ building supports the idea that the material in this building is largely in soluble nitrate forms.

Table A.1. Contamination Levels Assumed in Portions of 242-Z at Demolition

\begin{tabular}{|c|c|c|c|c|}
\hline Building Zone & $\begin{array}{l}\text { Area } \\
\left(\mathrm{ft}^{2}\right)\end{array}$ & $\begin{array}{l}\text { Approximate } \\
\text { mass (grams) }\end{array}$ & $\begin{array}{l}\text { Contamination } \\
\left(\mathrm{dpm} / 100 \mathrm{~cm}^{2}\right)\end{array}$ & $\begin{array}{l}\text { Inventory (alpha } \\
\text { curies) }\end{array}$ \\
\hline Control room walls & 2576 & $4.68 \mathrm{E}+07$ & 200,000 & $2.16 \mathrm{E}-03$ \\
\hline Control room ceiling & 640 & $1.16 \mathrm{E}+07$ & 200,000 & $5.36 \mathrm{E}-04$ \\
\hline Tank room walls & 2300 & $8.35 \mathrm{E}+06^{(1)}$ & 200,000 & $1.93 \mathrm{E}-03^{(4)}$ \\
\hline Tank room ceiling & 400 & $7.26 \mathrm{E}+06$ & 200,000 & $3.35 \mathrm{E}-04$ \\
\hline Annex walls & 520 & $6.54 \mathrm{E}+06^{(2)}$ & 10,000 & $2.18 \mathrm{E}-05$ \\
\hline Annex ceiling & 160 & $2.91 \mathrm{E}+06$ & 10,000 & $6.70 \mathrm{E}-06$ \\
\hline Hall walls & 520 & $4.72 \mathrm{E}+06^{(3)}$ & 10,000 & $2.18 \mathrm{E}-05$ \\
\hline Hall ceiling & 208 & $3.78 \mathrm{E}+06$ & 10,000 & $8.70 \mathrm{E}-06$ \\
\hline Totals & 7324 & $9.29 \mathrm{E}+07$ & & 0.005 \\
\hline
\end{tabular}

(1) excluding common wall with control room and tank room

(2) excluding common wall with control room

(3) excluding common walls with $236-Z$ building and control room

(4) about $40 \%$ of this will remain with the $236-Z$ wall

\section{A.2.1 Demolition Schedule}

The demolition schedule is undefined. The $242-Z$ building is a small, metal-frame building. Demolition of the 232-Z structure, of comparable size and contamination, was modeled as occurring over 5 days. The assumed schedule is provided in Table A.2.

Table A.2. Demolition Schedule

\begin{tabular}{cl}
\hline \multicolumn{1}{l}{ Day } & Building Location \\
\hline 1 & West annex \\
2 & East hallway \\
3 & Roof \\
4 & North wall (residual part of 234-5) \\
5 & East wall \\
6 & Center wall \\
7 & West wall \\
& (Leave south wall as part of PRF) \\
\hline
\end{tabular}




\section{A.2.2 Demolition Approach}

The building roof and walls are assumed to be demolished with a multiprocessor operating hydraulic shears. The walls are to be demolished from the top down, using a large excavator to manipulate the multiprocessor. This device will rip the metal sheeting and separate the steel framing. Misting, water, and fixatives will be used throughout the demolition process and load out to minimize airborne contamination spread. All demolition will only occur when sustained wind speeds are less than 15 miles per hour.

It is assumed that the lesser-contaminated outer structures (annex, eastern outside hallway) are removed first.

For structural reasons, it is assumed that the ceiling/roof is removed in one day. The floor of the building is assumed to be covered with sand (or a similar substance) to absorb the impact of falling debris and to minimize suspension of floor contamination. This action opens the main room to the atmosphere for the remainder of the demolition. The walls are removed in a logical order allowing access. The final wall shared with $236-\mathrm{Z}$ is left and removed with that building.

\section{A.2.3 Damage Ratio}

Mechanical shears are assumed to be used to demolish the 242-Z structure after it has been extensively prepared. The radioactive material at risk (MAR) is assumed to be evenly distributed over the entire contaminated area being worked on (wall segment, etc.). The damage ratio (DR) is that portion or percentage of the contaminated area acted on by the shear force, or the portion or percentage of the contamination acted on by shear forces. Shears are assumed to fracture, crush, spall, or otherwise impact the surface being sheared. The fraction of surface from which paints/fixatives are assumed to be removed (scratched, peeled) during shear operations is taken to be 0.1 .

\section{A.2.4 Airborne Release Fraction}

DOE's factors for impaction stress due to vibration and shock for materials that do not brittle fracture (e.g., ductile metal sheeting) were selected as the most representative release fractions for the crushing processes; the factors selected were 0.001 (DOE 1994, Section 5.3.3.2.2) for removable contaminants and one percent of that (0.00001) for contaminants with a double layer of paint/fixative (TRUTech 2001).

Surfaces not directly impacted by cutting will be disturbed from a variety of sources, including the cutting process (especially for shear cutting), movement and placement of material, general shaking of the building surface, vibrations from heavy equipment, and vibration from fall of rubble to the floor surface. Releases from these surfaces will be controlled by existing fixative, periodic application of fresh fixative, continually wet surfaces, and water spray/mist in the air. These controls are assumed to be sufficient to prevent any emissions from vibration of noncontact surfaces.

As the material falls to the ground from the elevated location on the walls where it originates, it will be subject to entrainment in the air. The EPA method described in Section A.1.4 is used. Because sheet metal is less likely to be dusty than pulverized concrete rubble, the results of this calculation were reduced to $1 \times 10^{-6}$ for application to $242-Z$. In addition, this release fraction is applied only to the $10 \%$ of the material that has had the fixatives damaged. 
Surfaces exposed to the atmosphere between shifts will be subject to resuspension processes. A fresh coat of fixative will be applied to all exposed surfaces (covering any gaps and material deposited on the existing fixative) at the end of demolition operations for a day. Therefore, it is assumed that there is no resuspension between shifts.

\section{A.2.5 Leak Path Factor}

The LPF is the fraction of the radionuclides in the aerosol transported through some confinement deposition or filtration mechanism. For the purpose of this study, the LPF is used to address any controls applied during and after the demolition process. This includes the effects of water mists, sprays, and fixatives applied to surfaces and rubble after demolition.

The LPF for shearing is assumed to be 0.1 , as discussed in Section A.1.

\section{A.2.6 Respirable Fraction}

As discussed in Section A.1, a respirable fraction of 1.0 is applied in the Source Term equation because the removal of nonrespirable particles from the plume is treated separately as a transport and dispersion function within the AERMOD modeling.

\section{A.3 234-5Z Building}

The 234-5Z building is approximately $152 \mathrm{~m}(500 \mathrm{ft})$ long and $55 \mathrm{~m}(180 \mathrm{f})$ wide. The floor levels are the basement, first story, duct level, and second story. The frame is structural steel with an outer sheathing of aluminum panels over rock wool insulation and 16-guage sheet metal. There are also $20 \mathrm{~cm}(8 \mathrm{in})$ thick interior reinforced concrete walls, principally running in the east-west direction, and two box-type reinforced concrete stairwells. The stairwells extend to the roof; the reinforced concrete walls stop at the second floor. Contamination levels are quite variable within this large structure; the bulk of residual contamination is expected to reside in the central core and on the duct level.

Staff of CHPRC have proposed levels of contamination that could remain following planned ongoing cleanout operations for this building. On the first floor, the old Recuplex area (current HP office), RMA and RMC lines, and room 236 will be assumed to be at $200,000 \mathrm{dpm} / 100 \mathrm{~cm}^{2}$. This is the area between columns C-E north/south and 4-23 east/west, excluding room 235D (columns C-D and 18-23). This is assumed to continue up into the "Duct Level" because these rooms extend up this high with overlooking mezzanines, etc. (This consists of Hoy and Teal's subdivisions 2, 3, 4, and half of 5.) 


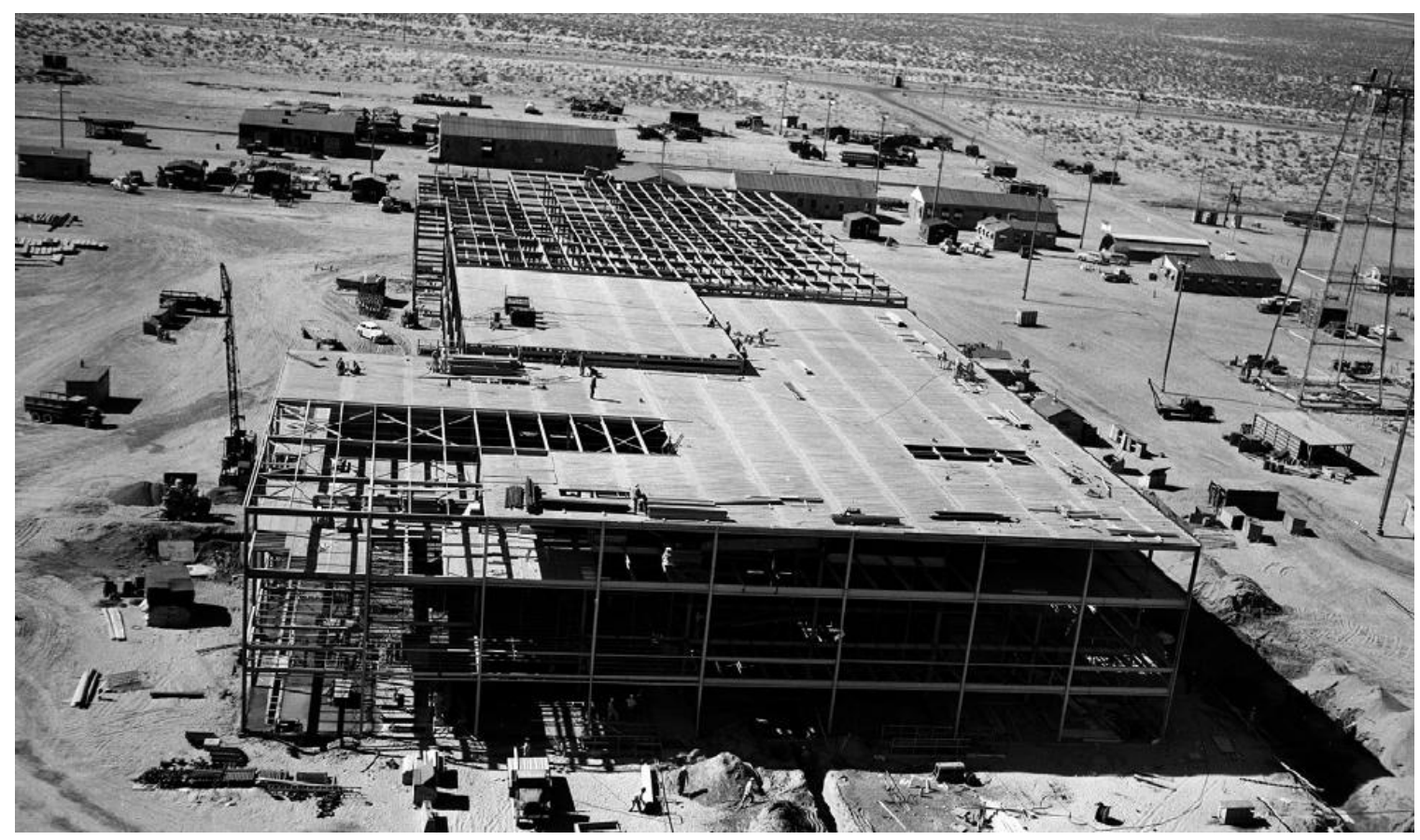

Figure A.2. 234-5Z Building Under Construction, Showing Steel Structure. Building column grid A-J (omitting I) is from right to left in this photo; column lines 1-24 begin at this eastern end and work toward the west. The $242-\mathrm{Z}$ and $236-\mathrm{Z}$ buildings had not been started when this photo was taken.

The area used as the analytical laboratory will be assumed to be at $50,000 \mathrm{dpm} / 100 \mathrm{~cm}^{2}$. This is the area between columns E-J north/south and 1-7 east/west. (This consists of Hoyt and Teal's subdivision 8.) The area that in later years was the development laboratory will be assumed to be at $50,000 \mathrm{dpm} / 100 \mathrm{~cm}^{2}$. This is roughly the area between columns E-G north/south and 14-22 east/west. (This consists of Hoyt and Teal's subdivision 10.On the duct story, the three areas immediately above RMA/RMC and the analytical and development laboratories are assumed to be at the same contamination levels, with the exception of the area above the HP Office and adjacent rooms. On the "second" story, the old E-4 filter rooms 309 and 310 will be assumed to be at $200,000 \mathrm{dpm} / 100 \mathrm{~cm}^{2}$. These are approximately between columns E-F north/south and 7-10 east/west. Room 320 will be assumed to be at $50,000 \mathrm{dpm} / 100 \mathrm{~cm}^{2}$; this room is approximately at columns D-E and 17-19. (These rooms are in Hoyt and Teal's "hot side" subdivision 12.) The average of "the rest of the building surfaces" will be taken as $1 / 10$ th of $20,000 \mathrm{dpm} / 100 \mathrm{~cm}^{2}=2000 \mathrm{dpm} / 100 \mathrm{~cm}^{2}$.

These areas are illustrated in the idealized plan view of the building shown in Figure A.3. 


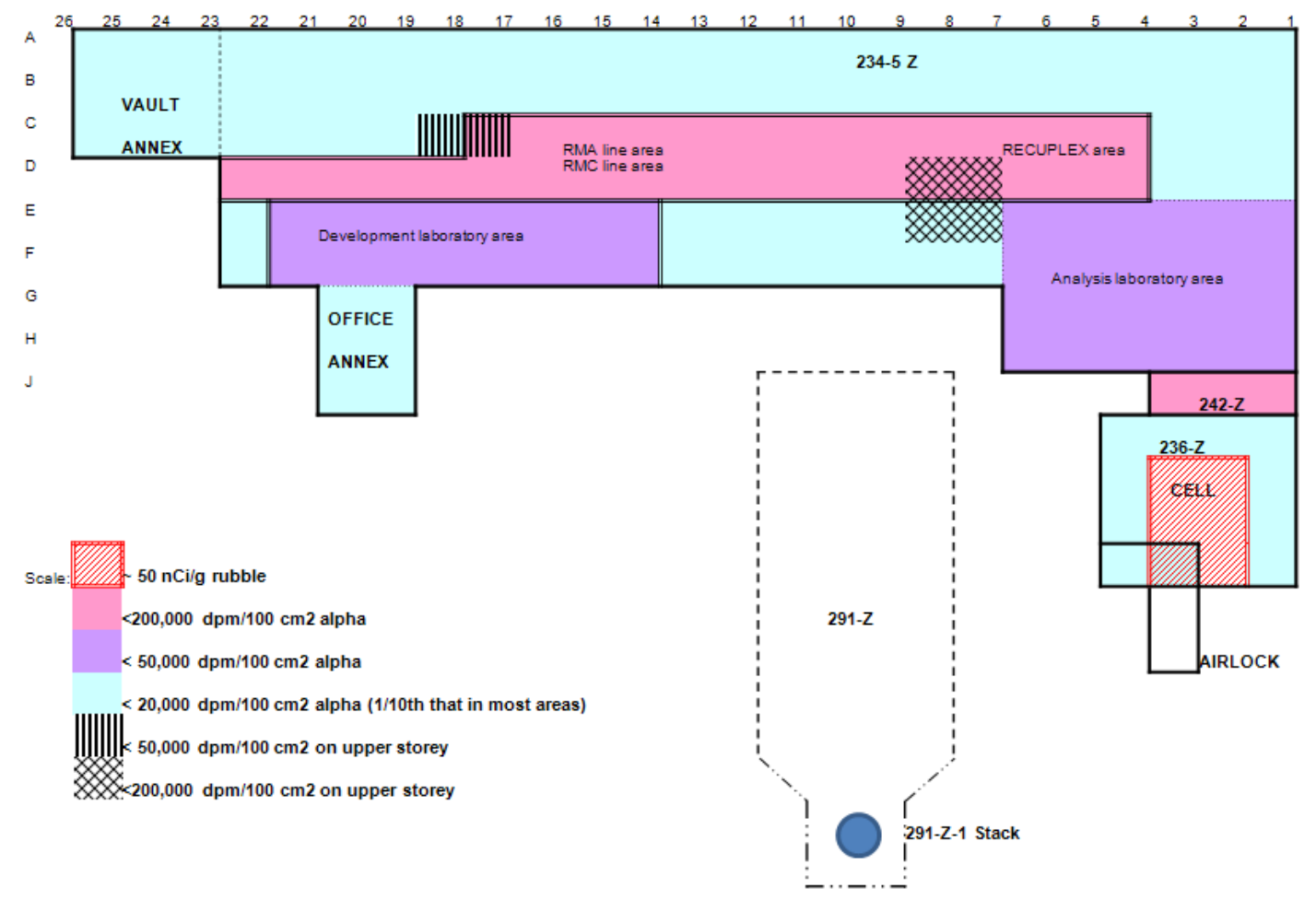

Figure A.3. Contamination Levels in the PFP Complex

\section{A.3.1 Demolition Schedule}

An official schedule has not been defined. Therefore, an example schedule has been prepared to allow calculations. The building has been divided into "demolition zones." It is assumed that demolition will take one work week per zone; an additional week per zone will be required to load the rubble into ERDF containers before demolition can commence on the subsequent zone. The demolition zones assumed are illustrated in Figure A.4. The schedule that results from these assumptions is given in Table A.3. 


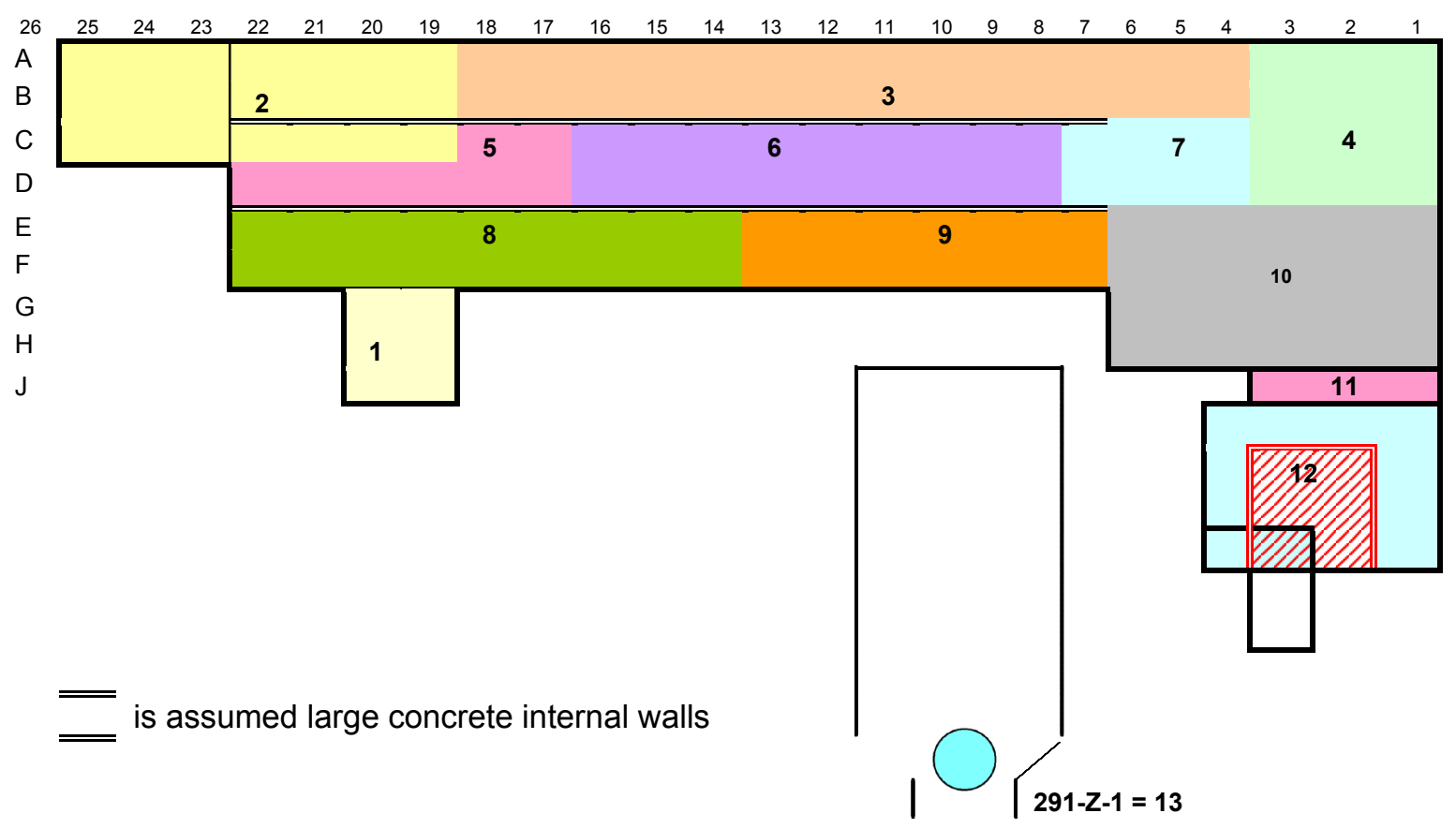

Figure A.4. Demolition Zones Assumed for Analysis

Table A.3. Demolition Schedule for $234-5 Z$

\begin{tabular}{cccc}
\hline ZONE: & Rubblize & \multicolumn{2}{r}{ Containerize } \\
\hline 1 & 1 & 1 & weeks \\
2 & 1 & 1 & weeks \\
3 & 1 & 1 & weeks \\
4 & 1 & 1 & weeks \\
5 & 1 & 1 & weeks \\
6 & 1 & 1 & weeks \\
7 & 1 & 1 & weeks \\
8 & 1 & 1 & weeks \\
9 & 1 & 1 & weeks \\
10 & 1 & 1 & weeks \\
& Total & 20 & weeks \\
\hline
\end{tabular}

\section{A.3.2 Demolition Approach}

It is assumed that the lesser-contaminated outer structures (office annex, vault annex) are removed first.

The building roof and walls are assumed to be demolished with a multiprocessor operating hydraulic shears. The walls are to be demolished from the top down, using a large excavator to manipulate the multiprocessor. This device will rip the metal sheeting, rubblize the lath and plaster walls, and separate the steel framing. Misting, water, and fixatives will be used throughout the demolition process and load out to minimize airborne contamination spread. All demolition will only occur when sustained wind speeds are less than 15 miles per hour. It is assumed that the steel structure will be the final portion of each zone removed, in a manner similar to recent demolition of the 212-R building at Hanford, as illustrated in Figure A.5. The piles of rubble will be sorted into ERDF boxes and removed; during the next zone demolition, the ERDF boxes will be placed in locations on the floor of the prior zone for loading. 


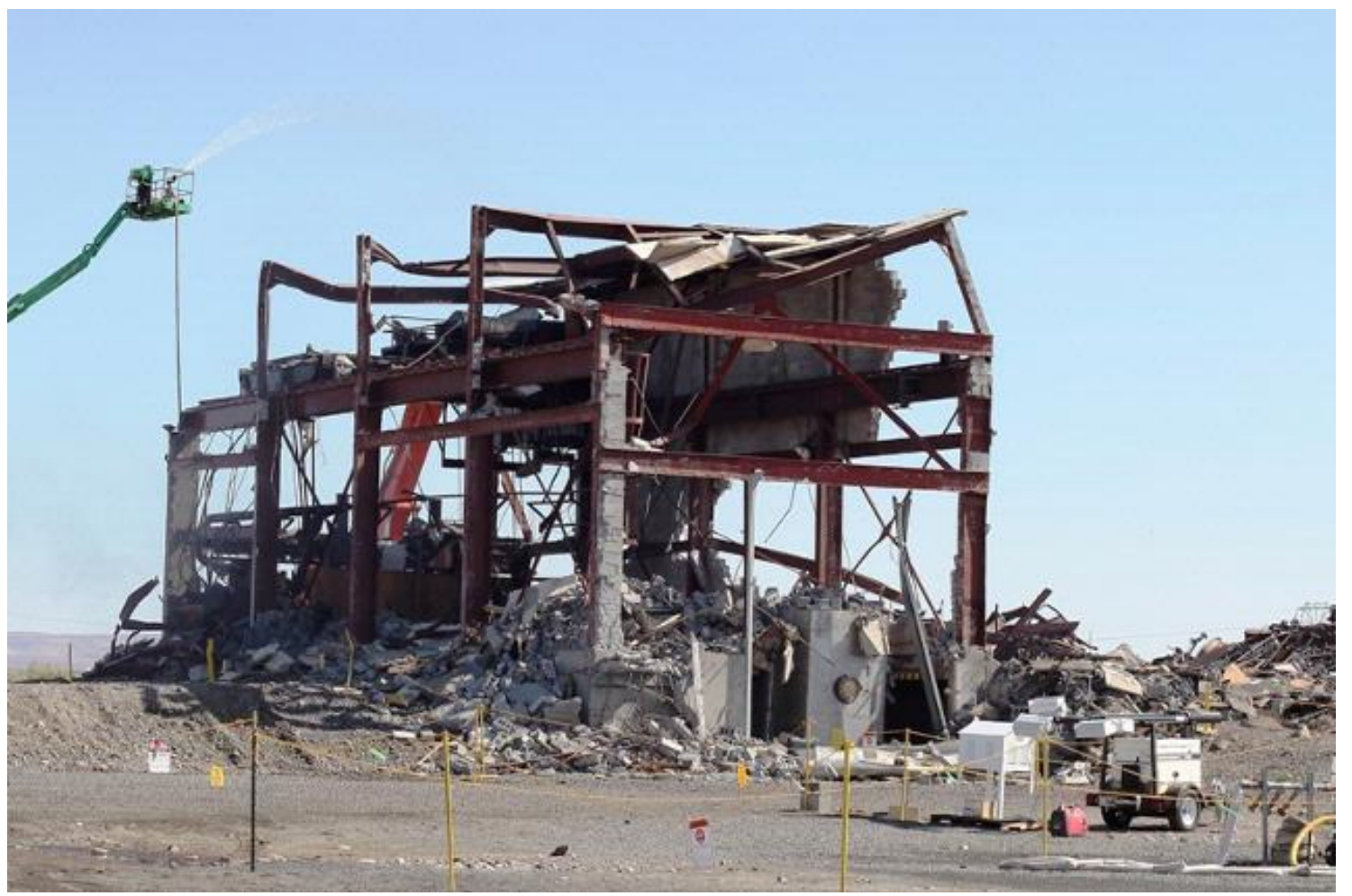

Figure A.5. Assumed Interim Demolition Conditions: Roof and Walls Rubblized Prior to Shearing of Steel Framework (212-R building used as example)

\section{A.3.3 Damage Ratio}

The external walls of the 234-5-Z building are aluminum panels with insulation and a thin steel inner liner. These external wall panels will not be extensively contaminated. The mass of the wall panels is about 5 pounds $/ \mathrm{ft}^{2}$. The inner building walls are lath-and-plaster construction. Lath-and-plaster as applied in the late 1940s was a sand-cement layer mortared onto extruded metal mesh. Each side of a wall is assumed to be about 8 pounds $/ \mathrm{ft}^{2}$ primarily of concrete.

Mechanical shears are assumed to be used to demolish the 234-5-Z structure. The radioactive material at risk (MAR) is assumed to be evenly distributed over the entire contaminated area being worked on (wall segment, etc.). The damage ratio (DR) is that portion or percentage of the contaminated area acted on by the shear force, or the portion or percentage of the contamination acted on by shear forces. Shears are assumed to fracture, crush, spall, or otherwise impact the surface being sheared. The fraction of surface from which paints/fixatives are assumed to be removed (scratched, peeled) during shear operations is taken to be 0.9 .

The effectiveness of the fixative on the rubblized material (approximately $90 \%$ of the sheared material) will conservatively be considered totally lost (i.e., all of the contamination on these pieces will be considered removable). The fixative covering the larger pieces (approximately $10 \%$ of the sheared material, essentially all of the cut material) will be considered largely intact and remain effective. All of the material cut by shears will be piled on the ground until placed in the ERDF boxes. Approximately $90 \%$ of the sheared material will be subject to resuspension as rubble, while $10 \%$ will be subject to resuspension as larger pieces. 
DOE's factors for impaction stress due to vibration and shock for materials that do not brittle fracture (e.g., ductile metal sheeting) were selected as the most representative release fractions for the crushing processes; the factors selected were 0.001 (DOE 1994) for removable contaminants and one percent of that (0.00001) for contaminants with a double layer of paint/fixative (TRUTech 2001).

Surfaces not directly impacted by cutting will be disturbed from a variety of sources, including the cutting process (especially for shear cutting), movement and placement of material, general shaking of the building surface, vibrations from heavy equipment, and vibration from fall of rubble to the floor surface. Releases from these surfaces will be controlled by existing fixative, periodic application of fresh fixative, continually wet surfaces, and water spray/mist in the air. These controls are assumed to be sufficient to prevent any emissions from vibration of noncontact surfaces.

As the material falls to the ground from the elevated location on the walls where it originates, it will be subject to entrainment in the air. The EPA method for determining the airborne emission rate is that described in Section A.1.4. Because sheet metal is less likely to be dusty than pulverized concrete rubble, the results of this calculation were reduced to $1 \times 10^{-6}$ for application to $234-5-\mathrm{Z}$. In addition, this release fraction is applied only to the $90 \%$ of the material that has had the fixatives damaged.

Surfaces exposed to the atmosphere between shifts will be subject to resuspension processes. A fresh coat of fixative will be applied to all exposed surfaces (covering any gaps and material deposited on the existing fixative) at the end of demolition operations for a day. Therefore, it is assumed that there is no resuspension between shifts.

\section{A.3.4 Leak Path Factor}

The LPF is the fraction of the radionuclides in the aerosol transported through some confinement deposition or filtration mechanism. For the purpose of this study, the LPF is used to address any controls applied during and after the demolition process. This includes the effects of water mists, sprays, and fixatives applied to surfaces and rubble after demolition.

The LPF for shearing is assumed to be 0.1 , as discussed in Section A.1.

\section{A.3.5 Respirable Fraction}

As discussed in Section A.1, a respirable fraction of 1.0 is applied in the Source Term equation because the removal of nonrespirable particles from the plume is treated separately as a transport and dispersion function within the AERMOD modeling.

\section{A.3.6 234-5Z Building Surface Areas}

Using cleanup criteria based on $\mathrm{dpm} / 100 \mathrm{~cm}^{2}$ within the building is a simple approach to determining residual contamination. The total inventory of potentially releasable material must then be based on the total surface area of each demolition zone. The total surface areas were estimated on the basis of detailed drawings of the building. The walls were approximated as being 13 feet high on the first story, 14 feet high on the duct level, and 15 feet high on the second story. Total linear feet of walls was estimated from the drawings. Area was length times the height, doubled to account for both sides of the walls. The overall surface area - directly related to the total radionuclide inventories - is given for each zone in Table A.4. Note that the floor of the first story will not be removed and is not included in the estimates. 
Zones on the duct level with "no floor" are open areas above the first story ("mezzanine"-type areas). Contamination levels intermediate between the 2,000, 50,000, and 200,000 dpm/100 $\mathrm{cm}^{2}$ values are approximations based on a few rooms with higher contamination in larger, cleaner areas.

Table A.4. Dimensions of the Demolition Zones for the 234-5Z Building

\begin{tabular}{|c|c|c|c|c|c|c|c|}
\hline $\begin{array}{l}\text { Zone } \\
\text { No. }\end{array}$ & Description & $\begin{array}{c}\text { Cont. Level } \\
\text { dpm/100 } \mathrm{cm}^{2} \\
\text { (Alpha) }\end{array}$ & $\begin{array}{c}\text { wall } \\
\text { height } \\
\text { ft }\end{array}$ & $\begin{array}{c}\text { wall length } \\
\text { (approx) } \\
\text { ft }\end{array}$ & $\begin{array}{c}\text { ceiling } \\
\text { area } \\
\mathbf{f t}^{2}\end{array}$ & $\begin{array}{c}\text { floor area } \\
\mathbf{f t}^{2}\end{array}$ & $\begin{array}{c}\text { Total } \\
\text { Surface Area } \\
\mathbf{f t}^{2}\end{array}$ \\
\hline \multirow[t]{2}{*}{1} & Office Annex & & & & & & \\
\hline & 1st story & 2000 & 13 & 842 & 2940 & 0 & 13,886 \\
\hline \multirow[t]{3}{*}{2} & Vault Annex plus NW & corner & & & & & \\
\hline & 1st story & 2000 & 13 & 1598 & 5600 & 0 & 26,374 \\
\hline & duct level & 2000 & 14 & 420 & 5600 & 5600 & 17,080 \\
\hline \multirow[t]{4}{*}{3} & Northern quarter & & & & & & \\
\hline & 1 st story & 2000 & 13 & 2200 & 16000 & 0 & 44,600 \\
\hline & duct level & 2000 & 14 & 1150 & 16000 & 16,000 & 48,100 \\
\hline & 2nd story & 2000 & 15 & 2200 & 16000 & 16,000 & 65,000 \\
\hline \multirow[t]{4}{*}{4} & Northeast corner & & & & & & \\
\hline & 1st story & 2000 & 13 & 1574 & 12600 & 0 & 33,059 \\
\hline & duct level & 2000 & 14 & 472 & 12600 & 12,600 & 31,805 \\
\hline & 2nd story & 2000 & 15 & 701 & 12600 & 12,600 & 35,711 \\
\hline \multirow[t]{4}{*}{5} & Original metalworkin & g area & & & & & \\
\hline & 1st story & 200,000 & 13 & 805 & 0 & 0 & 10,468 \\
\hline & duct level & 200,000 & 14 & 634 & 5,550 & 0 & 14,432 \\
\hline & 2nd story & 52,000 & 15 & 328 & 5,550 & 5,550 & 16,014 \\
\hline \multirow[t]{4}{*}{6} & RMA/RMC areas & & & & & & \\
\hline & 1 st story & 200,000 & 13 & 2196 & 0 & 0 & 28,548 \\
\hline & duct level & 200,000 & 14 & 1342 & 12,000 & 0 & 30,788 \\
\hline & 2nd story & 2,000 & 15 & 1966 & 12,000 & 12,000 & 53,484 \\
\hline \multirow[t]{4}{*}{7} & RECUPLEX area & & & & & & \\
\hline & 1 st story & 200,000 & 13 & 1122 & 4,200 & 0 & 18,791 \\
\hline & duct level & 2,000 & 14 & 454 & 4,200 & 4,200 & 14,754 \\
\hline & 2nd story & 82,000 & 15 & 1165 & 4,200 & 4,200 & 25,872 \\
\hline \multirow[t]{4}{*}{8} & Development lab area & & & & & & \\
\hline & 1st story & 50,000 & 13 & 1415 & 11,350 & 0 & 29,748 \\
\hline & duct level & 2,000 & 14 & 268 & 11,350 & 11,350 & 26,458 \\
\hline & 2nd story & 2,000 & 15 & 581 & 11,350 & 11,350 & 31,422 \\
\hline \multirow[t]{4}{*}{9} & Southern quarter & & & & & & \\
\hline & 1 st story & 2,000 & 13 & 1291 & 8,000 & 0 & 24,780 \\
\hline & duct level & 2,000 & 14 & 159 & 8,000 & 8,000 & 18,220 \\
\hline & 2nd story & 30,000 & 15 & 1105 & 8,000 & 8,000 & 32,575 \\
\hline \multirow[t]{4}{*}{10} & Analysis lab area & & & & & & \\
\hline & 1st story & 50,000 & 13 & 2820 & 11,475 & 0 & 48,132 \\
\hline & duct level & 2,000 & 14 & 273 & 11,475 & 11,475 & 26,776 \\
\hline & 2nd story & 2,000 & 15 & 446 & 11,475 & 11,475 & 29,643 \\
\hline
\end{tabular}




\section{A.4 291-Z-1 Stack}

The 291-Z building houses the final exhaust plenum, fans, and 200-foot discharge stack for the 234-5Z (PFP), 232-Z (incinerator - previously decommissioned), and the 236-Z (plutonium reclamation) buildings. Exhaust from the three facilities enters a large (15-ft x $20-\mathrm{ft})$ central concrete plenum. Several stainless steel centrifugal fans located on both sides of this central plenum draw air from the central plenum and move the air into two lower plenums on each side of the central plenum below the fans. The two plenums join together downstream of the fans at a $\mathbf{V}$ shape junction and the combined flow eners the base of the 291-Z-1 stack (Figure A.6). The stack is a concrete structure $200 \mathrm{ft}$ high with an inside diameter of 16.5 feet at the base and 13.5 feet at the top. An access door is located near the base of the stack, and a sampling system with constant air monitors (CAMs) that alarm at pre-set levels and record samplers for data collection is located at the 50-foot level. The stack was designed to have the entire interior surface receive two coats of paint.

The 291-Z-1 stack, attached to the 291-Z building, began operation in 1949. CHPRC staff have recommended that all facilities will be cleaned up to a minimum of $10,000 \mathrm{dpm} / 100 \mathrm{~cm}^{2}$ for "light contamination" areas and 200,000 dpm/100 $\mathrm{cm}^{2}$ for "heavy contamination" areas. For the purposes of this analysis, the stack is assumed to have "light" contamination. Residual contamination is assumed to be covered with fixatives inside the stack.

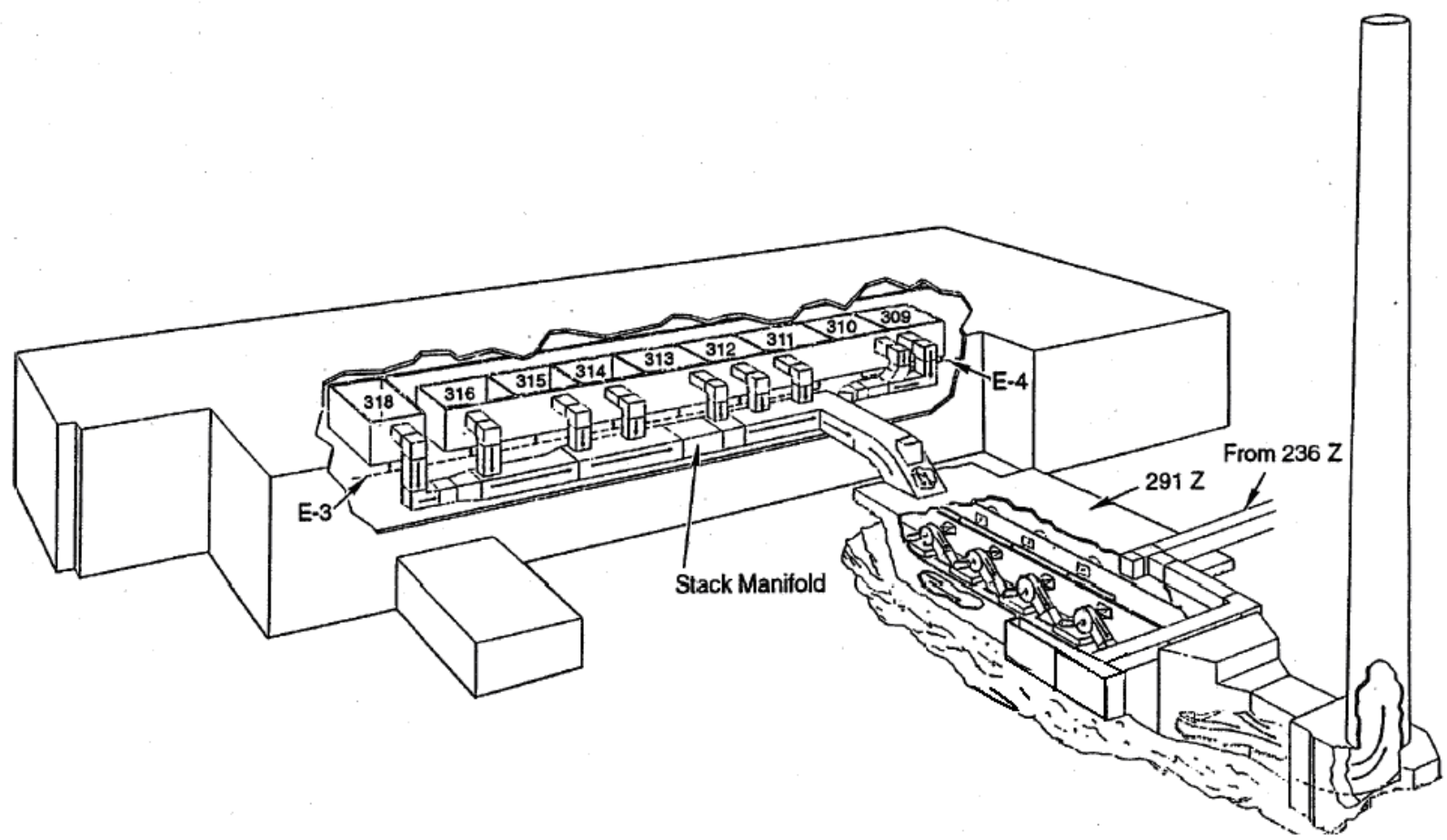

Figure A.6. Cutaway View of 234-5Z and 291-Z Ventilation Exhaust System (adapted from Mahoney et al. 1994) 


\section{A.4.1 Demolition Schedule}

The demolition schedule is undefined. The $291-Z-1$ stack is a 200 -foot-tall, slip-formed reinforcedconcrete structure. Most similar large stacks at Hanford have been removed by explosive demolition, toppling the more-or-less intact stack to the ground and then disposing of the pieces at ground level. It is assumed that this will also happen to the 291-Z-1 stack. The assumed schedule is provided in Table A.5

Table A.5. Demolition Schedule for $291-Z$

\begin{tabular}{c|l}
\hline Day & Building Location \\
\hline 1 & Topple stack \\
$2-6$ & Size-reduce concrete \\
$2-6$ & Load rubble into ERDF boxes \\
\hline
\end{tabular}

\section{A.4.2 Demolition Approach}

It is assumed that, after some preparatory weakening of the stack base, a small explosive charge is used to weaken the stack so that it falls into a prepared trench in the neighboring soil. A charge of $5 \mathrm{~kg}$ of high explosives is assumed. It is assumed that demolition occurs on a day of "favorable" weather.

When the stack has been brought to ground level, a multiprocessor with jackhammer or shears is assumed to break the reinforced concrete into approximately 1-foot by 1-foot pieces. These pieces and associated rubble are loaded into ERDF boxes located nearby with front-end loaders.

\section{A.4.3 Damage Ratio}

The small portion of the stack at ground level that is cut with explosives will be extensively pulverized. However, only the inner surface is contaminated, so the release of radioactive material will be minimal. It is assumed that the amount of dust generated is 1-for-1 with the mass of HE used (DOE 1994), so about $5 \mathrm{~kg}$ of dust will be generated. If the area impacted by the explosion is one-half of the stack circumference to a height of 1 foot, the impacted mass is about $150 \mathrm{lb} / \mathrm{ft}^{3} * 29$ feet $* 1$ foot thick * 1 foot high. The ratio of the dust to the total mass is about 0.0014 .

Mechanical shears are assumed to be used to demolish the 291-Z-1 stack after it has been toppled. The radioactive material at risk (MAR) is assumed to be evenly distributed over the entire inner surface of the stack. The damage ratio (DR) is that portion or percentage of the contaminated area acted on by the shear force, or the portion or percentage of the contamination acted on by shear forces. Shears are assumed to fracture, crush, spall, or otherwise impact the surface being sheared. The damage ratio (DR) is that portion or percentage of the contaminated area acted on by the shear force, or the portion or percentage of the contamination acted on by shear forces. Shears are assumed to fracture, crush, spall, or otherwise impact the surface being sheared. The fraction of surface rubblized during shear operations is taken to be 0.5 .

The effectiveness of the fixative on the rubblized material (approximately $50 \%$ of the sheared material) will conservatively be considered totally lost, i.e., all of the contamination on these pieces will be considered removable. The fixative covering the larger pieces (approximately $50 \%$ of the sheared material, essentially all of the cut material) will be considered largely intact and remain effective. All of 
the material cut by shears will be piled on the ground until placed in the ERDF boxes. Approximately $50 \%$ of the sheared material will be subject to resuspension as rubble, while $50 \%$ will be subject to resuspension as larger pieces.

\section{A.4.4 Airborne Release Fraction}

DOE's factors for impaction stress due to vibration shock were reviewed as the most representative release fractions for the explosive demolition (DOE 1994); the factor of 0.001 is very similar to that derived above of 0.0014 on the basis of dust generation.

DOE's factors for impaction stress due to vibration shock were selected as the most representative release fractions for the crushing processes; the factors selected were 0.001 for removable contaminants and one-tenth that (0.0001) for fixed contaminants (DOE 1994). The EPA's (EPA 1995) compilation of airborne release fractions includes a range of uncontrolled release fractions for crushing of ores and rocks that range from 0.012 to 6 pounds per ton of ore, which relates to an ARF of $6 \times 10^{-6}$ to $3 \times 10^{-3}$ - these ranges overlap, supporting the selection of the DOE values.

Surfaces exposed to the atmosphere between shifts will be subject to resuspension processes. A fresh coat of fixative will be applied to all exposed surfaces (covering any gaps and material deposited on the existing fixative) at the end of demolition operations for a day. Therefore, it is assumed that there is no resuspension between shifts.

During loading of rubble into ERDF boxes, as the material falls, it will be subject to entrainment in the air. The ARF for rubble-handling is estimated to be $2.3 \times 10^{-6}$, as discussed for similar activities in Section A.1.

\section{A.4.5 Leak Path Factor}

The LPF is the fraction of the radionuclides in the aerosol transported through some confinement deposition or filtration mechanism. For the purpose of this study, the LPF is used to address any controls applied during and after the demolition process. This includes the effects of water mists, sprays, and fixatives applied to surfaces and rubble after demolition.

For the initial explosive puff, no credit is given for water sprays; for this step the LPF is 1.0.

The application of a water mist to contaminated surfaces during demolition serves to reduce the percentage of airborne particulates in the respirable size range. The LPF for shearing is assumed to be 0.1 , as discussed for similar activities in Section A.1.

\section{A.4.6 Respirable Fraction}

The RF is the fraction of airborne radionuclides as particles that can be transported through air and inhaled into the human respiratory system. A respirable fraction of 1.0 is applied in the Source Term equation because the removal of nonrespirable particles from the plume is treated separately as a transport and dispersion function within the AERMOD modeling. 


\section{A.5 References}

AlphaTRAC. 2003. Demolition Scenarios and Source Terms for Atmospheric Modeling. AlphaTRAC, Inc., 8670 Wolff Court, Suite 120, Westminster, Colorado.

DOE - U.S. Department of Energy. 1994. DOE Handbook, Airborne Release Fractions/Rates and Respirable Fractions for Nonreactor Nuclear Facilities, Volume 1 - Analysis of Experimental Data. DOE-HDBK-3010-94, Washington, D.C.

Droppo JG, Jr, BA Napier, ER Lloyd, DS Mantooth, MJ Minette, and EM Mattlin. 2007. "Operational Limitations for Demolition of a Highly Alpha-Contaminated Building - Modeled Versus Measured Air and Surface Activity Concentrations." In 2007 Midyear Topical Meeting - Decontamination, Decommissioning, and Environmental Cleanup, January 21 - 24, 2007, Knoxville, Tennessee. PNNLSA-52608, Pacific Northwest National Laboratory, Richland, Washington.

EPA - U.S. Environmental Protection Agency. 1995. Compilation of Air Pollutant Emission Factors AP-42, Fifth Edition, Volume 1: Stationary Point and Area Sources. Research Triangle Park, North Carolina.

Mahoney LA, MY Ballinger, WE Davis, SJ Jette, LM Thomas, JA Glissmeyer. 1994. Literature Review Supporting Assessment of Potential Radionuclides in the 291-Z Exhaust Ventilation. PNL-9995, Pacific Northwest Laboratory, Richland, Washington.

Slinn, WGN 1984. "Precipitation Scavenging." Chapter 11 in Atmospheric Science and Power Production, D Randerson, ed., DOE/TIC-27601, U.S. Department of Energy, Washington, D.C.

TRUTech. 2001. Decommissioning Criteria Document for the United States Department of Energy Plutonium Facilities. TRUTech, L.L.C., P.O. Box 1365, Idaho Falls, Idaho. 

Appendix B

Atmospheric Model Selection 



\section{Appendix B - Atmospheric Model Selection}

Releases of contaminants to the air during the demolition activities described in Appendix A potentially can have impacts in terms of the resulting increases in air and soil concentrations. An atmospheric dispersion modeling analysis has been conducted to generate estimates of these concentrations.

The air dispersion model AERMOD was selected for doing simulations of the potential air and soil exposures from the proposed demolition of the structures at the Plutonium Facility Plant (PFP). The AERMOD modeling system is the preferred/recommended air dispersion model to be used in almost all circumstances, including for State Implementation Plans (SIP) revisions for existing sources and for New Source Review (NSR) and Prevention of Significant Deterioration (PSD) programs. In addition to being a recommended model, AERMOD also has modeling capabilities needed to address the dispersion from the proposed demolition of the PFP structures. AERMOD includes formulations for addressing air dispersion in the immediate vicinity of air emission sources. The model has dry deposition algorithms that account for the particle-size distribution and density as well as local surface and meteorological conditions. Important in the selection of AERMOD for this application is its ability to address building wake effects; the current version of AERMOD incorporates the building wake formulations developed by EPRI.

A potential limitation of AERMOD for Hanford applications is the model's use of straight-line trajectories for the modeled airborne plumes. This model feature means that the model cannot account for downwind changes in wind direction. The Hanford Site does have complex wind patterns and AERMOD may not be an appropriate model for modeling potential concentrations at far-field distances (i.e., beyond the Hanford Site boundary). However, AERMOD is quite appropriate for near-field plume simulations being conducted in this effort. 



\section{Appendix C}

\section{Air Dispersion Modeling Assumptions}





\title{
Appendix C - Air Dispersion Modeling Assumptions
}

\begin{abstract}
AERMOD information and documentation is available on the U.S. Environmental Protection Agency's (EPA's) website for regulatory air models (EPA 2008). The most recently released version of AERMOD was used. AERMOD is considered a commercial model. For Hanford Site applications, such a model must be tested to ensure it is operating correctly in its current implementation (Project Hanford Management System 2002). A series of test cases distributed with AERMOD obtained from the EPA website (EPA 2008) was run before and after the computations reported here. The AERMOD runs were conducted using two computers (PNNL property numbers WD 49474 and WE 13827) with the Windows XP operating system with recent updates installed. Test case results showed the code to be working correctly before and after the production runs.
\end{abstract}

After the potential source terms are defined, the second step in the PFP complex emissions analysis is to compute the airborne and deposited concentrations using the AERMOD air dispersion model. This appendix documents the air dispersion modeling approach, assumptions, and input data.

\section{C.1 Air Dispersion Modeling Approach}

The various phases of the demolition of the PFP facilities will generate fugitive dust emissions that are expected to have low levels of particulate transuranic content. The AERMOD air dispersion model is used to assess air quality resulting from complex onsite fugitive dust emissions accounting for the combination of ambient transport and dispersion dust and building wake effects.

The air dispersion modeling approach is designed to provide output products that are useful in the PFP demolition planning process in terms of providing an understanding of the air and soil impact levels projected for a given demolition option. An approach is needed that can address the potentially very large number of permutations and combinations of ambient weather conditions and the multi-faceted demolition options for each of the components of the PFP facilities.

The approach is to consider each major demolition component of the PFP facilities separately. These computations are used to build a cumulative picture of potential environmental contamination from the full demolition of the PFP facilities. The air exposure analysis is independent of the demolition start date. Because the deposition analysis is based on the summation of the impacts of a series of events, the deposition analysis requires an assumption of a postulated start date and definition of a period of time elapsed during the year for the demolition of each component.

In addition to emission rates from the source term analysis being highly dependent on the demolition options that are selected, the location and size of those emissions are also defined for each of the selected demolition options.

As the result of their different measures of exposure levels, different approaches are used for the air concentration exposures and soil deposition totals. The concern for air exposures is based on the potential levels of air concentration during the demolition of each component. The concern for soil exposures is based on the total deposition not exceeding a specified surface concentration. 


\section{C.2 Airborne Exposures}

Airborne exposures (time-integrated air concentrations) are evaluated in terms of weekly total exposures. A total weekly exposure limit is defined as 12 DAC-hours/week. For the evaluation of potential air exposures, the duration of the demolition activities is important only in terms of what activities are expected to occur in a one-week time frame. Thus, assuming that the demolition of each component of the PFP complex does not overlap within the same week, the potential air exposures can be independently evaluated for each component.

The analysis determines the maximum weekly air exposures downwind of the demolition activities accounting for the week-to-week variations in potential release rates and ambient meteorological conditions. The demolition activities involving the largest estimated release rates are evaluated first. These results define the largest potential air exposures. The results for the air dispersion modeling are presented as maps of maximum potential weekly air exposures computed over some meteorological time span (annual, seasonal, etc.). The results for the air modeling are presented in terms of maximum potential weekly air exposures at selected environmental locations.

\section{C.3 Deposition Exposures}

Deposition exposures (cumulative depositions) are evaluated in terms of total accumulations on ground level surfaces downwind of the demolition activities. A total alpha deposition concentration limit of $20 \mathrm{dpm} / 100 \mathrm{~cm}^{2}$ is used. For the evaluation of potential deposition exposures, the duration of the demolition activities is important. That is, the deposition patterns from the sequential demolition of each of the various components of the PFP facilities must be cumulatively added to evaluate the potential total deposition exposure.

The analysis of each component structure determines the total potential deposition exposures resulting from the demolition of that component alone. The demolition activities involving each of the components are evaluated. To allow logical sequencing of the deposition results, the demolition of each component is assumed to occur over some specific period of elapsed time that represents the "window" during a year that demolition is assumed to occur. The order of deposition analyses follows the air exposures analyses. Assuming the deposition results for each component are less than the air exposure limit, then the potential total deposition exposures from all components are computed.

For each facility or facility component, the soil deposition results are presented as maps of potential total deposition amounts from all of the demolition activities.

The patterns of total deposition for a demolition activity are computed for the demolition period using the average emission rate for that demolition activity. These deposition patterns are evaluated for some appropriate period of meteorological data. The results for the air dispersion modeling are presented as maps of total maximum potential deposition exposures computed for activities during the component's period of elapsed time. 


\section{C.4 AERMOD Modeling Assumptions and Input Data}

The modeling of potential exposures accounting for building wake effects with AERMOD requires the use of point source releases. Area sources such as walls and ceilings are approximated by a grid of point sources. The use of points to approximate an area is useful in that it does allow, if needed, the analysis to account for concentration variations over those areas.

Source Characteristics: The main sources for air emissions will be the building structure demolition and waste loading activities. These sources were modeled as a matrix of point sources. The AERMOD runs were configured to directly produce maximum hourly concentration and deposition values for the days associated with the demolition activities.

Meteorological Data: The air dispersion analysis used multiple years of local meteorological data to define the local dispersion climatology. Five recent years of meteorological data records (calendar years 2005 to 2009) were obtained from the Hanford Meteorological Station (HMS) database for the analysis. Surface meteorological input data to AERMOD consisted of a merged dataset containing surface data incorporating wind speed and direction data from the Hanford telemetry station number 19 located in the 200W area combined with meteorological surface observations from the central HMS station. Vertical structure input data to AERMOD consisted of radiosonde data from the meteorological station at the Spokane airport. ${ }^{2}$

Figure C. 1 shows a wind rose plot $^{3}$ based on all conditions for this five years of record. Reflecting the modeling assumption that all demolition activities occur either during the morning shift (9am to $12 \mathrm{pm}$ ) or during an afternoon shift (1pm to $4 \mathrm{pm})$, Figures C.2 and C. 3 show a summary of the wind conditions for those two time periods, respectively. Figures C.4 and C.5 show how the wind conditions vary as function of the time of year for the morning and afternoon shifts.

The year 2009 is being used to generate modeling results for case studies that consider the full demolition sequence. Figures C.5 to C.10 correspond to the 1-year average values shown in Figures C.1 to C.5. Comparison of these figures shows the major features are essentially the same between the fiveand one-year plots.

\footnotetext{
${ }^{1}$ Ken Burk, Hanford Meteorological Station, Email dated 12/13/2007 defining link for Hanford meteorological data.

${ }^{2}$ Forecast Systems Laboratory (FSL)/National Climatic Data Center (NCDC) Radiosonde Database Access, http://raob.fsl.noaa.gov/ for radiosonde data for Spokane, Washington.

${ }^{3}$ Meteorological convention is used, which defines winds by direction from which they come.
} 


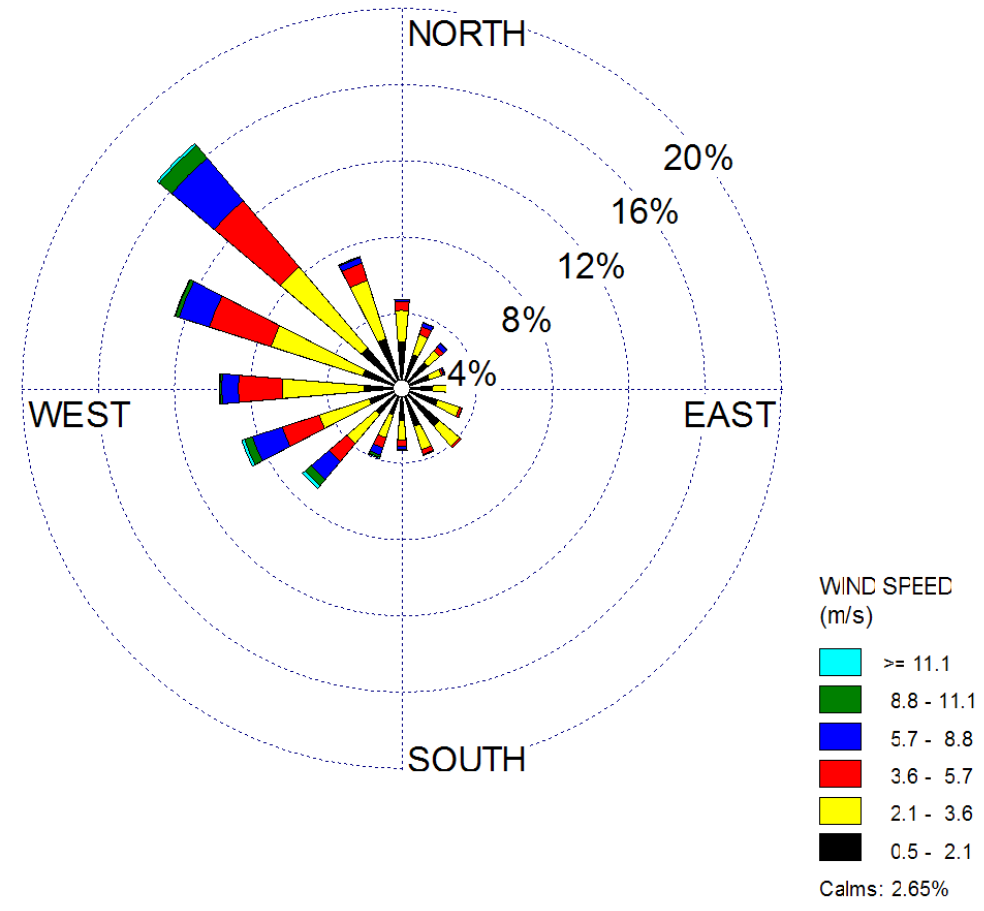

Figure C.1. Average Five Year (2005-2009) Wind Rose - All Conditions

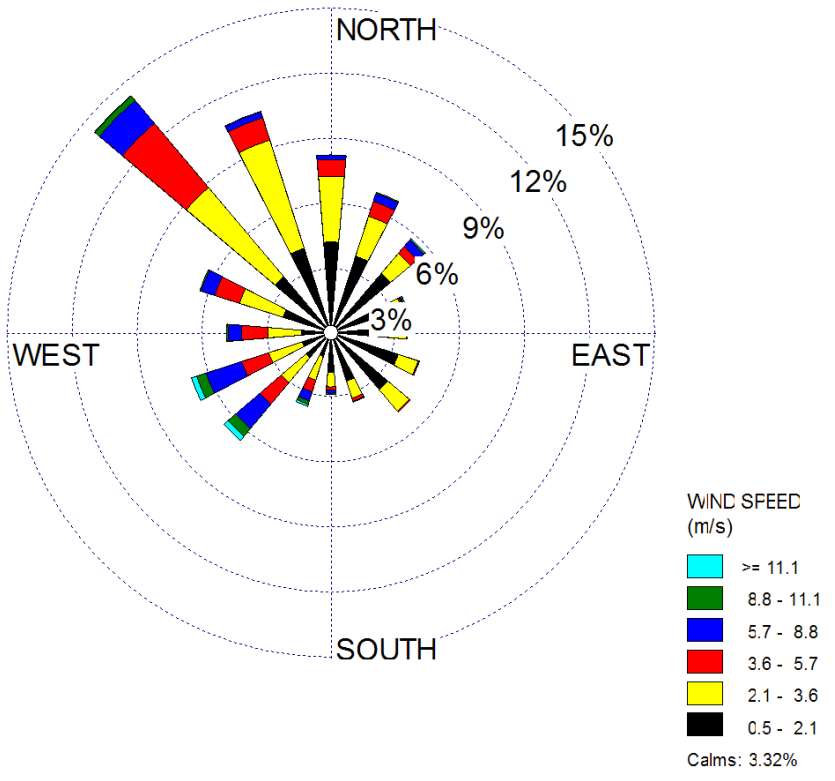

Figure C.2. Average Five Year (2005-2009) Wind Rose - Morning Shift Conditions 


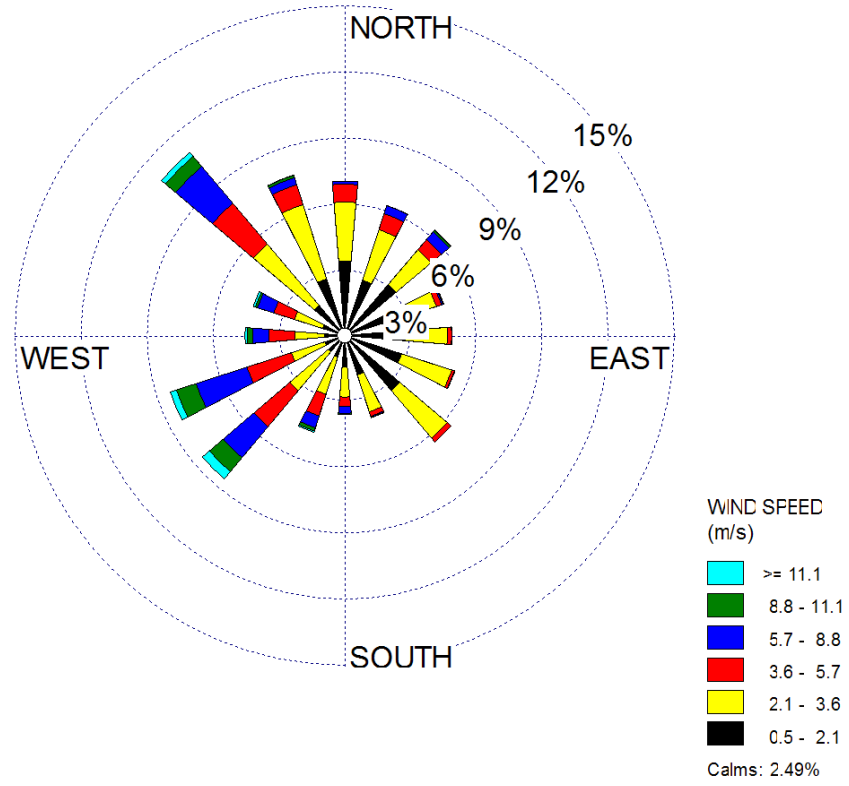

Figure C.3. Average Five Year (2005-2009) Wind Rose - Afternoon Shift Conditions 

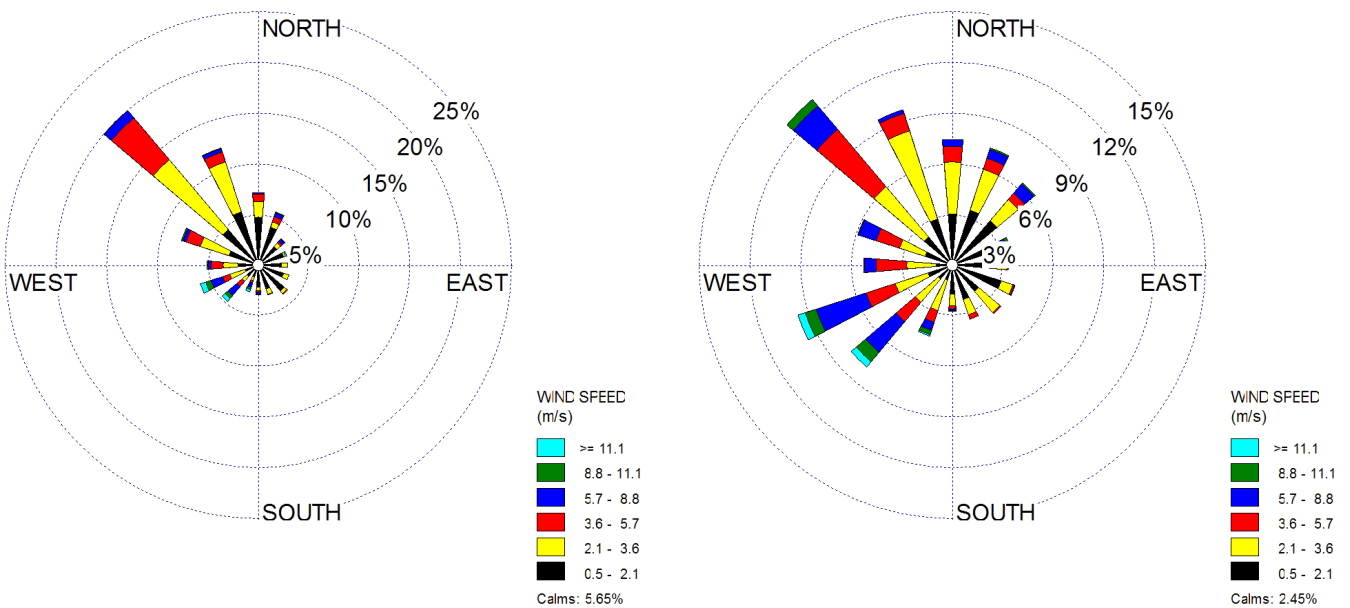

Winter (December - February)
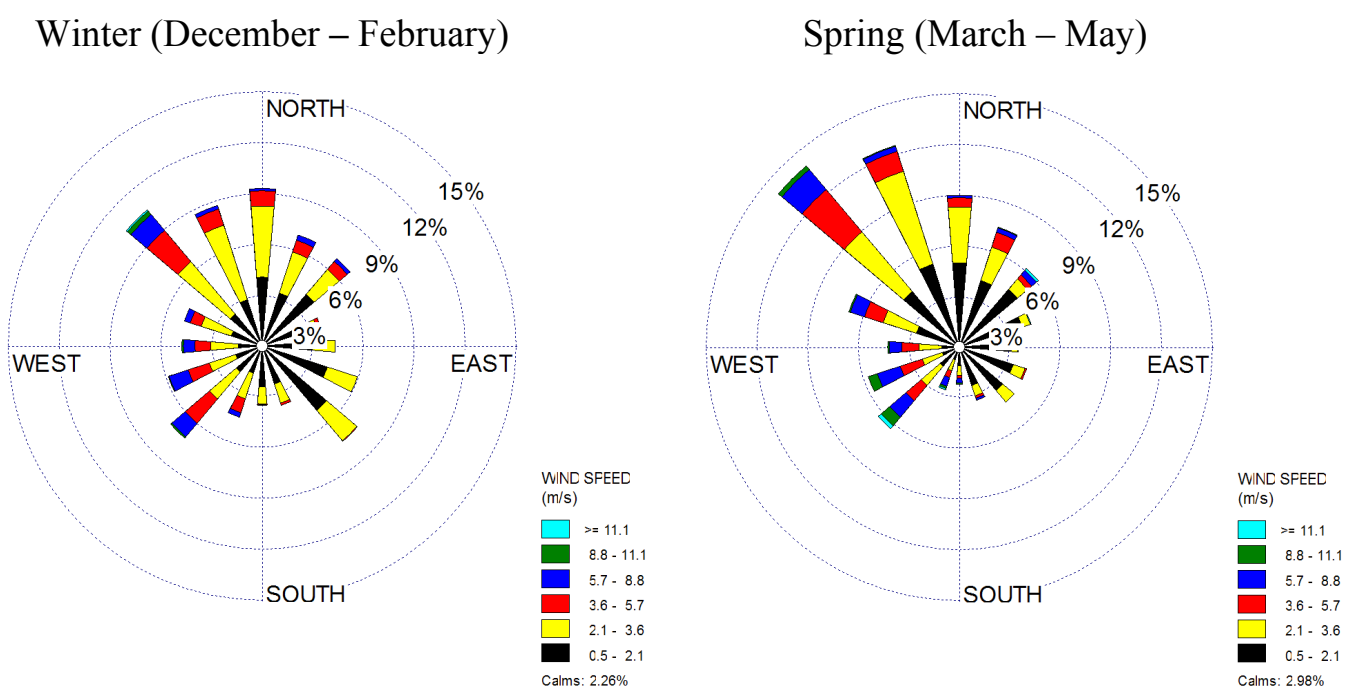

Summer (June - August)

Fall (September - November)

Figure C.4. Seasonal Average Five Year (2005-2009) Wind Rose - Morning Shift Conditions 

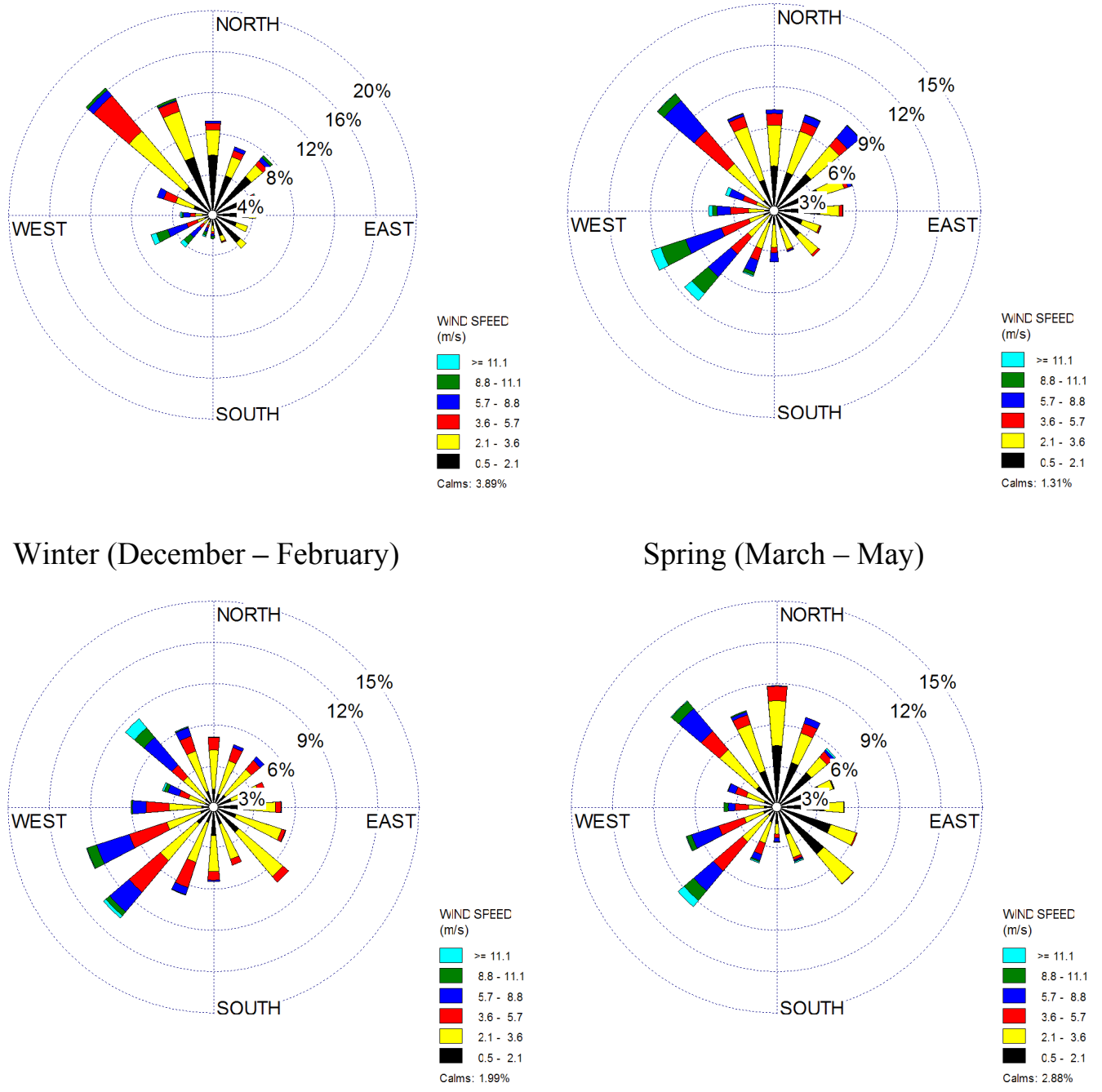

Summer (June - August)

Fall (September - November)

Figure C.5. Seasonal Average Five Year (2005-2009) Wind Rose - Afternoon Shift Conditions 


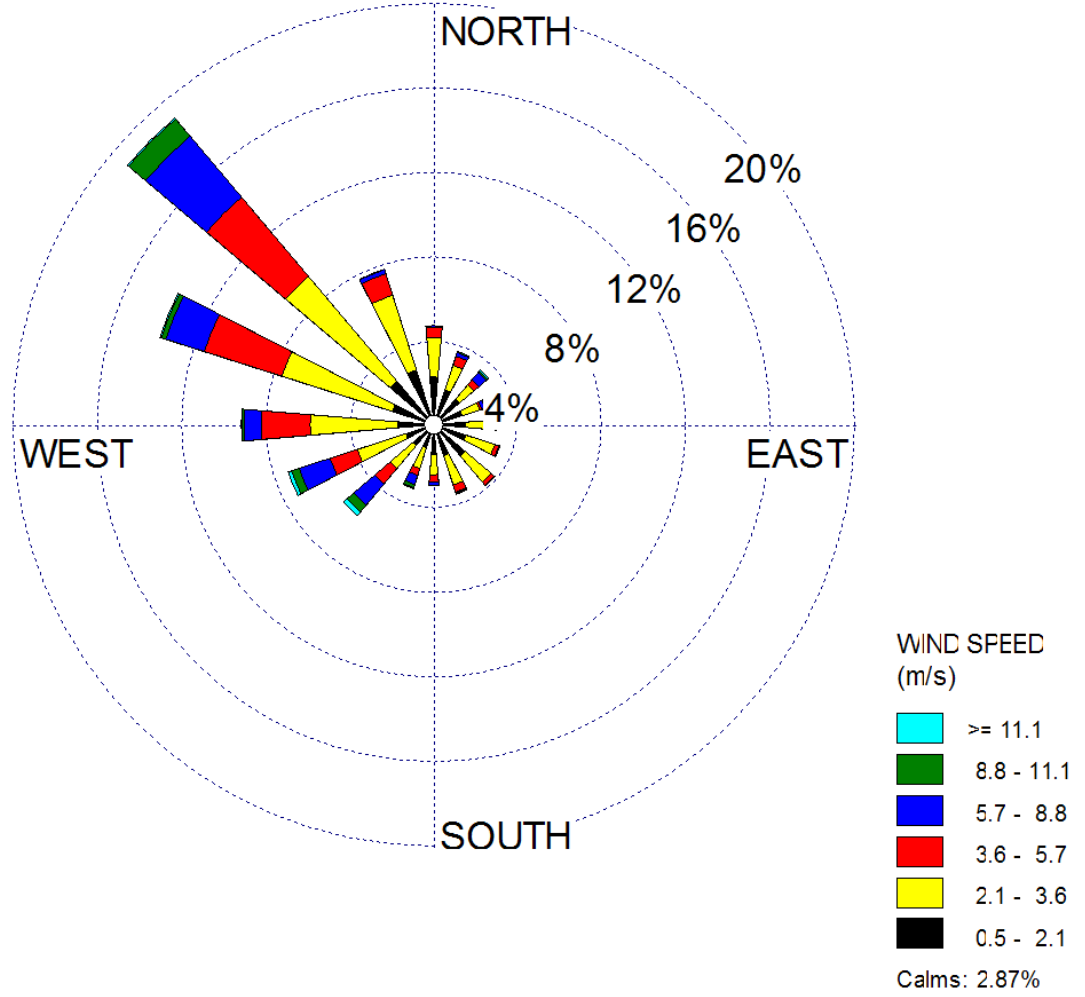

Figure C.6. Annual (2009) Wind Rose - All Conditions
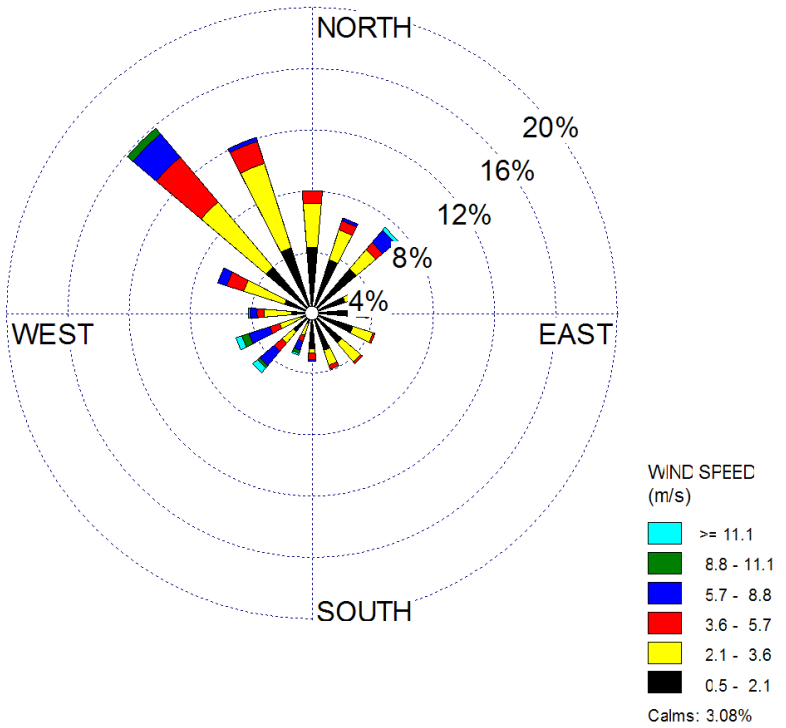

Figure C.7. Annual (2009) Wind Rose - Morning Shift Conditions 


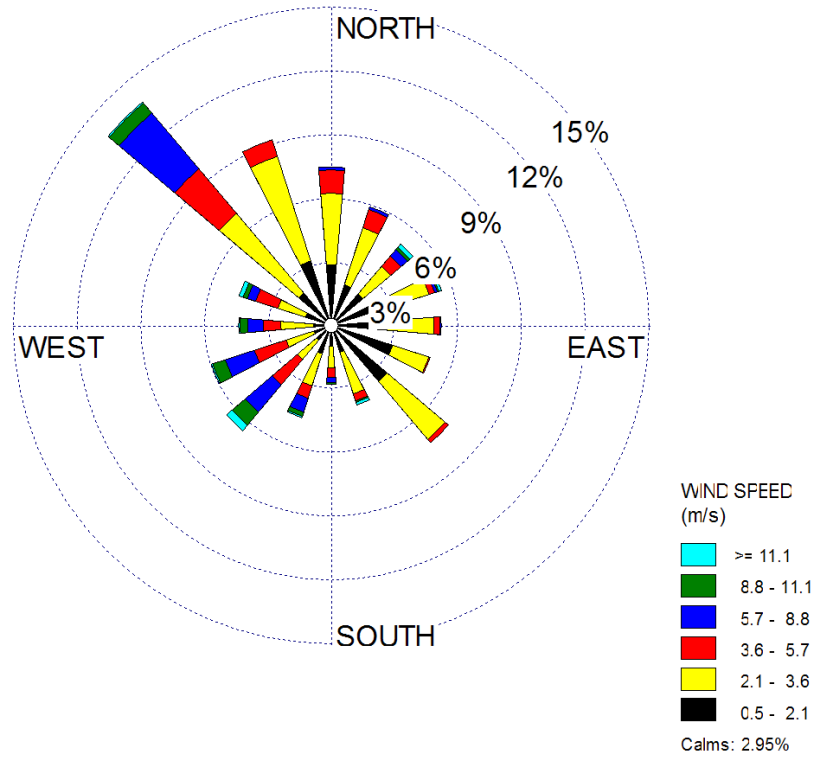

Figure C.8. Annual (2009) Wind Rose - Afternoon Shift Conditions 

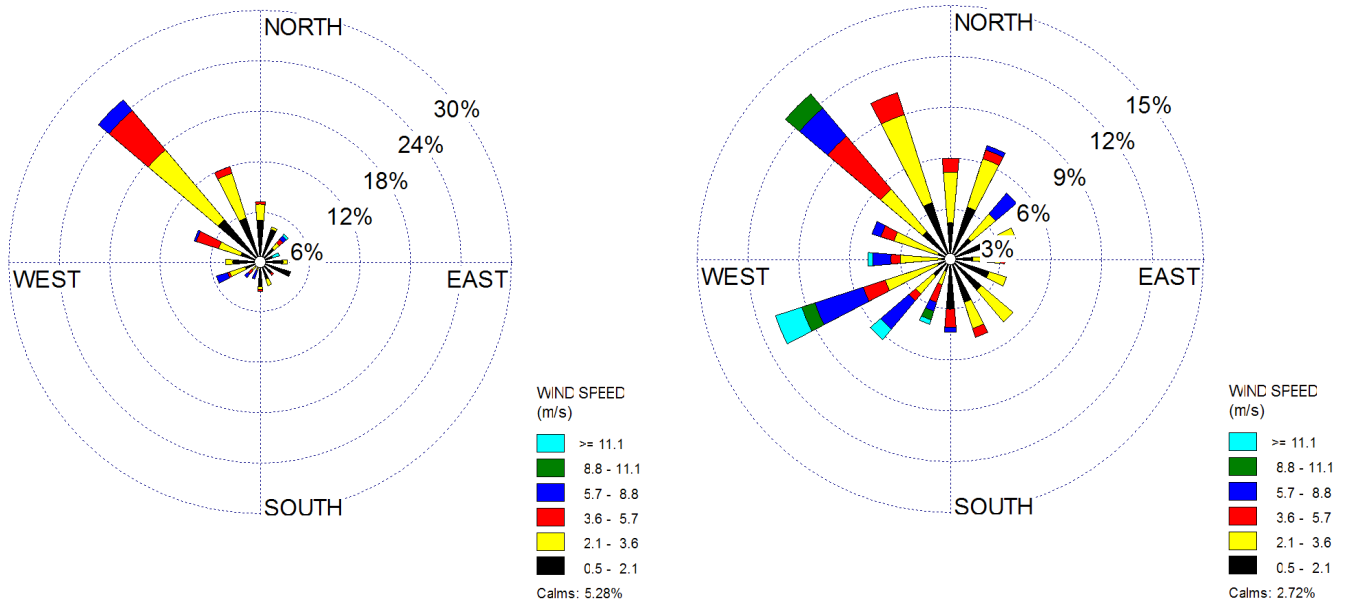

Winter (December - February)

Spring (March - May)
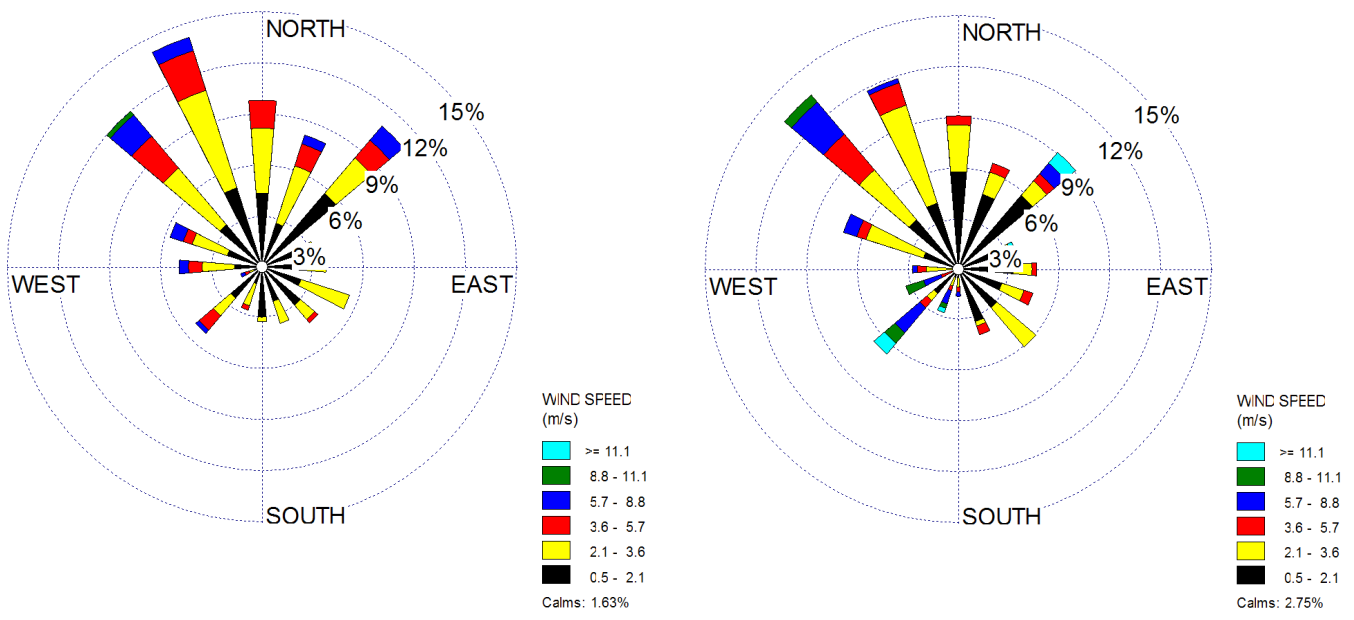

Summer (June - August)

Fall (September - November)

Figure C.9. Seasonal Annual (2009) Wind Rose - Morning Shift Conditions 

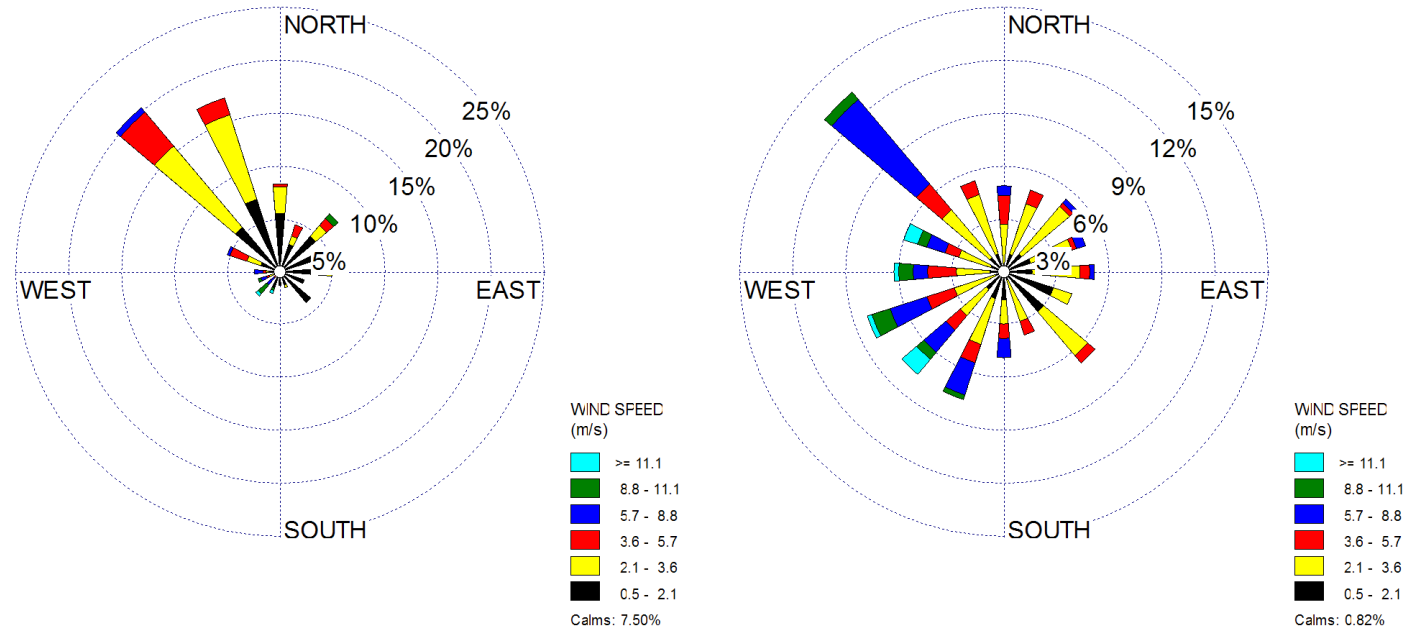

Winter (December - February)

Spring (March - May)
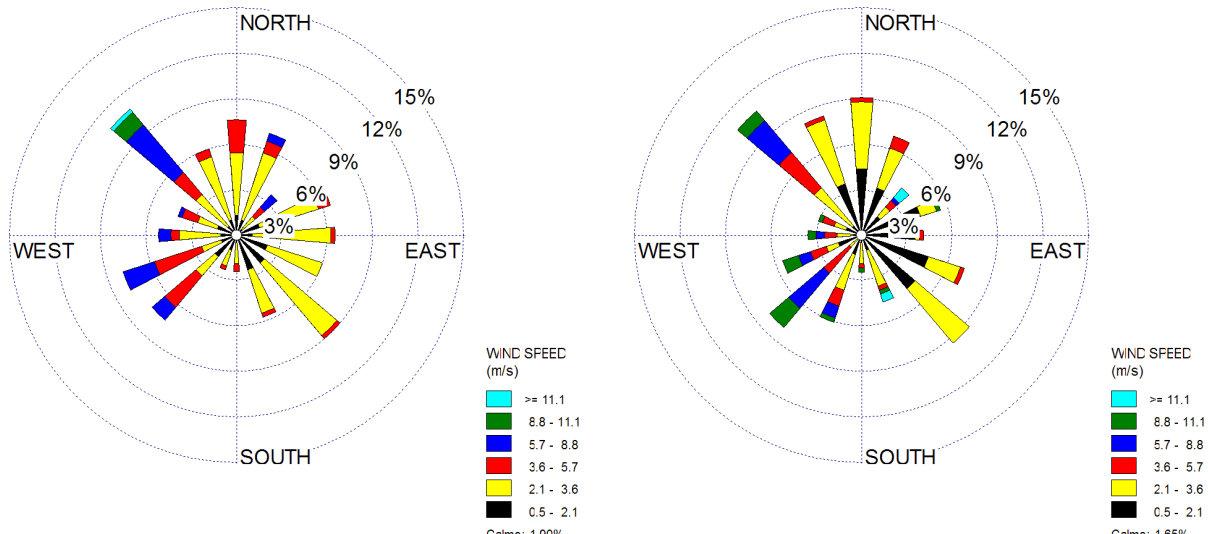

Summer (June - August)

Fall (September - November)

Figure C.10. Seasonal Annual (2009) Wind Rose - Afternoon Shift Conditions

Modeling Approach: The demolition activities are to occur during the day shift. The worst-case scenario resulting in the highest air concentrations is for the majority of the release to occur over a short time period. To evaluate the potential exposure levels from the planned demolition activities, the local patterns of potential peak air concentrations and soil deposition were computed as though the estimated release from each of the buildings occurred during one hour. By looking at the potential peaks for all the hours during the planned work periods, the worst case values are defined. The two proposed 3-month time periods for the demolition activities are included in this annual bounding computation.

Receptor Grids: Computations were made for a rectangular receptor grid appropriate for defining the spatial patterns of the locations of the maximum air concentrations and deposition amounts. 


\section{C.5 References}

EPA - U.S. Environmental Protection Agency. 2008. Technology Transfer Network Support Center for Regulatory Air Models, http://www.epa.gov/scram001/(Access last checked 6/5/2008).

Project Hanford Management System. 2002. Computer Software Management. HNF-PRO-309. October 24, 2002. Fluor Hanford, Inc. Richland, Washington 


\section{Appendix D}

\section{Alternative Demolition Approaches Considered}





\section{Appendix D - Alternative Demolition Approaches Considered}

\section{D.1 Preparations for demolition of 236-Z: Strongback Removal}

Plutonium-bearing solutions were processed in critically-safe "pencil tanks" within the 236-Z main process cell. The pencil tanks were supported by metal "strongbacks" that held the tanks and allowed them to be moved and attached via jumpers to associated piping within gloveboxes located around the outside of the main cell. Upon demolition, the pencil tanks will have been drained and removed.

The contents and most structural components of the gloveboxes will also be removed prior to demolition. The strongbacks and the jumper receptacles (the liner and piping connecting the glovebox to the jumper through the cell wall) remain.

In order to evaluate the potential for releases from removal of the strongbacks from the cell prior to cell demolition, a simple scenario was developed for analysis. The releases resulting from this particular scenario are presented for planning purposes only; this scenario was not considered to be part of the actual facility demolition.

It is assumed that 2 strongbacks per day can be lowered to the floor of the cell using the overhead crane, cleaned, cut into manageable sized pieces, stabilized, and moved out through the cell door through the Equipment Transfer Facility and loaded into containers. Operations within the cell are assumed to occur in an atmosphere at the maximum permissible air concentration with supplied-air respirators of 1000 DAC. (One DAC is evaluated as $0.284 \mathrm{~Bq} / \mathrm{m}^{3}$ ) Removal of the strongback pieces through the open doors of the cell and Transfer Facility room will result in releases of radioactive material to the outside atmosphere, at ground level. There are 19 potential locations for strongbacks on the cell west wall, and 18 more on the east wall. Not all of these locations currently hold strongbacks - at least one of the spots is reserved for maintenance and some of the others may have already been removed. If a moderate air exchange rate of 0.1 air exchanges/hour is assumed for two 3-hour periods per day, with air at a concentration of $1000 \mathrm{DAC}$, for 15 working days (a total of maybe 30 strongbacks), the total release would be about $0.1 \mathrm{mCi}$ of plutonium mixture.

Following removal of the strongbacks, it is assumed that the power to the building is cut and demolition of the building itself begins. A week is allocated for removal of the relatively uncontaminated Equipment Transfer Facility (the garage-like structure in front of the main cell door) and the gas cylinder storage area along the outer east wall, with some additional clean-up and site preparation.

\section{D.2 Demolition of PRF Main Cell with Wire Saw}

Because of the high levels of contamination of the 236-Z (PRF) main cell, it may be desirable to use techniques with result in a lower release fraction of the radioactive materials. Such an option is represented by use of a wire saw to dismantle large portions of the cell with relatively little disturbance of the contaminated surfaces. A hypothetical schedule is described, upon which is based the emissions estimates.

For structural reasons, it is assumed that the ceiling/roof of the cell is removed first. The floor of the cell is assumed to be covered with sand (or a similar substance) to absorb the impact of falling debris and to minimize suspension of floor contamination. Cutting of key locations takes place, and then large 
sections of the roof are lowered into the cell. This action opens the main cell to the atmosphere for the remainder of the demolition. These activities are assumed to take 4 days.

Structural materials high in the cell are assumed to be removed. The crane maintenance platform at the north end of the cell, and the crane itself, are removed. The Maintenance Station in the northeast corner of the cell is removed, including the small shield wall. These activities take 5 working days.

In order to make access easier, the south wall is then removed. This wall is thinner ( 1 foot) and contains a 12-foot wide door extending into the second story. The door is topped with a concrete beam; above that construction is of cinder block. Demolition of this wall takes 5 days.

The use of wire saws will allow somewhat easier removal of the jumper receptacles in the side walls. Initially, the upper portions of the wall will be removed. A segment of the 2 -foot-thick wall that is 4 feet by 4 feet would weight about 2 tons; this is assumed to be the size cut. Pieces of this size imply that 3 rows of pieces would be removed from the upper portion of the wall before the first row of jumper receptacles was encountered; this is assumed to take 4 days. Removal of one row of receptacles (cutting between and below each so that they can be removed and packaged as TRU waste) is assumed to take 10 days. Removal of the concrete between rows is assumed to take an additional 4 days, so that each of the 4 rows of receptacles thus requires about 14 days. This process is repeated for the opposite side wall.

Finally, the north wall is removed. Five days is allocated for this, including any final cleanup of the area.

Falling rubble and large cut panels are generally directed into the cell, rather than out into the surrounding area. Pick-up of rubble is done with a front loader and thumb-and-bucket on the excavator; it is assumed that a mobile crane will be used to lower the cut panels. The rubble will be picked up and placed into transfer boxes just outside the location of the door in the south wall, in the general area of the Equipment Transfer Facility. Material in the transfer boxes may be further staged at a sorting station located nearby. No additional containment structures (tents, etc.) are assumed for this activity; however, like the demolition itself, misting, water, and fixatives will be used to minimize airborne contamination spread. All loading and sorting will only occur when sustained wind speeds are less than 15 miles per hour.

The damage ratio for this alternative demolition technique is evaluated for the walls of the main cell. The walls are assumed to be covered with fixatives (paint, etc.). A wire saw will be used to make long cuts in the concrete to separate panels for removal. Because the area of the saw kerf is impacted, the DR is the ratio of the area cut to the total surface area. The area of the two longer walls of the cell is about 65 feet by $34 \mathrm{feet}=2210 \mathrm{ft}^{2}$. In order to cut the wall into roughly $4 \mathrm{ft} \times 4 \mathrm{ft}$ panels, with additional cutting between the jumper receptacles, about 1100 linear $\mathrm{ft}$ of cuts, each of which will be $1 \mathrm{~cm}(0.033 \mathrm{ft})$ wide. The fraction of the area impacted is:

$$
(1100 \mathrm{ft})(0.033 \mathrm{ft}) /\left(2210 \mathrm{ft}^{2}\right)=0.016
$$

The north and south walls, and the ceiling, would require somewhat fewer cuts because these surfaces do not contain potential TRU wastes that must be segregated; the DR would be somewhat lower for these walls. 
The airborne release fraction for the decommissioning of the 233-S building (AlphaTRAC 2003) was assigned the release fraction of $5 \times 10^{-3}$, using the analogy to gases blowing over powders (AlphaTRAC 2003). For sawing the portions of the cell walls, that analogy seems inappropriate; the diamond wire saws are cooled with large amounts of water and the waste comes off in a wet slurry. The DOE handbook recommended release fraction for free-falling slurry spills is $4 \times 10^{-4}$ and for jet spray releases of liquids is $1 \times 10^{-4}$; a value of $5 \times 10^{-4}$ is adopted here.

\section{D.3 Individual Glovebox Removal}

At the request of the client, an individual source of additional residual contamination beyond the "baseline" initially defined is included. This is represented by the HA-46 glovebox located in the 234-5Z building. This glovebox was used in the fluorination process near the head-end of the RMA Line, and is heavily contaminated with transuranic materials. The glovebox has the dimensions shown in Figure D.1, and an upper-bound inventory (estimated by assuming the glovebox averages $80 \mathrm{nCi} / \mathrm{g}$ overall) as shown in Table D.1. The location of the glovebox in the building is illustrated in Figure D.2. A back calculation indicates that the mass of the glovebox itself is 1.52 tonnes. The glovebox is potentially too large to easily remove from its room in PFP; an option would be to demolish it with the building, another is to ease its removal by opening the building around it.

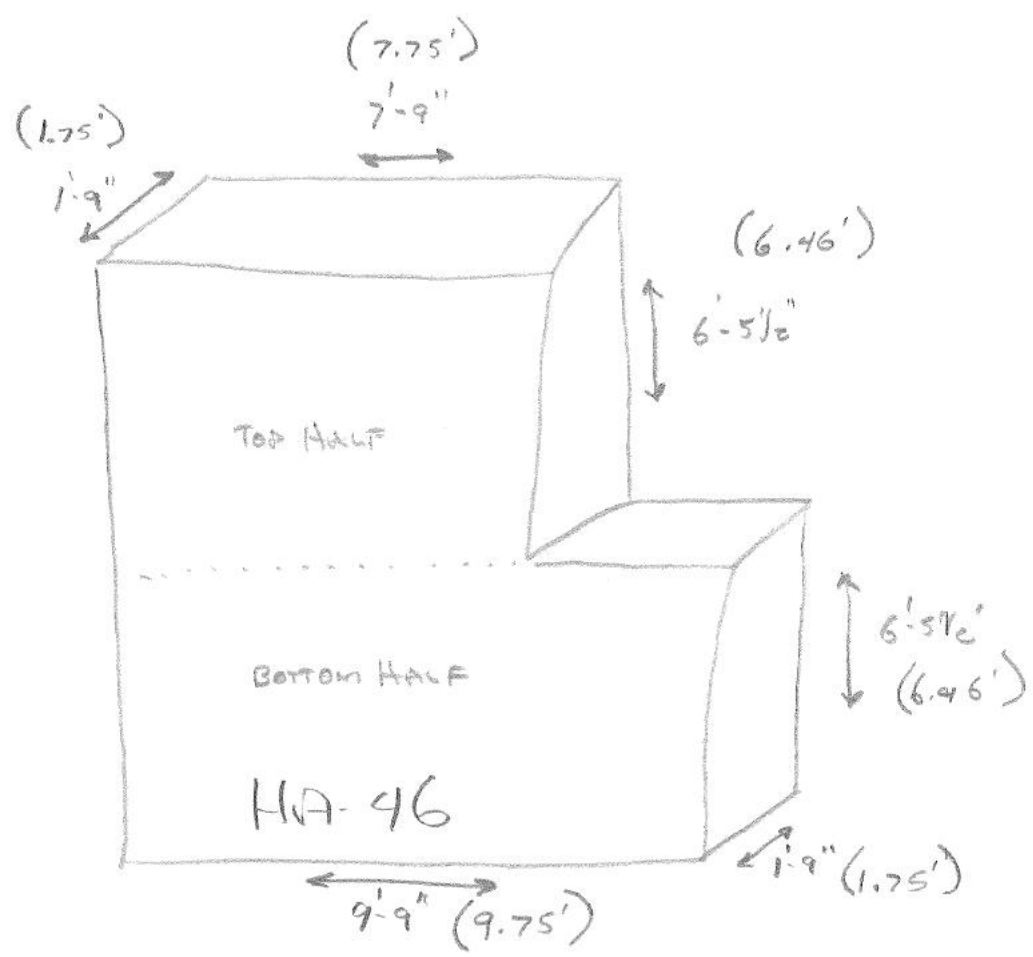

Figure D.1. Approximate Dimensions of Glovebox HA-46 (units of feet and inches) 
Table D.1. Radionuclide Inventory of Glovebox HA-46. The information provided by the client did not include numeric values for $\mathrm{Pu}-241$ grams or nanocuries; these values were added.

\begin{tabular}{ccrcc}
\hline & wt $\%$ & \multicolumn{1}{c}{$\%$ act } & grams & nCi \\
\hline $\mathrm{Pu}-238$ & 0.010 & $0.77 \%$ & $1.36 \mathrm{E}-04$ & $2.39 \mathrm{E}+06$ \\
$\mathrm{Pu}-239$ & 93.449 & $29.87 \%$ & $1.45 \mathrm{E}+00$ & $8.97 \mathrm{E}+07$ \\
$\mathrm{Pu}-240$ & 6.023 & $7.03 \%$ & $9.35 \mathrm{E}-02$ & $2.11 \mathrm{E}+07$ \\
$\mathrm{Pu}-241$ & 0.249 & $59.59 \%$ & $1.75 \mathrm{E}-03$ & $1.79 \mathrm{E}+08$ \\
$\mathrm{Pu}-242$ & 0.040 & $0.00 \%$ & $6.18 \mathrm{E}-04$ & $2.44 \mathrm{E}+03$ \\
$\mathrm{Am}-241$ & 0.159 & $2.74 \%$ & $2.41 \mathrm{E}-03$ & $8.26 \mathrm{E}+06$ \\
\hline
\end{tabular}

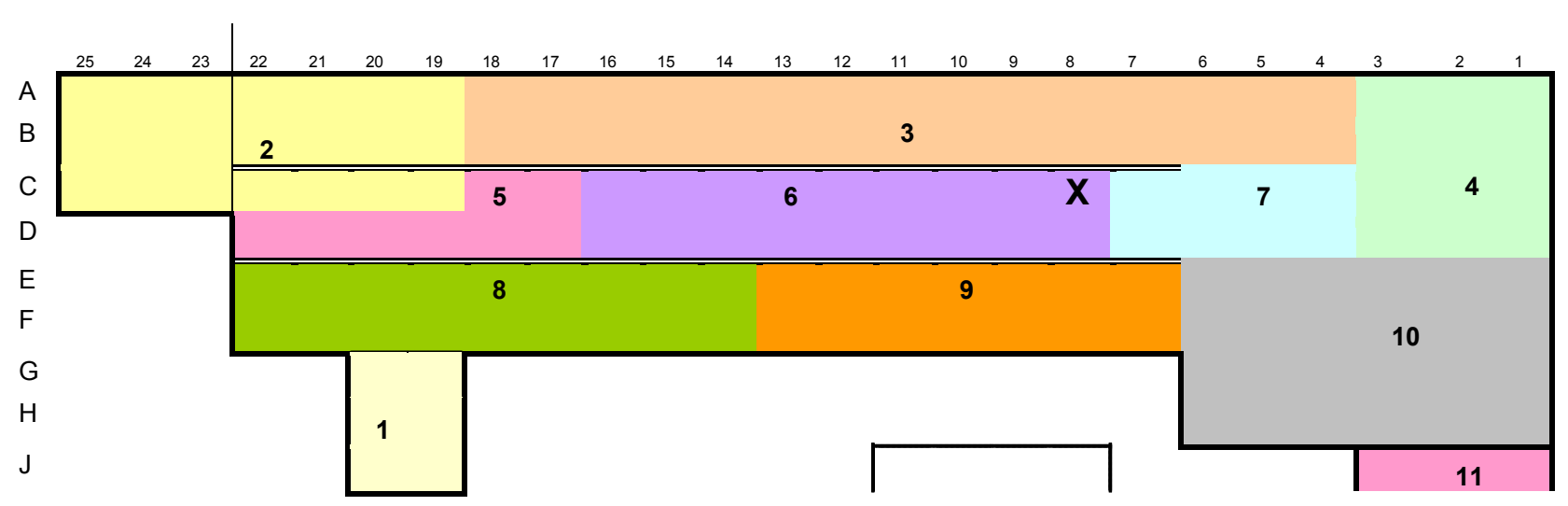

Figure D.2. Location of Glovebox HA-46 Illustrated by the ' $\mathrm{X}$ ' on the Ground Floor of the 234-5Z Building

The possible effect on decommissioning of the 234-5Z building above the baseline caused by including this source in the demolition of Zone 6 (indicated in Figure D.2) is investigated. Two possible demolition scenarios for this glovebox are considered: aggressive demolition, and protective extraction. Aggressive demolition is defined to be consistent with removal of the rest of the Zone with track-mounted shears. Protective extraction is defined as a more careful removal, including foaming of the glovebox volume and segmentation in place.

The inventory of this glovebox has a different isotopic spectrum than assumed for the remainder of the building. Thus, a separate calculation of DAC is required. Assuming that activity $\%$ is correct in Table D.1, then the result is $0.45 \mathrm{~Bq} / \mathrm{m}^{3}$, which is equal to one DAC.

All other calculations for 234-5Z are based on mass of contaminated dust arising from demolition of contaminated concrete (and other) surfaces, and are thus primarily non-radioactive dusts. The HA-46 glovebox is a large stainless-steel container with small amounts of plutonium adhered to the inner walls (see Figure D.3 for an analogue). Relatively little dust will arise from its dismantlement - but a great deal of TRU release may occur. 


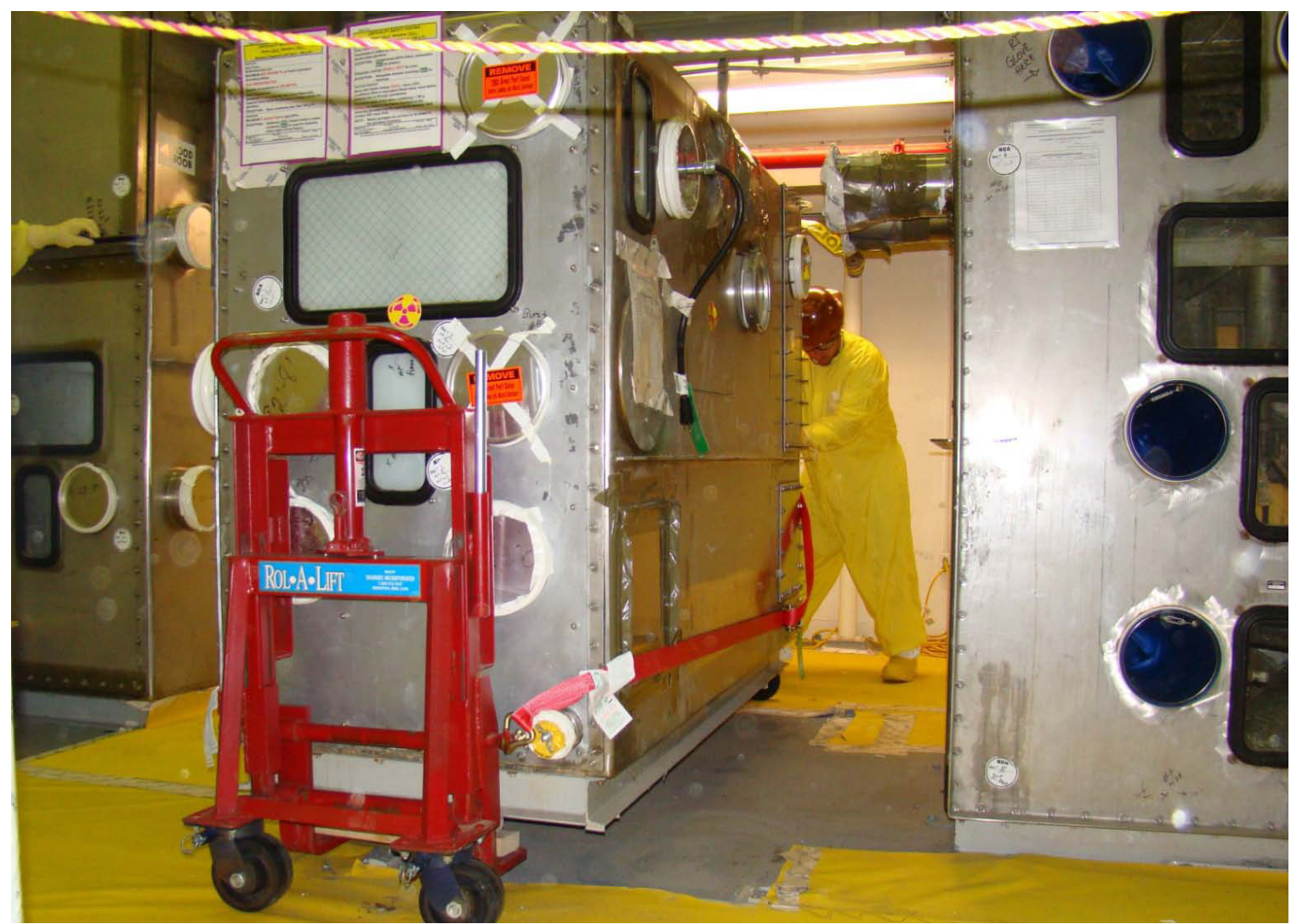

Figure D.3. The HA-46 Glovebox will be Similar to These, but Larger and Built into the Wall

\section{Option 1: Aggressive Dismantlement}

It is assumed that the glovebox is size-reduced during the demolition of Zone 6. A bucket on the end of a boom is used to topple the box onto the floor and to squash the glovebox into a smaller, flat size suitable for loading into an ERDF box and removed. Similar flattening is performed at other Hanford demolition sites on pipes, ducts, and other hollow objects destined for ERDF disposal (see Figure D.4). This is a vigorous process, with substantial bending of the metal, breaking of viewports, and opening of seams. For this type of activity, the DOE Handbook release fraction applicable to stress/impact on metal surfaces of 0.001 is applicable (DOE 1994). One day of size reduction (6 working hours) and one day of equivalent activities during loading into the ERDF box (an additional 6 hours) is assumed. Particle size for this activity can be assumed to be in the range of $1-5$ micrometers. Water sprays will have minimal reduction of this size range.

The glovebox contains a total of about 1.54 grams $\left(0.3 \mathrm{Ci} ; 1.1 \times 10^{10} \mathrm{~Bq}\right)$ of plutonium-related material. A release fraction of 0.001 yields a release of about 0.0015 grams $\left(3 \times 10^{-4} \mathrm{Ci} ; 1.1 \times 10^{7} \mathrm{~Bq}\right)$. The release is assumed to occur over 6 hours in one day during demolition, and a second release of the same size and duration a week later during the loading process.

One DAC is $0.45 \mathrm{~Bq} / \mathrm{m}^{3}$. The deposition limit is $20 \mathrm{DPM}$ alpha per $100 \mathrm{~cm}^{2}$; this is equivalent to $50 \mathrm{DPM}$ total, or $0.83 \mathrm{~Bq} / 100 \mathrm{~cm}^{2}$ (about $1.2 \times 10^{-12}$ grams of Pu mixture per $\mathrm{cm}^{2}$ ). 


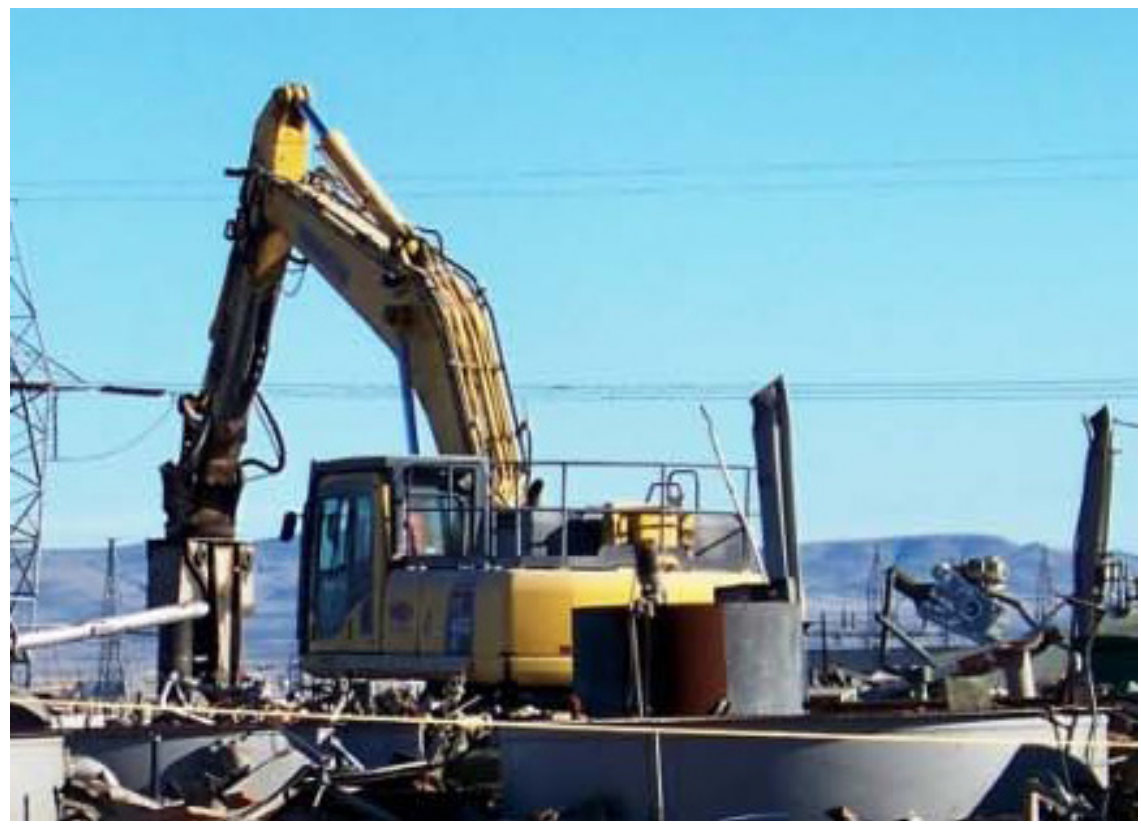

Figure D.4. A Multi-processor Size-reducing Large Pieces of Equipment

\section{Option 2: Protective Extraction}

It is probably not possible to carefully take down the $234-5 \mathrm{Z}$ building without causing some damage to the glovebox (at least, not in any economical fashion). Therefore, a scenario with some damage to the glovebox, including a period of size reduction, is developed.

Prior to demolition of the portion of the building containing the glovebox, the glovebox is prepared and slightly "hardened." The glovebox is assumed to be filled with expansive foam to fill voids and cover internal surfaces. Ports and windows are covered with metal plates to prevent fracturing them while the nearby lath-and-plaster walls and ceilings are removed with the shears. The glovebox could also be wrapped in plastic sheeting. Damage from falling cement plaster is assumed to dent and rip portions of the box. A release, mitigated by the foam and plastic, of $1 \times 10^{-6}$ of the contents is assumed on the day of building removal. This is $1.5 \times 10^{-6}$ grams, or $16,500 \mathrm{~Bq}$.

The following week, the rubble around the glovebox is collected. At this time, the box is segmented with a power saw into three pieces. The part labeled "top half" in Figure D.1 is removed, and the lower portion is cut into two pieces, each about 5 feet by 6.5 feet by 2 feet. This requires 19 feet of cuts in the metal to remove the top portion and another 14.7 feet of cuts to segment the bottom portion. (The relatively clean foam inside would also need to be cut; no release is assigned to this.) The kerf from cutting is assumed to be one-quarter inch wide. The total surface area of the inside of the box that is impacted is $0.7 \mathrm{ft}^{2}$. Because the inner surface area of the glovebox is about $302 \mathrm{ft}^{2}$, this is a damage ratio of 0.00233. For the decommissioning of the 233-S building (AlphaTRAC 2003), releases via saw cuts were assigned the release fraction of $5 \times 10^{-3}$, using the analogy to gases blowing over powders (AlphaTRAC 2003). For lack of a better value, that is used here for sawing the portions of the glovebox walls. Therefore, a total release fraction of $1.2 \times 10^{-5}$ is assigned to segmenting the glovebox. It is assumed that the glovebox pieces are then wrapped in plastic and removed. A total release during the size reduction of $1.8 \times 10^{-5}$ grams of transuranics would be released (about $2.0 \times 10^{5} \mathrm{~Bq}$ [5.5 microcuries]). 


\section{D.4 References}

AlphaTRAC. 2003. Demolition Scenarios and Source Terms for Atmospheric Modeling. AlphaTRAC, Inc., 8670 Wolff Court, Suite 120, Westminster, Colorado.

DOE - U.S. Department of Energy. 1994. DOE Handbook, Airborne Release Fractions/Rates and Respirable Fractions for Nonreactor Nuclear Facilities, Volume 1 - Analysis of Experimental Data. DOE-HDBK-3010-94, Washington, D.C. 

Appendix E

\section{Quality Control Procedures}





\section{Appendix E - Quality Control Procedures}

\section{E.1 Overview}

QA requirements specified by PNNL were followed. A QA review of computations and results was conducted. Special aspects of QA requirements for this project are:

1. All modeling computations will be performed with commercial software: either by EXCEL or by AERMOD codes.

2. The equations for all computations in EXCEL will be documented in the project report.

3. The AERMOD model will be tested with the AERMOD distribution test cases before and after modeling efforts are conducted -- to assure the AERMOD model is operating as expected. Documentation of run time options will be documented in the project report.

4. The versions of EXCEL and AERMOD, the computer platforms, and the computer operating system versions will be documented in the final report.

5. Electronic copies of all EXCEL spreadsheets and AERMOD run files used in the project results will be stored in the project file.

Descriptions of the details of this approach relative to conducting simulations with AERMOD are given below.

\section{E.2 AERMOD Simulations Validation and Verification Approach}

The following guidance documents the approach used by PNNL for validating and verifying model runs made in the EPA's AERMOD dispersion model. In short, the guidance ensures that the appropriate model version is being used, the modeling system is functioning as expected, and the model inputs are reasonable and correct for the scenario. A checklist has been developed to aid the modeler in validating and verifying model inputs; the checklist can be completed and submitted along with the model report to document validation and verification procedures used in performing the AERMOD model run.

1. Determine which model is appropriate for the current modeling application:

a. The AERMOD modeling system is the preferred/recommended dispersion model to be used in almost all circumstances, including State Implementation Plans (SIP) revisions for existing sources and New Source Review (NSR) and Prevention of Significant Deterioration (PSD) programs.

b. Alternative models (e.g., ISC) can be used in regulatory applications, but require case-by-case justification from the reviewing authority.

2. Verify the latest regulatory version of the modeling system is being used:

a. The EPA releases new versions of the AERMOD modeling system to correct known issues or to implement new features in the model. Verify the correct regulatory version of AERMOD modeling system is being used by contacting the software distributor (e.g., www.breezesoftware.com, www.lakes-envirionmental.com) or by reviewing the model change bulletins available on the EPA's website: http://www.epa.gov/scram001/dispersion_prefrec.htm. 
b. If necessary, download and install the regulatory version of the AERMOD modeling system from the vendor or the EPA.

3. Validate the modeling system is working properly:

a. The AERMOD modeling system should be validated to ensure it is working properly prior to using it for the intended application. Test cases are installed by the model vendor (e.g., www.breeze-software.com, www.lakes-envirionmental.com) and should be run to make sure the model output agrees with the original output. File comparison software, such as "Beyond Compare" available from PNNL's Managed Software, make comparison of the model output files a simple process.

i. If the file output differs, further investigation will be required to determine the source (e.g., model version) of the difference and determine if the results are acceptable.

b. The EPA provides model test cases on their website, http://www.epa.gov/scram001/dispersion_prefrec.htm, which can also be used to validate the modeling system is running properly.

4. Enter all model inputs applicable to the modeling scenario. If using vendor software (e.g., BREEZE, Lakes Environmental), model input entry will be performed through a Windows interface (preferred). If using the EPA's DOS version, model entry will be performed via a formatted text input file. AERMOD input is echoed to the primary output file; these inputs should be verified and validated to ensure entered values are correct. A checklist was used as guidance to verify and validate model inputs. Key issues to consider when creating model scenarios include:

a. Terrain - if terrain is to be considered, source and receptor locations should be entered using the proper Universal Traverse Mercator (UTM) coordinates. The latest regulatory version of AERMAP should be used, along with the appropriate digital elevation model (DEM) files, to determine terrain heights for model objects.

b. Building Downwash - point sources (e.g., stacks) on or near buildings may be subject to building downwash. Include all downwash structures in the modeling analysis, including structures not located on the facility's property if applicable. Downwash structures outside of 5L may be excluded from the analysis (note: "L" is defined as the lesser of the height or maximum projected width for a particular tier or structure). All non-downwash structures should be excluded from the modeling analysis. Non-downwash structures include lattice-type structures such as switchyards, water towers, and elevated storage tanks. Perform a building downwash analysis using the latest version of the Building Profile Input Program (BPIP-PRIME). Downwash calculations should not be performed until all point sources and buildings have been entered into AERMOD and terrain has been imported; this ensures that all model objects have the correct relative heights.

c. Receptors - receptor spacing of sufficient coverage and density should be chosen to ensure sufficient density to determine worst-case predicted ground level concentrations in off-property areas. Predicted concentrations should decrease near the edges of the receptor grid(s).

d. Meteorology - meteorological data should be processed by a qualified meteorologist using the latest regulatory version of AERMET. Selection criteria for the choice of the meteorological station(s) and surface characteristics should be documented by the analyst processing the meteorological data in AERMET. In general, the latest years of meteorological data should be used in the dispersion modeling analysis. However, the modeler should seek approval from the regulator prior to using the meteorological dataset in a specific application. 
5. Verify the echoed model inputs in the AERMOD output file: After completing a model run, the model inputs - which are echoed to the primary AERMOD model output file - should be reviewed to verify values have been entered correctly. Model output should be reviewed to determine if output concentration and/or deposition values are reasonable.

6. Verify the AERMOD modeling system continues to perform as expected: To ensure the AERMOD modeling system performed as intended, the modeler can re-run the model test cases and verify testcase model outputs continue to agree (see Step 3a, above).

A checklist is used to verify and validate AERMOD model runs being used to support compliancerelated work. The checklist can be completed by the modeler and affixed to the model report as supporting documentation on model verification and validation. Use of this checklist will ensure a consistent modeling approach has been followed. In addition, the checklist will help to identify and avoid common modeling errors such as:

- Emission rates or stack parameters that are unacceptable and require revision.

- Modeled emission rates or parameters that do not match the permit application.

- Buildings/property boundary/emission unit locations that do not match the plot plan.

- Inconsistent base elevations for buildings and stacks.

- Incorrect source inputs and dimensions.

- Sources with horizontal or obstructed exhaust modeled with an incorrect exit velocity.

- Terrain elevations missing or incorrect.

- Receptor grid extent is insufficient.

- Meteorological data are not appropriate.

- Use of the incorrect model or model version. 



\title{
Appendix F
}

\section{Input Data for PFP Building Simulations}

\author{
(Included on $\mathrm{CD}$ only)
}





\section{Appendix G}

\section{AERMOD Output File Listing}

(Included on CD only) 

PNNL-20173

\section{Distribution}

No. of

Copies

30 CH2M HILL Plateau Remediation Company

RW Bloom(28)

GT Clinton

SA Richey
No. of

Copies

2 Pacific Northwest National Laboratory

JG Droppo (2) K9-30

LK Berg (PDF)

BA Napier $\quad$ (PDF)

JP Rishel

(PDF)

Distr.1 




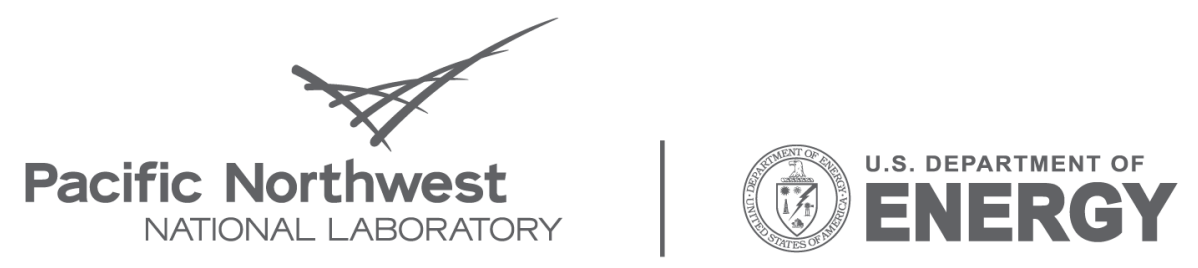

Proudly Operated by Battelle Since 1965

902 Battelle Boulevard

P.O. Box 999

Richland, WA 99352

1-888-375-PNNL (7665)

www.pnl.gov 